\title{
CHANGES IN SOIL PROPERTIES DUE TO TOPOGRAPHY, TILLAGE AND TIME IN THE GUELPH SOIL CATENA AT THE ONTARIO BENCHMARK SITE \# 14\&44 (ROCKWOOD, ONTARIO)
}

by

David John Kroetsch B.Sc. Hons.

\author{
A thesis submitted to \\ The Faculty of Graduate Studies and Research \\ in partial fulfillment of \\ the requirements for the degree of \\ Masters of Science
}

Department of Geography and

Environmental Studies

\author{
Carleton University \\ Ottawa, Ontario \\ (C) David Kroetsch, 2004
}




\author{
National Library \\ of Canada \\ Acquisitions and \\ Bibliographic Services \\ 395 Wellington Street \\ Ottawa ON K1A ON4 \\ Canada
}

Bibliothèque nationale

du Canada

Acquisisitons et services bibliographiques

395 , rue Wellington Ottawa ON K1A ON4 Canada
Your file Votre référence ISBN: 0-612-93983-9

Ourfile Notre référence ISBN: 0-612-93983-9
The author has granted a nonexclusive licence allowing the National Library of Canada to reproduce, loan, distribute or sell copies of this thesis in microform, paper or electronic formats.

The author retains ownership of the copyright in this thesis. Neither the thesis nor substantial extracts from it may be printed or otherwise reproduced without the author's permission.
L'auteur a accordé une licence non exclusive permettant à la Bibliothèque nationale du Canada de reproduire, prêter, distribuer ou vendre des copies de cette thèse sous la forme de microfiche/film, de reproduction sur papier ou sur format électronique.

L'auteur conserve la propriété du droit d'auteur qui protège cette thèse. $\mathrm{Ni}$ la thèse ni des extraits substantiels de celle-ci ne doivent être imprimés ou aturement reproduits sans son autorisation.
In compliance with the Canadian Privacy Act some supporting forms may have been removed from this dissertation.

While these forms may be included in the document page count, their removal does not represent any loss of content from the dissertation.
Conformément à la loi canadienne sur la protection de la vie privée, quelques formulaires secondaires ont été enlevés de ce manuscrit.

Bien que ces formulaires aient inclus dans la pagination, il n'y aura aucun contenu manquant. 


\begin{abstract}
Changes in soil properties due to topography, tillage and time in the Guelph soil catena were investigated at the Ontario Benchmark Sites. Data collection in 1991, when the sites were established, provided a reference point for monitoring changes over time of dynamic soil properties for the no-till and conventional till sites at this location. Resampling of 20 locations on the benchmark monitoring grids, and comparable sampling on an uncultivated control site, in 2001, used the same methodologies and sample points. Differences in depth of solum, $\mathrm{pH}$, organic carbon and bulk density were attributable to topography within each of the sites, and differences in the same suite of parameters were observed at similar topographic positions across the three sites. The selected soil properties were sufficiently sensitive to management to be useful indicators of soil property change in the sloping landscape of the Guelph catena soils. The use of the 'benchmark' data collected in 1991 allowed the evaluation of trends over time in soil property change. Detailed soil pedons in each major slope position of the three sites allowed the determination of whether the changes that have occurred under the different tillage systems have changed the horizonation sufficiently to affect the taxonomy of the soil.
\end{abstract}




\section{Preface}

"The nation that destroys its soil, Destroys itself."

Franklin Delano Roosevelt

I would like to express my sincere gratitude to my advisors Ken Torrance and Chang Wang, for their encouragement, friendship and support throughout this project. I would also like to offer my appreciation to Art Davis and to the Greenspan Corporation for giving me permission to resample these important sites and for answering my many questions. I would also like to acknowledge the contribution of Don King and Greg Wall for giving me access to data as well as their intimate knowledge gathered for this site. I want to thank Les White for his encouragement and his persistence that got me started on my studies and to my colleagues Ted Huffman and Ed Gregorich who supported me during this entire process.

The laboratory analysis was completed with the generous assistance of Jeff Brown. I want to thank David Lapen for his advice on statistical analysis. I would also like to thank Hazel Anderson for helping me through my trials with registration. I want to thank Jeff Brown for assisting with field data collection and for Chang Wang for his wise mentoring and knowledgeable teaching in the fine art of soil sampling and description.

I would also like to thank and acknowledge Dr. Alex McKeague for his role as External Examiner for my Thesis defense. I truly admire and appreciate his fairness and attention to detail which greatly benefited me and helped me focus and prepare a much better final product.

Finally I would like to thank my family for their ongoing support throughout this project. I want to thank my brother Tom for his example and guidance. I am particularly thankful to Sheila who believed that I should pursue my education and was patient and supportive to the extreme during the entire process. 


\section{Table of Contents}

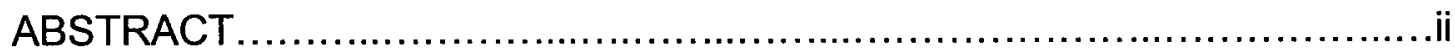

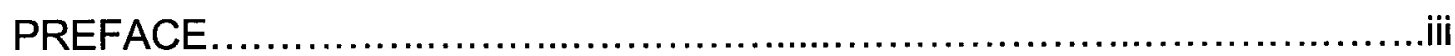

TABLE OF CONTENTS .....................................................

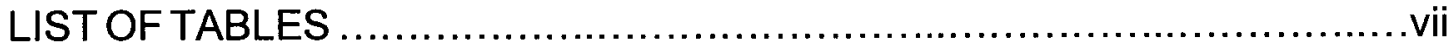

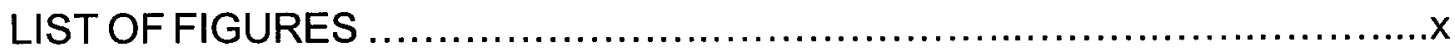

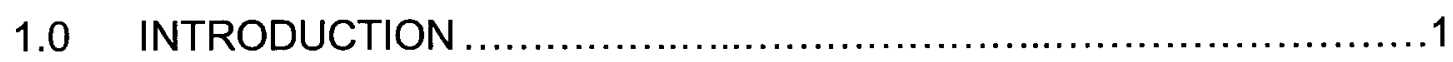

2.0 LITERATURE REVIEW .............................................

2.1 SOIL FORMATION: FACTORS AND PROCESSES .................. 6

2.2 TOPOGRAPHIC AND TILLAGE EFFECTS ON SOIL PROPERTIES, QUALITY AND TAXONOMY ........................ 12

2.2.1 Effects of Topography ....................................... 12

2.2.2 Effects of Tillage and Time ................................ 16

2.2 .3 Effects on Taxonomy ....................................... 18

2.3 SUMMARY .......................................................... 21

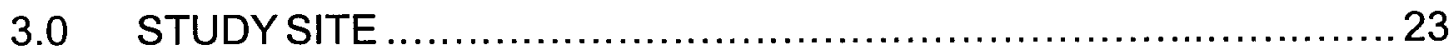

3.1 SITE LOCATION AND CHARACTERIZATION: ....................... 23

3.2 DESCRIPTION OF THE ECODISTRICT, ECOREGION AND

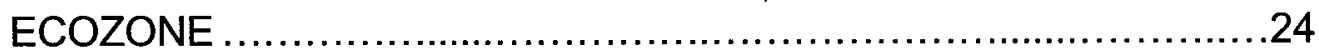

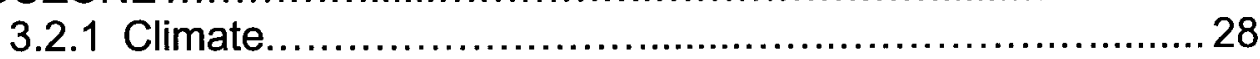

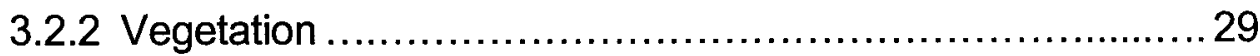

3.2 .3 Site Physiography........................................... 29

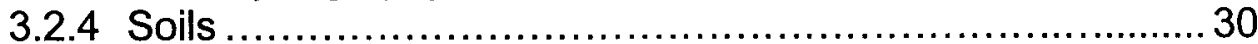

3.2.4.1 Guelph Series ....................................... 31

3.2.4.2 Parkhill Series ...................................... 32

3.3 SITE HISTORY, MANAGEMENT AND CROP ROTATION: ............ 33

4.0 THE FIELD AND LABORATORY PROGRAM ........................ 36

4.1 SOIL PEDON DESCRIPTION AND SAMPLING .................... 36

4.2 BENCHMARK GRID RESAMPLING ............................. 37

4.2.1 Sampling at a Grid Point ....................................... 38

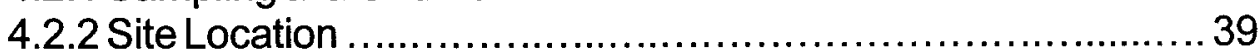

4.2.3 Depth of Solum Transects ................................. 39

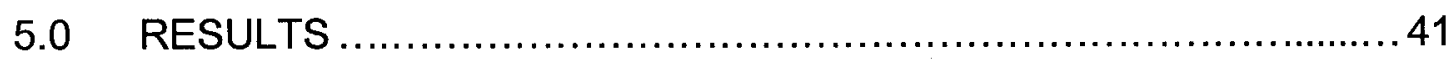

5.1 PEDON DESCRIPTIONS ....................................... 42

5.1.1 Control Pit \#1 - Upper Slope Position ......................... 43

5.1.2 No-till Pit \#1 - Upper Slope Position ............................ 44

5.1.3 Conventional Pit \#1 - Upper Slope Position. ...................45 
5.1.4 Control Pit \#2 - Mid Slope Position ................................46 46

5.1.5 No-till Pit \#2 -Mid Slope Position ............................... 47

5.1.6 Conventional Pit \#2 - Mid Slope Position ..................... 48

5.1.7 Control Pit \#3 - Lower Slope Position ............................ 49

5.1.8 No-till Pit \#3 - Lower Slope Position .............................. 50

5.1.9 Conventional Pit \#3 - Lower Slope Position ....................... 51

5.2 STATISTICAL ANALYSIS OF SOIL PROPERTIES ......................52

5.2 .1 Solum Depth ............................................. 52

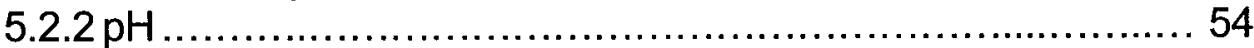

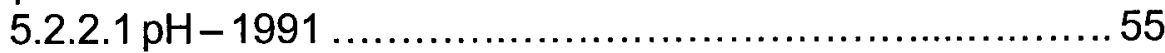

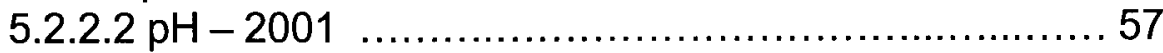

$5.2 .2 .3 \mathrm{pH}$-Change Over Time ............................... 59

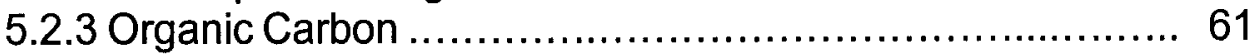

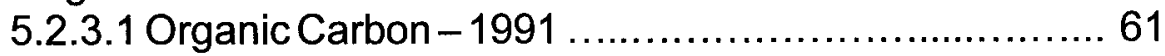

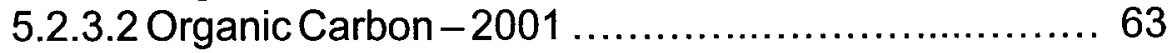

5.2.3.3 Organic Carbon - Change Over Time .....................6 65

5.2.4 Bulk Density................................................. 67

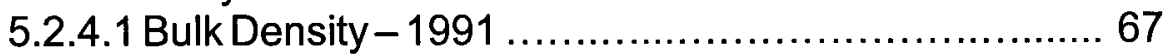

5.2.4.2 Bulk Density-2001 ................................... 69

5.2.4.3 Bulk Density-Change Over Time ........................ 71

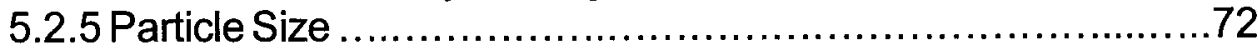

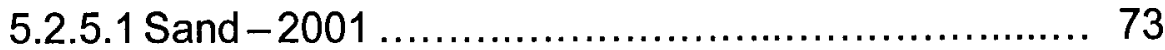

5.2.5.2 Silt-2001 ............................................. 75

6.0 DISCUSSION AND CONCLUSION ...................................... 78

6.1 SOIL PROPERTY DIFFERENCES RELATED TO TOPOGRAPHIC POSITION .............................................................. 82

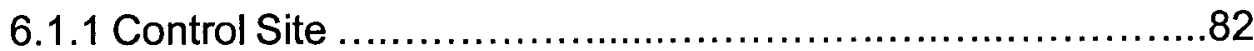

6.1.2 No-till Site ........................................................... 84

6.1.3 Conventional Till Site .............................................. 86

6.1.4 Summation of Topographic Effects .............................88

6.2 SOIL PROPERTY DIFFERENCES RELATED TO TILLAGE: ...... 88

6.2.1 Comparison of the Control, No-Till and Conventional Till Sites................................................................. 89

6.2.2 Summation of Tillage Effects ..................................... 94

6.3 SOIL PROPERTY DIFFERENCES RELATED TO TILLAGE

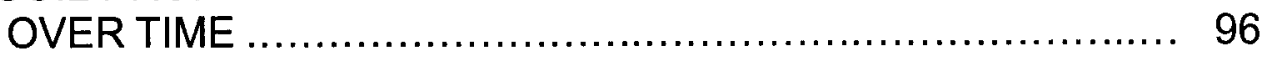

6.3.1 No-till Site .......................................................... 96

6.3.2 Conventional Till Site ............................................... 98

6.3.3 Summation of Tillage Effects over Time ..........................99

6.4 EFFECTS ON SOIL TAXONOMY RELATED TO TILLAGE........ 101 


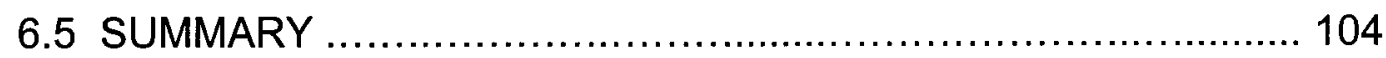

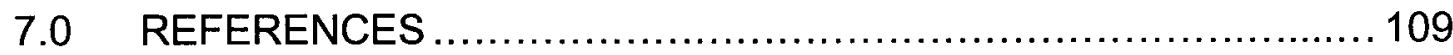

8.0 APPENDICES ....................................................... 112

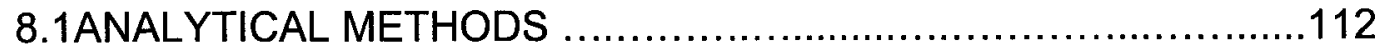

8.1.1 Bulk Density (Core Method) ………................................. 112

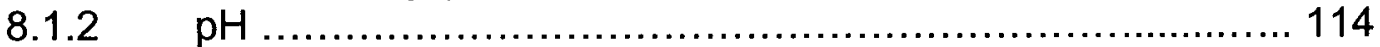

8.1.3 Total Carbon, Leco Induction Furnace ........................ 115

8.1.4 Particle Size Distribution .................................... 119

8.2 SITE ANALYTICAL DATA …......................................... 125

Table 8.2.1 Site \# 14 - 1991 Data ................................... 125

Table 8.2.2 Site \# 44 - 1991 Data ................................ 126

Table 8.2.3 Site \# 14 - 2001 Data ................................... 127

Table 8.2.4 Site \# 44 - 2001 Data ..................................128

Table 8.2.5 Control Site - 2001 Data .................................. 129

Table 8.2.6 Detail Soil Pits - 2001 Data. ..............................130

Table 8.2.7 Solum Depth Measurement Transects By Slope

Position - 2001.......................................... 131

8.3 TILLAGE SYSTEM INFORMATION ...................................... 132 


\section{LIST OF TABLES}

Table 3.1 Temperature and Precipitation for Ecodistrict \#560 from Canadian

Ecodistrict Climate Normals 1961-1990.

Table 3.2 Crop types and number of reporting and hectares reported Eramosa Township, Wellington County from the 1996 Census of Agriculture.

Table 4.1 The number of sample points in the solum transects in each Landscape position.

Table 5.1 Means and t-test results for solum depth for land management systems and slope positions for 2001 data.

Table 5.2 Means and t-test results for solum depth for slope positions between land management systems for 2001 data.

Table 5.3 Means and t-test results for $\mathrm{pH}$ for land management systems and slope positions for 1991 data.

Table 5.4 Means and t-test results for $\mathrm{pH}$ for slope positions between land management systems for 1991 data.

Table 5.5 Means and t-test results for $\mathrm{pH}$ between slope positions within land management systems for 2001 data.

Table 5.6 Means and t-test results for $\mathrm{pH}$ between land management systems for all slope positions for 2001 data.

Table 5.7 Mean surface $\mathrm{pH}$ values and t-test results comparing 1991 and 2001 data for all slope positions for the no-till and conventional till sites.

Table 5.8 Means and t-test results for surface organic carbon (\%) for land management systems and slope positions for 1991 data.

Table 5.9 Means and t-test results for surface organic carbon (\%) for slope positions between land management systems for 1991 data.

Table 5.10 Summary of means and t-tests for surface organic carbon \% results for land management systems and slope positions for 2001 data. 
Table 5.11 Means and t-test results for surface organic carbon $\%$ for slope positions between land management systems for 2001

data.

Table 5.12 Mean surface organic carbon values (\%) and t-test results comparing 1991 and 2001 data for all slope positions for the no-

till and conventional till sites.

Table 5.13 Means and t-tests for mean bulk density $\left(\mathrm{g} \mathrm{cm}^{-3}\right)$ results for no-till and conventional till land management systems and slope positions for 1991 data.

Table 5.14 Means and t-tests for mean bulk density $\left(\mathrm{g} \mathrm{cm}^{-3}\right)$ results for slope positions between the no-till and conventional till land management systems for 1991 data. .68

Table 5.15 Means and t-tests for mean bulk density $\left(\mathrm{g} \mathrm{cm}^{-3}\right)$ results for land management systems and slope positions for 2001 data .70

Table 5.16 Means and t-tests for mean bulk density $\left(\mathrm{g} \mathrm{cm}^{-3}\right)$ results for slope positions between land management systems for 2001 data. ....70

Table 5.17 Mean surface bulk density $\left(\mathrm{g} \mathrm{cm}^{-3}\right)$ values and t-test results comparing 1991 and 2001 data for all slope positions for the notill and conventional till sites.

Table 5.18 Means and t-test results for mean sand fraction (\%) for land management systems and slope positions for 2001 data.

Table 5.19 Means and t-test results for the sand fraction (\%) for slope positions between the land management systems for 2001 data.

Table 5.20 Means and t-test results for mean silt fraction (\%) by land management systems and slope positions for 2001 data. 76

Table 5.21 Means and t-test results for mean silt fraction (\%) by slope positions between land management systems for 2001 data. ....76

Table 6.1 Slope position within treatment comparison - significant differences (increasing or decreasing). 85

Table 6.2 Slope position comparison across management systemssignificant differences (increasing or decreasing). 
Table 6.3 Trends in soil property change between land management Systems (C - NT - CT) by slope position.

Table 6.4 Comparison across time (1991-2001), within treatment differences (significant/not significant-increasing/decreasing). ...98

Table 6.5 Summary of the soil classifications by management system and slope position. 


\section{LIST OF FIGURES}

Fig 2.1 Hypothetical scheme for soil horizon differentiation. Based on R. W. Simonson (1959).

Fig 3.1 Location of Benchmark Sites \#14 \& \#44 in Ecodistrict \#560 near Guelph, Ontario.

Fig 3.2 Location of the Ontario Benchmark sites \#14 \& \#44 near Rockwood Ontario.

Fig 4.1 Locations of transects, grid point and pedon (detail pit) sampling locations at the Ontario Benchmark Sites \# 14, \#44 and Control (Rockwood, Ontario) 2001.

Fig 5.1 Landscape and soil profile photographs for the Control site for the upper slope position (Oct 11, 2001)...

Fig 5.2 Landscape and soil profile photographs for the No-till site for the upper slope position (Oct. 11, 2001).

Fig 5.3 Landscape and soil profile photographs for the Conventional till site for the upper slope position (Oct 11, 2001).

Fig 5.4 Landscape and soil profile photographs for the No-till site for the mid slope position (Oct 1 2001).

Fig 5.5 Landscape and soil profile photographs for the Conventional till site for the mid slope position (Oct 11, 2001).

Fig 5.6 Landscape and soil profile photographs for the Control site for the lower slope position (Nov. 7, 2001).

Fig 5.7 Landscape and soil profile photographs for the No-till site for the lower slope position (Nov. 7, 2001).

Fig 5.8 Landscape and soil profile photographs for the Control site for the lower slope position (Nov. 4, 2001).

Fig 5.9 Means and standard deviations of solum depth for three land management systems and three slope positions, 2001. .53

Fig 5.10 Means and standard deviations of surface (A-horizon) $\mathrm{pH}$ for the no-till and conventional till land management systems and three slope positions for the 1991 data. 
Fig 5.11 Means and standard deviations of surface (A horizon) $\mathrm{pH}$ for three land management systems and three slope positions for the 2001 data.

Fig 5.12 Means and standard deviations of mean surface (A-horizon) $\mathrm{pH}$ for the no-till and conventional till land management systems and three slope positions between the 1991 and 2001 data.

Fig 5.13 Means and standard deviations of surface (A-horizon) organic carbon (\%) for no-till and conventional till land management systems and three slope positions for the 1991 data.

Fig. 5.14 Means and standard deviations of surface (A-horizon) organic carbon (\%) for three land management systems and three slope positions for the 2001 data.

Fig 5.15 Means and standard deviations of mean surface (A-horizon) organic carbon (\%) for the no-till and conventional till land management systems and three slope positions for the 1991 and 2001 data.

Fig 5.16 Means and standard deviations of mean surface (A-horizon) Bulk Density $\left(\mathrm{g} \mathrm{cm}^{-3}\right)$ for the no-till and conventional till land management system and three slope positions for the 1991 data.

Fig. 5.17 Means and standard deviations of mean surface (A-horizon) Bulk Density $\left(\mathrm{g} \mathrm{cm}^{-3}\right)$ for three land management systems and three slope positions for the 2001 data.

Fig. 5.18 Means and standard deviations of surface (A-horizon) bulk density $\left(\mathrm{g} / \mathrm{cm}^{-3}\right)$ for the no-till and conventional till land management systems and three slope positions for the 1991 and 2001 data.

Fig. 5.19 Means and standard deviations of mean surface (A-horizon) Sand fraction (\%) for three land management systems and three slope positions for the 2001 data.

Fig. 5.20 Means and standard deviations of the mean surface (A-horizon) silt fraction (\%) for three land management systems and three slope positions for the 2001 data. 


\subsection{INTRODUCTION}

"Soil at Risk", a publication by the Standing Senate Committee on Agriculture, Fisheries and Forestry (1984), highlighted the threat to Canadian soils due to the impacts of agricultural practices. This report stated that "we are clearly in danger of squandering the very soil resource on which our agricultural industry depends". This report and other studies led to major research initiatives to address soil quality and health issues in Canadian soils. In "Health of Our Soils", a comprehensive summary of the state of the soil environment in Canada, Acton and Gregorich (1995, p. IX), state "The health of the agricultural industry depends upon both the quantity and health of the soil". Soils that have been cleared and that have been intensively cultivated have undergone significant changes in their chemical and physical properties. These changes have influenced the quality of the soil as indicated by decreased biological productivity (Viger et al. 1999).

The study of soil and landscape change as related to major soil landform types and soil series was initiated by a data collection and analysis project called the Ontario Soil Landscape Attribute Project (OSLAP), in which the author was a co-operand (Jarvis et al 1996). It was noted that a number of soils (including the Guelph soil, studied in the current research) that have been cleared and under long-term intensive cultivation differ from the original mapped soil series description, in terms of pedon development, soil attributes and in some cases taxonomy. The erosion and redistribution of soils on sloping landscapes in areas of intensive cultivation was particularly noted. 
Viger et al. (1999) state that there is a need to develop quantitative methods to determine soil quality at the farm and regional level. From the literature, a summary can be made of the measurable soil attributes that best define, measure and monitor soil quality. Webb et al. (2000) performed a statistical analysis on a benchmark site in central Nova Scotia with the objective of quantifying temporal changes in soil properties of agricultural importance $(\mathrm{pH}$, organic $\mathrm{C}$, total $\mathrm{N}$ and available $\mathrm{P}$ and $\mathrm{K})$ in order to determine how changes in soil properties relate to the soil landscape and soil series components of the mapped soils. Manning et al. (2001), in a study to determine the influence of topography on variability of soil properties, measured the thickness of each genetic horizon, depth to parent material, Ahorizon thickness, solum thickness and depth to carbonates to characterize the distribution of soil properties within the soil landscape. The development of a research project to measure and analyze agronomically significant soil attributes collected from the same sample points at different times could provide the basis for the identification of change trends in soil quality (Wang et al. 1994).

Soil genesis, as described by Simonson (1957) is a two step process involving the 'accumulation' of parent materials and the subsequent differentiation of soil layers or horizons in the profile. The horizon development is a result of four basic types of changes: additions, losses, transfers and transformations of chemical, physical and biological elements within the soil profile. These changes may promote horizon differentiation or 
may instead offset or retard horizonation. Land clearing and cultivation act as factors in soil development by altering and controlling the amount of organic matter and other components of the surface soil that is available for biological production and for chemical and physical weathering. Clearing and cultivation also expose the soil surface to the erosive forces of wind and water, and tillage operations displace soil. The effects of agricultural land management practices on soil development can be determined by examining their impacts on the additions and removals of components from the soil profile. Clearing and cultivation may also promote or retard the development of soil horizons and change measured soil properties through their effects on transfers of water, air, biological products and nutrients within the profile. Therefore examination of appropriate properties of the soil horizons in cultivated and comparable uncultivated sites could provide indications of the changes in soil formation due to soil management practices.

These changes can be noted and evaluated at the landscape level by measuring attributes of the soil profiles in various topographic locations. Soils that develop on similar parent materials and under similar climatic conditions, but have unlike characteristics because of differences in relief and drainage (topographic position) would respond differently to the effects of cultivation. Bergstrom et al (2001) concluded that the spatial variation of soil properties at a site is at a scale comparable with topographic variation. They determined that mapping at the detail of soil series provided a basis for investigation of subsequent changes in soil properties due to agricultural practices. Soil 
series, alone or grouped by drainage class, therefore, provided a framework by which to stratify the site for evaluation of effects of tillage practices on organic carbon mass and extrapolation of results to comparable sites within the same landscape (Bergstrom et al 2001). The soil series is the basic unit of soil classification, and consists of soils that are essentially alike in all major profile characteristics except the surface texture (Agriculture Canada 1976).

The purpose of this research study of the Guelph Catena soils at the Ontario Benchmark sites \#14 \& \#44 will be to assess the extent of soil property change in a sloping landscape due to erosion and compaction (as a consequence of cultivation and time). In addition, this study will provide quantification of the change in soil properties according to slope position when evaluated against a control site. This research study will test the utility of: the benchmark site as an appropriate study site to compare different cultivation systems; the value of 'uncultivated' control sites in the same soil catena; the use of historical benchmark data for this site to assess the extent of soil property change; and the value of detailed in-field pedon samples to provide context and integrate information. This study will use the measurements of solum thickness (measured as depth to carbonates, a criterion that is specific to soils on calcareous parent materials), bulk density, organic carbon content and $\mathrm{pH}$, and particle size fractions of the surface horizon to define and evaluate changes in soil properties due to slope position and cultivation practices at different slope positions. This research study will examine soil property change with landscape position, land management 
practice and time by comparing systematically-obtained current soil data against previously obtained benchmark site data, and data from detailed infield pedon descriptions in cultivated and 'uncultivated' control sites. 


\subsection{LITERATURE REVIEW}

The objective of this literature review is to focus on the methodologies and studies that deal with aspects of changes of soil properties due to topography and agricultural land management practices. To do this also requires reading on soil genesis, inherent and dynamic soil properties, the influence of different tillage practices on various soil properties, the influence of topography on soil properties and soil development, and spatial and temporal scales of study of soil properties.

Simonson's $(1957,1978)$ 'conceptual model' of soil processes has been utilized in the formation of a research hypothesis on the changes to soil properties and soil formation processes caused by agricultural land management practices in terms of additions, removals, transfers and transformations acting to promote or retard the development of horizons and to change measurable soil properties.

\subsection{SOIL FORMATION: FACTORS AND PROCESSES}

Jenny (1980) uses five factors to define the state of the soil system. He presented the equation $S=\int(\mathbf{c}, \mathbf{o}, \mathbf{r}, \mathbf{p}, \mathbf{t} \ldots .$.$) where (\mathrm{S})$ the soil that is formed is a function of the variable factors of climate (c), organisms (o), topography/relief $(r)$, parent material $(p)$, time $(t)$ and any other factors $(\ldots)$ that may affect soil formation. Johnson and Watson-Stegner (1987) describe the factors of soil formation formulated by Jenny as the functional-factorial model. The 'hypothetical message' that is demonstrated by the functionalfactorial model is that soils form and develop progressively under the control 
of the biophysical factors (Johnson and Watson-Stegner 1987). This model predicts that soils may progress from simple to complex and ultimately relatively stable or mature states over a period of time.

Buol et al. (1997) describe soil forming processes as "an assemblage of reactions occurring simultaneously or in sequence that create soil components and morphological features". For a given soil property to be present or measurable it must be able to co-exist with the current soil environment. Jenny (1980) used the term pedogeneic process for any process taking place in the soil space. These processes include the physical infiltration of water, eluviation of clay particles, microbial respiration, decomposition, tunneling by macrofauna and many others.

Simonson $(1957,1978)$ described soil formation as two overlapping steps, the first being the accumulation of parent material and the second, horizon differentiation. Each pedon results from combinations of processes, which have endured for a period of time (Simonson 1978). Figure 2.1 illustrates that soil genesis involves 'the combined effects of additions to the ground surface, transformations within the soil, vertical transfers (up or down) within the soil profile and removals from the soil" (Birkeland 1999). 

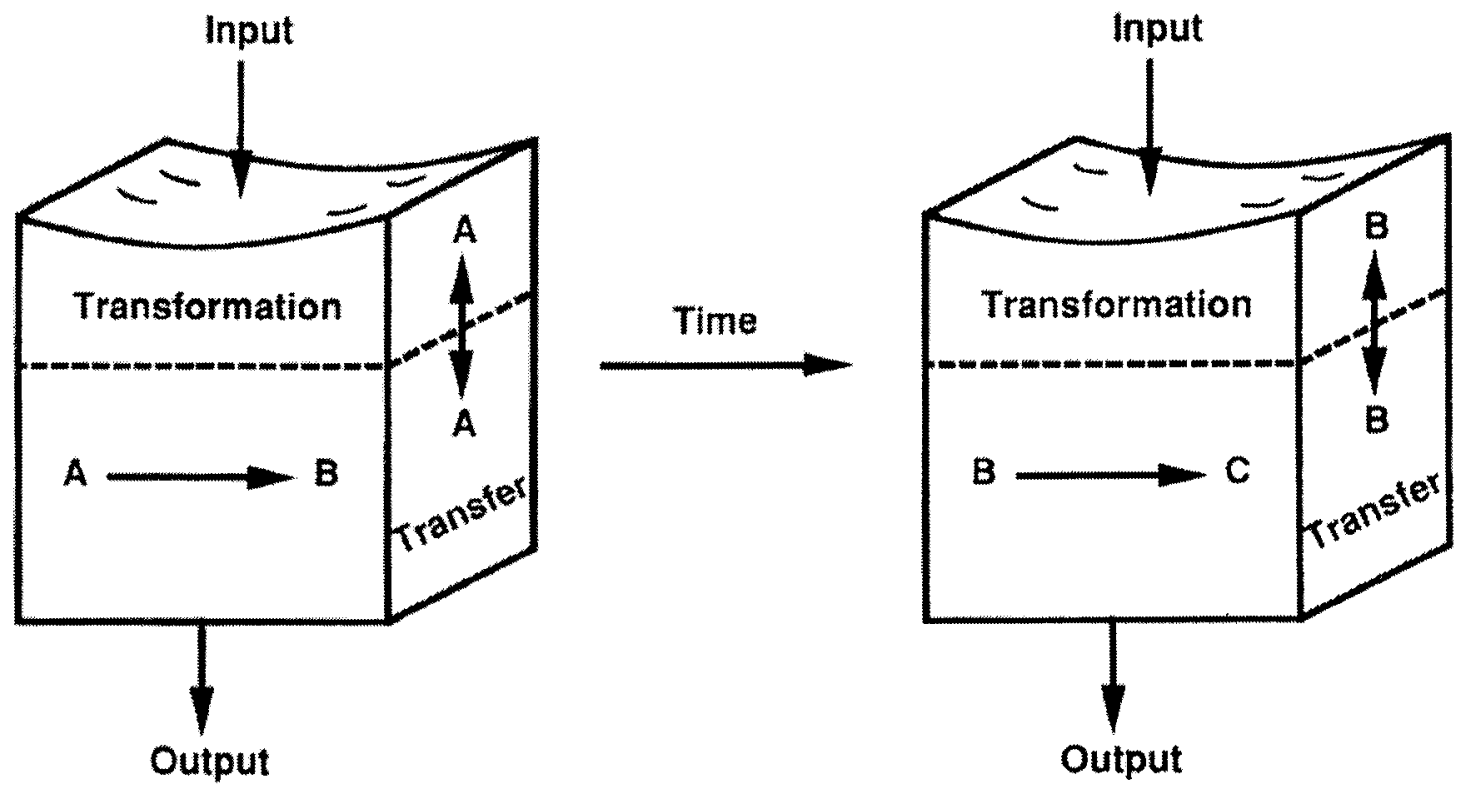

Fig 2.1 Hypothetical scheme for soil horizon differentiation. Based on R. W. Simonson (1959)

Simonson (1978) discusses additions to the soil in terms of: energy in the form of radiant energy; energy that has been incorporated in organisms and organic residues; atmospheric water with dissolved materials; oxygen in the soil atmosphere and dissolved in solution; organic matter from the remains and waste products of living flora and fauna; dust from the atmosphere; and eroded materials transported from elsewhere by wind and water.

The losses of energy and matter from the soil profile may occur during horizon differentiation. Losses may be the result of leaching, removal by erosion, and volatilization (Simonson 1978). Decomposition of organic matter is an example of a process which involves losses from the soil system $\left(\mathrm{CO}_{2}\right.$ goes to the atmosphere) but also produces a transformed residue within the profile. Soluble organic acids which are products of partial decomposition of 
organic matter and other soluble products can be leached from the soil in solution and enter the groundwater system. Simonson (1978) also states that runoff, percolation and substance removal can result in the loss of silica and silicates from the pedon.

Transformations in the pedon involve changes in both composition and form (Simonson 1978). Decomposition involves the transformation of organic matter in the pedon. For example, in a mixed or deciduous wood lot in southern Ontario most of the organic matter (i.e. leaf litter) added to the soil surface during the growing season is decomposed within the year; only a small fraction will persist for longer periods and may become a long-term part of the humus in the soil profile. Simonson (1978) also gives the example of primary silicate minerals degraded to form secondary minerals, which can be further decomposed to form other secondary materials. Some losses of soluble materials normally occur during this transformation process.

A fundamental concept that Simonson (1978) presents is that the "key to the nature of every soil is the balance over time of a host of individual processes; this balance determines the characteristics of the soil profile". In the span of geological time, soils and soil profiles are temporary or transient phenomena, soils have been formed and degraded and reformed a number of times. Soils may be altered by changes in the environment, but do not have to be destroyed. The path of horizon formation and differentiation may be altered as the soil forming factors change and new characteristics are expressed. 
Simonson (1978) states that these processes of soil formation do not necessarily promote horizon differentiation; some tend to retard or offset differentiation, while others promote it. The processes that function to develop and differentiate horizons are often interrelated, for example the process of decomposition of organic matter (transformation) can alter the chemical properties of the soil that promote the transfer of mineral and organic material which could ultimately be lost or removed from the profile. As noted from Simonson (1980) certain changes (profile development) may proceed in one direction and some in the other, the progressive route is not the only pathway of soil development. Certain processes and conditions such as pedoturbation, erosion or compaction due to cultivation can lead to simplification of or to regressive pedogenesis (Johnson and Watson-Stegner 1987).

Johnson and Watson-Stegner (1987) cite a model by Johnson (1985) of soil thickness that incorporates some of the concepts of Simonson into an integrative equation. The thickness $(T)$ of any soil is function of the variable processes of removals $(R)$, upbuilding $(U)$, and deepening (D). Where $\mathbf{T}=\int(\mathbf{D}+\mathbf{U}-\mathbf{R})$.

Johnson and Watson-Stegner (1987) integrate the concepts of 'horizonation/progressive' pedogenesis and 'simplification/regressive' pedogenesis with the soil thickness model. The assumptions that they incorporate into this model are: "soils are complex open systems, continuously adjusting by variable degrees, scales and rates to variable energy and mass fluxes, thermodynamic gradients, and other changing 
exogenous environmental conditions" (Johnson and Watson-Stegner 1987). This evolutionary model was developed to help account for the phenomena of soil thickness changes, increased horizon development (genetic complexity) with time and the fact that the rate and direction of soil development can also be altered. The formula derived for this model is: $\mathbf{S}=\int(\mathbf{P}, \mathbf{R}) . \mathbf{S}$ the soil that is formed is a function of; $\mathbf{P}$ - progressive pedogenesis: "those processes, factors and conditions that promote differentiated profiles leading to chemical and physical stability, observable as horizonation, developmental assimilative deepening or upbuilding"; and a function of $\mathbf{R}$ - regressive pedogenesis: "soil regression, processes, factors and conditions that lead to simplifying profiles, described as rejuvenation processes such as surface removals and retardant upbuilding" (Johnson and Watson-Stegner 1987).

Birkeland (1999) does not list agricultural clearing and cultivation as an obvious cause of regressive pedogenesis. However clearing and cultivation are similar to the effects of fire (which he cites) and can promote surface runoff and rapid soil loss. The removal of the protective surface vegetative layer and the creation of a less permeable surface (i.e. through compaction) reduce surface infiltration and promote runoff and erosion. The effects of cultivation and the scale at which agriculture is practiced globally are among of the most significant factors controlling regressive pedogenesis, soil evolution and changing soil properties and ultimately the productivity (quality) of the soils. Norfleet et al. (2003) state that management can affect ongoing pedogenesis processes. For the near-surface properties of the soil, human 
activity (organisms in the Jenny equation) is a dominant force in pedogenesis. Through management humans can change the nature of the soil in a very short time. Norfleet et al. (2003) note that not all practices are regressive; the increase in the use of fertilizers increases the nutrient status of the soil and can increase the organic mass of the soil to more than that of the native soil and can enhance soil functions.

\subsection{TOPOGRAPHIC AND TILLAGE EFFECTS ON SOIL PROPERTIES, QUALITY AND TAXONOMY}

The evaluation of changes in soil quality or soil health involves the detection of changes of soil chemical, physical or biological properties in space and time. An understanding of baseline or long term conditions or a good understanding of local or regional soil resources and management practices is a requirement to determine the type and nature of soil quality change. Olson et al. (1994) identify the requirement of determining the properties of the uneroded pedon as the benchmark to which eroded soils of the same taxon can be compared.

\subsubsection{Effects of Topography}

Jenny $(1941,1980)$ incorporated topography as a 'state factor' in his conceptual model of soil formation. The research papers reviewed below have investigated the role of topography in the change of soil properties in various land management systems. Bergstrom et al. (2001) state that the influence of topography on soil organic matter content has long been recognized. The objective of the study by Bergstrom et al. (2001) was to 
relate the spatial dependence of soil organic carbon mass in two adjacent fields with contrasting tillage practices (no-till and conventional till) to topographic features and soil series. Agriculture and Agri-Food Canada established a network of 23 soil quality benchmark sites in different regions across Canada in 1991(Wang et al. 1994). Webb et al. 2000 performed a statistical analysis on one of these Agriculture and Agri-Food benchmark sites in central Nova Scotia in an attempt to quantify temporal changes in soil properties of agricultural importance $(\mathrm{pH}$, organic $\mathrm{C}$, total $\mathrm{N}$ and available $\mathrm{P}$ and $\mathrm{K}$ ) in order to determine how differences in soil properties relate to the soil landscape and soil series components of the mapped soils. The influence of topography on the variability of soil properties was investigated by Manning et al. (2001) for an undulating Manitoba landscape in order to characterize the distribution of soil properties within topographic units in an undulating glacial till landscape.

Bergstrom et al. (2001) determined that in both the no-till and conventional till treatments the imperfectly drained soil series of the lower slope positions contained the largest mass of organic carbon in the Ahorizon, and the moderately well drained soil series characteristic of the upper to mid slope positions contained the least mass of organic carbon.

Bergstrom et al (2001) concluded that the spatial dependence of organic carbon mass was at a scale corresponding to topographic variation and that topography is the controlling process. Eroisional processes on sites in landscapes with variable relief can also influence soil carbon. The authors 
used soil series identified at sampling positions as a framework to stratify the site for evaluation of tillage effect on organic mass and to extrapolate to comparable sites within the same landscape. The use of soil series grouped by drainage class provided a tentative framework for stratifying the sampling site for the effects of management practices on organic mass at scales such as farm management units. They concluded that the use of soil taxonomic units allows the extension of results of the tillage comparison to comparable sites within the same landscape for which detailed soil taxonomic information is available.

Webb et al. (2001) concluded that the statistical analysis on an Agriculture and Agri-Food benchmark was successful in detecting changes in agronomically important soil properties $(\mathrm{pH}$, organic carbon, total nitrogen and available potassium) with varying levels of sensitivity. It was noted that for the interaction between particle size and slope positions, soils with coarseloamy sola on upper slopes had lower $\mathrm{pH}$ values than those soils on mid, lower or toe slope positions. Soils with coarse-loamy sola on mid and lower slope positions had significantly lower $\mathrm{pH}$ than on the toe slopes. The variability of soil properties used to monitor soil quality change at this benchmark site were correlated, to varying degrees, with components of the soil map unit (soil series), and to a much lesser extent, to landscape position. There was a higher correlation with soil series (coarser scale of resolution) components of the mapped soils than with site or slope specific data. 
Manning et al. (2001) state that "soil properties may be predicted as a function of topography, through mathematical models". They argue that at the landscape scale, soils form that are taxonomically and functionally distinct due to variable levels of accumulation of sediments and that the net effect of downward movement of water is controlled by the nature of the slope (convergent or divergent). The authors concluded that the analysis of landform element complexes (i.e. upper, mid and lower slope positions) detected differences in soil properties for convergent and divergent slope positions. The soil properties of organic $\mathrm{C}$ content, thickness of the $\mathrm{A}$ horizon, depth to carbonates and thickness of the solum were related to the degree of slope and whether the slope positions were water shedding or water holding. There was a consistent trend of lower>mid>upper with respect to depth of carbonates, A-horizon thickness, solum thickness and organic carbon content. The division of the site into landscape elements represents a means for capturing 'gross' variability in the soil attributes. They determined that the scale of measurement, the influence of pedogenic controls and agricultural management practices could limit the applicability of this methodology.

The approach utilized by Bergstrom et al. (2001) provides a sound method of extrapolating results to comparable sites within the same landscape, and provides a more robust framework for interpolation than the Webb et al. (2000) approach. Although the study by Bergstrom et al. (2001) was not designed to investigate soil quality, the methodology would allow this type of evaluation to be made when utilized at a different site, due to the 
ability to detect change due to cultivation in these sloping landscapes. Manning et al. (2001) presents a methodology that would be useful in the division of the site into landscape elements and a means for capturing change in the soil attributes due to topographic position.

While is has been known and documented for a long period of time that soil material is eroded from upper and mid slope positions and deposited in lower slope positions, the recent literature cited in this review is included to confirm the current knowledge and research that has been done in Canada. In particular, it is being used to set the context for change and quantification of change for the purpose of this study.

\subsubsection{Effects of Tillage and Time}

The role of tillage in the change of soil properties in various land management systems is summarized from several sources.

Boehm and Anderson (1997) conducted research with the objective being able to assess soil quality at the landscape scale in farmers' fields which were managed under three farming systems common on the prairies: alternating crop-fallow; fallow every 3-5 years; and no fallow (continuous cropping). They evaluated the influence of tillage on carbon sequestration scale dependence on a till site in Manitoba. The authors were testing for an interaction between tillage practice (no-till (NT) and conventional till (CT)) and topography as determinants of organic $C$ stocks in the entire solum and defined layers at a field scale. They concluded that, even with consideration of the relatively large variability (some attributable to topography and some 
random) in farmers' fields, systematic changes in organic C, bulk density, plow layer depth, $\mathrm{pH}$ and soil respiration were sufficiently sensitive to be useful indicators of soil quality. Soils under continuous cropping had thicker sola, slightly more organic $\mathrm{C}$ and higher infiltration rates; bulk density of the plow layer, $\mathrm{pH}$ and soil respiration were lower. Their experimental design provides the basis for development of a testing procedure for the detection of systematic changes in soil properties resulting from land use practices.

Bergstrom et al (2001) evaluated the influence of scale dependant carbon sequestration on a till site in Manitoba. The scales for comparison of data were defined as the soil horizon, the solum, the soil series and the drainage unit. The objective stated by the authors was to test for an interaction between no-till and conventional till land management practices and topography as determinants of organic $C$ stocks in the entire solum and defined layers at a field scale. The different tillage practices had been maintained over a substantial length of time (21 years). Bergstrom et al. note that because the study was not replicated it represents a single case and should only be considered as providing a hypothesis that can be tested at other sites. The effect of cultivation was evaluated by comparison of organic $\mathrm{C}$ mass between four uncultivated plots and four adjacent cultivated positions on the same soil series in each field. The effect of tillage practice on organic C mass was found to be dependent on slope position and sampling depth. The use of a no-till land management practice increased organic $C$ stocks in the surface layer $(0-8 \mathrm{~cm})$ for the well drained upper slope positions, but not 
at imperfectly drained lower slope positions. At lower slope positions there was more organic carbon in the entire A-horizon of the CT than the NT field. The results demonstrate that the influence of the topographic factor must be a considered when assessing the effect of tillage practice at scales such as farm management units.

Both the papers presented by Webb et al. (2000) and Bergstrom et al. (2001) have a temporal component to their investigations. The study by Webb et al. (2000) performed a statistical analysis on an Agriculture and Agri-Food benchmark site in central Nova Scotia in an attempt to quantify temporal changes in soil properties of agricultural importance $(\mathrm{pH}$, organic $\mathrm{C}$, total $\mathrm{N}$ and available $\mathrm{P}$ and $\mathrm{K}$ ). Bergstrom et al. noted that the difference in tillage practice over a substantial length of time (21 years) was a major factor in evaluating the effects of no-till and conventional till management between the two.

Webb et al. (2000) were able to determine that mean $\mathrm{pH}$, organic carbon, C: $\mathrm{N}$ ratio, and available $\mathrm{P}$ declined over the 5 year period of sampling of the benchmark site they studied, while values for total $\mathrm{N}$ and available $\mathrm{K}$ remained the same. Penetration resistance at various depths increased significantly during this time period.

\subsubsection{Effects on Taxonomy}

The definition of 'modern pedology', "how soils form, their distribution on the landscape, and how their properties influence, or are influenced by, land use"Norfleet et al. (2003) encompasses aspects of soil quality ". This is 
slightly different from the standard definition as pedology being, "the study of soils as natural bodies, the properties of the soil horizons, and the relationship among soils within a landscape (Brady et al 1996), linking the soil properties to land use. Soil classification as defined in U.S. Soil Taxonomy is based on diagnostic criteria associated with soil horizons and properties (Soil Survey Staff 1999). Pedology can be the unifying concept integrating concepts from geology, geography and botany. Norfleet et al. (2003) argue that soil quality (the capacity of a specific kind of soil to function, within managed or natural ecosystem boundaries, to sustain plant and animal productivity, maintain or enhance water and air quality and support human health and habitation) plays a similar role to" integrate physical, chemical and biological portions of the soil with agricultural sustainability, economic viability and environmental quality".

Soil classification and mapping focus on inherent soil properties "that aspect of soil quality relating to a soil's natural composition and properties as influenced by the factors and processes of soil formation" http://soils.usda.gov/; these are the properties of the soil that are more or less permanent. These inherent soil properties have been termed use-invariant (Nofleet et al. 2003), but the properties of the plow layer which are critical to biological productivity and the 'healthy' functioning of the soils have been termed use dependent or dynamic soil properties. It should be noted however, that properties such as structure below the cultivated layer may be greatly affected by cultivation traffic. These latter are the properties that have to be measured and monitored and subsequently related to the inherent soil 
properties that are reported in the soil inventory databases (Norfleet et al. 2003). Soil surface properties that change and vary in response to land use and management practices are difficult to incorporate into soil classification and mapping. The key to soil quality studies then is an understanding of the inherent soil quality which is a result of inherent soil properties as a function of the five soil forming factors as defined by Jenny (1980) in conjunction with dynamic soil quality which takes into account the changes in soil properties as the result of land use and management (Norfleet 2003).

The information contained in soil surveys becomes the medium for communicating knowledge about soil form and function through measurement and description of selected soil properties, in turn providing information for land use planning and management decisions (Norfleet et al. 2003). The authors argue that soil quality relates changes in the soil's capacity to function for the soils intended purposes to changes in land use or management practices. Therefore pedology serves to gather and describe information regarding where soils occur and how they function, whereas the assessment of soil quality involves determining how the functioning of soil changes in response to land management practices.

Inherent soil properties enable the comparison of one soil to another and an evaluation of the suitability for use or function. Determinations of soil quality indicate the degree of change of the dynamic soil properties and the effect that this has on the system. It is suggested that determinations of soil 
quality should not be done across contrasting soil but across management practices on similar soils i.e. soil catenas (Norfleet et al 2003).

In an applied study to quantify soil loss from eroded soil phases, Olson et al. (1994) determined that a major problem in soil classification is determining the effects of rapid erosion on diagnostic surface horizons or shallow subsurface horizons and the impacts that these changes have on the classification and mapping of these affected soils. They state that "a slight change in thickness (mollic epipedon) can result in a change in classification at the highest categorical level (Order) of Soil Taxonomy". In their estimates of the quantities and rates of erosion on eroded phases they concluded that the most valid comparisons of soil loss were made when investigating "soils on similar landscape positions" and that the same applied for comparison of "soil property changes as a result of soil regeneration by soil forming processes". This is consistent with the discussion on the effects of topography on soil properties (Section 2.2.1)

\subsection{SUMMARY}

This review has summarized a range of the methodologies and studies that have dealt with changes to soil properties caused by agricultural land management practices and introduced their implication for soil taxonomic classification. To fully understand why and how soil properties change it is necessary to understand soil formation processes and how agricultural practices can interact with environmental factors to initiate and sustain change. The consideration of inherent soil properties that for the most part 
are unaffected by cultivation and the dynamic soil properties that are related to land management practices and interactions between the properties is critical to the understanding of how pedogenesis proceeds in agricultural landscapes. There is also a requirement to understand how soils under agriculture vary in space and time due to topographic position and tillage practices applied. 


\subsection{STUDY SITE}

Agriculture and Agri-Food Canada established a network of 23 soil quality benchmark sites in different regions across Canada between the years 1989 to 1992 (Wang et al. 1994). The sites were chosen to represent various Canadian agroecosystems. This monitoring of agronomically important soil attributes of the landscape under various farm production systems for a period of time (initially 10 years) was for the purpose of demonstrating and measuring changes in soil quality.

\subsection{SITE LOCATION AND CHARACTERIZATION}

Benchmark Sites \#14 and \#44, established in 1991, are located near Rockwood in southwestern Ontario at Latitude $43^{\circ} 38^{\prime}$ North and Longitude $80^{\circ} 11^{\prime}$ West (Fig. 1). These sites are located approximately $10 \mathrm{~km}$ northeast of the City of Guelph on Eramosa Township $4^{\text {th }}$ Line Road, Wellington County. Each site is about 2.5 ha in area. Both sites are on the side slope of a drumlin. The average slope for each site is $5 \%$ and slope lengths range from 200 to $300 \mathrm{~m}$. Site $\# 14$ is in a no-till (no-tillage or zero tillage cropping system) that has been under this management system since 1987 . No-till is a procedure whereby a crop is planted directly into the soil with no primary or secondary tillage since harvest of the previous crop, http://www.soils.org/) and site \#44 is managed under a conventional tillage (traditional fall plow) cropping system. The sites are separated by an 'uncultivated' (forested) road allowance (approximately 25 meters in width with a recreational trail down its length), which provided a 'control site' with the soil characteristics for the 
native condition. The sites were assessed and selected as benchmark sites because the cultivated area demonstrated some potential for change in chemical and physical properties as well as indications of soil degradation due to water erosion and soil compaction (Wang et al.1994). Selected soil variables have been assessed three times within this soil landscape: The first intensive sampling occurred in 1991, the second occurred in 1997 (both conducted by Dr. Chang Wang, Agriculture and Agri-Food Canada (AAFC), Ottawa and Don King of the Ontario Land Resource Unit AAFC, Guelph (Viger et al. 1999)), and the current sampling were conducted in 2001. Only the data from 1991 and 2001 was used for analysis and comparison for this study, due to the large volume of data and the scope of this study.

\subsection{DESCRIPTION OF THE ECODISTRICT, ECOREGION AND ECOZONE}

Benchmark sites \#14 \& \# 44 are located in Ecodistrict \# 560 (Figures

$3.1,3.2$ ), which is part of the Manitoulin - Lake Simcoe Ecoregion (\# 134), and part of the larger Mixedwood Plains Ecozone (\# 8) which covers the lower Great Lakes - St. Lawrence River Valley (Ecological Stratification Working Group 1995). The combination of geographic location, waterways, gentle topography, fertile soils, warm growing season and abundant rainfall have contributed to its being the most populated and intensely used area in Canada (Ecological Stratification Working Group 1995).

The Manitoulin - Lake Simcoe Ecoregion (\# 134) in southern Ontario extends from Manitoulin Island to Kincardine (Lake Huron) on the west with its southern boundary extending irregularly from Kincardine to Oshawa and 
along Lake Ontario to Kingston at the east end of Lake Ontario. The northern boundary for this ecoregion is the contact with the Canadian Shield. This ecoregion has one of the warmest climates in Canada. Ecodistrict \# 560 extends from Georgetown in the northeast to Cambridge in the southwest Ecological Stratification Working Group 1995). 


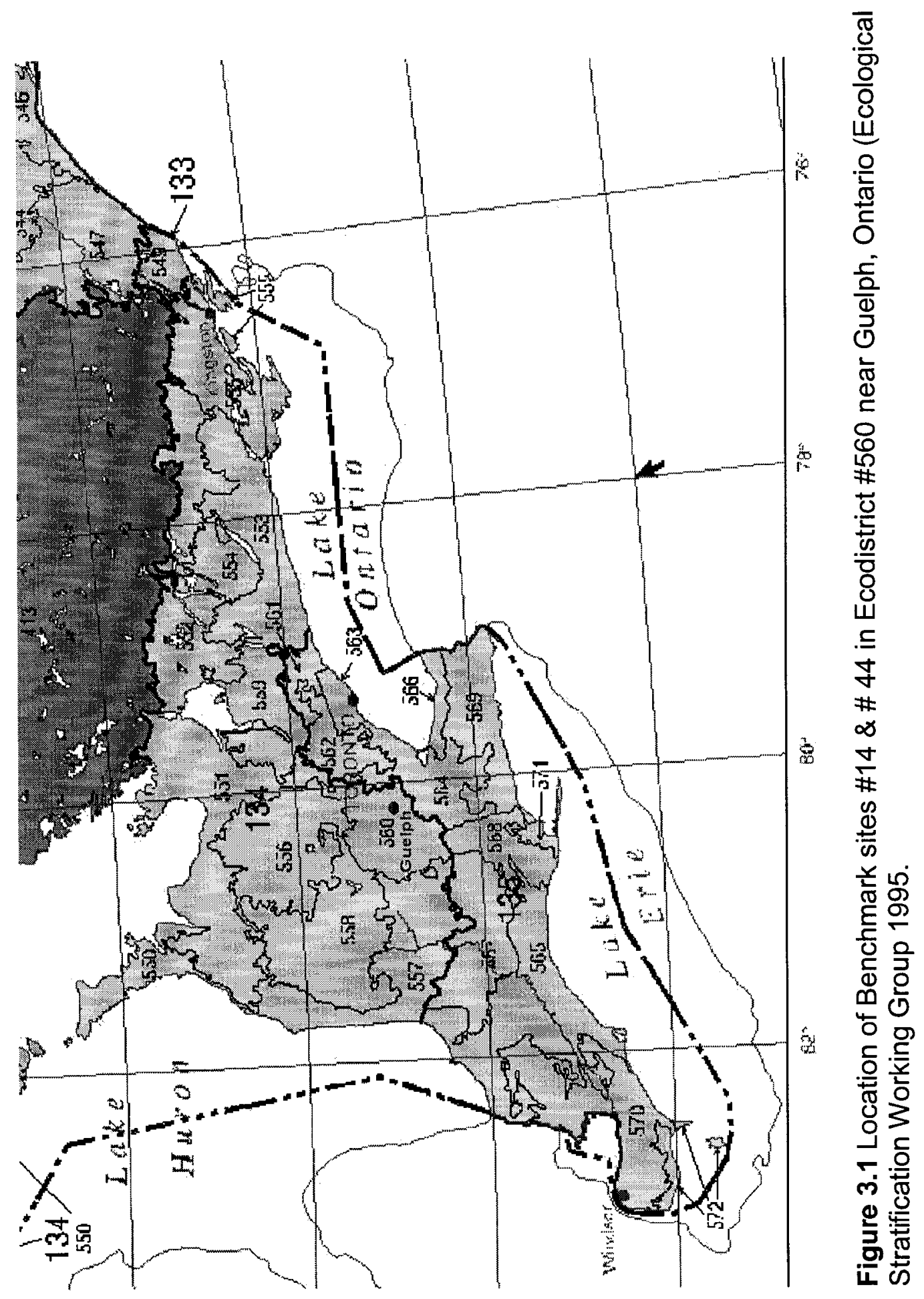




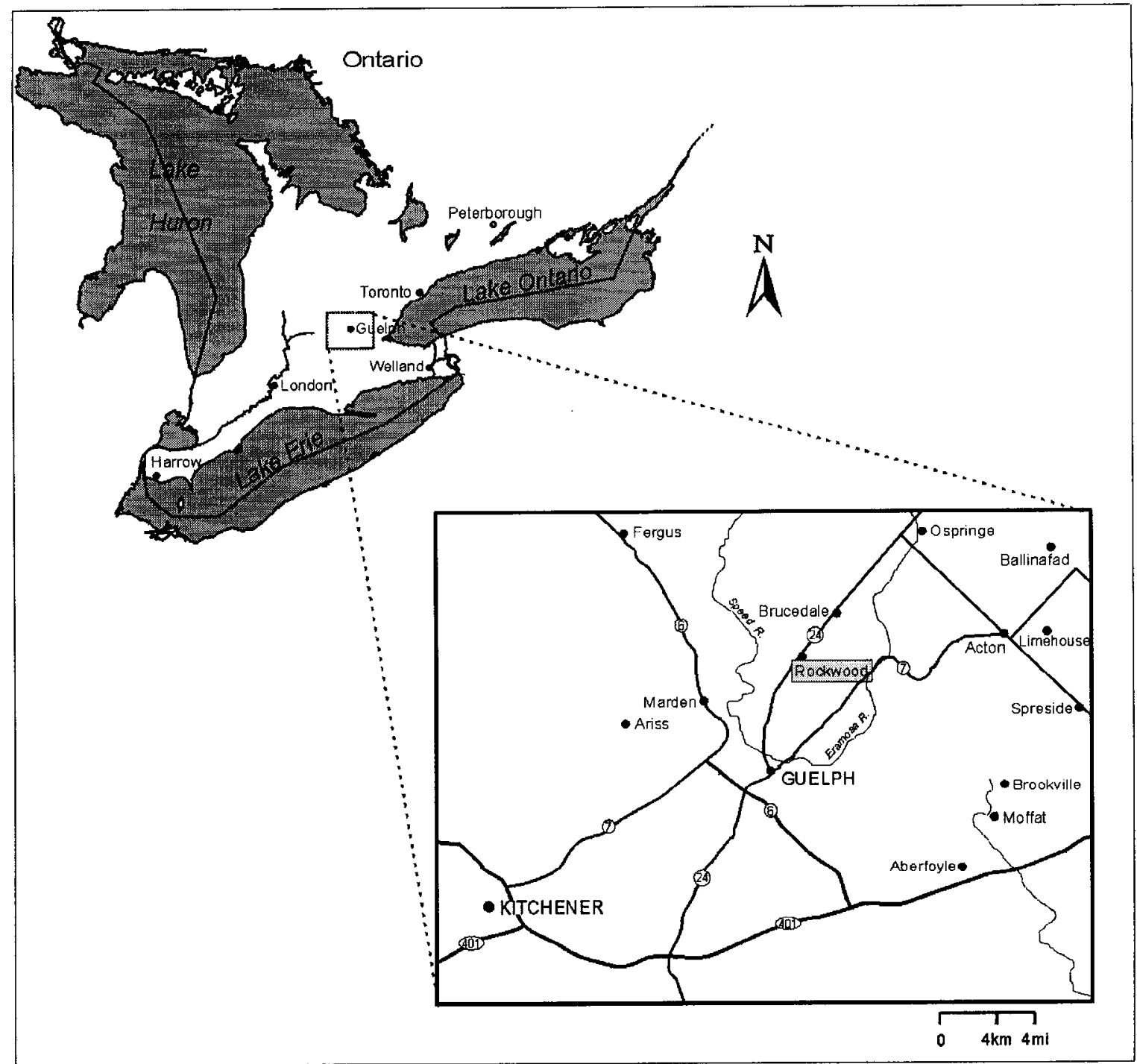

Figure 3.2 Location of the Ontario Benchmark sites \#14 \& \#44 near Rockwood Ontario. 


\subsubsection{Climate}

Ecodistrict \#560 is characterized by milder summer temperatures (18.8 ${ }^{\circ} \mathrm{C}$.) and somewhat cooler winters $\left(-6.1^{\circ} \mathrm{C}\right.$.) than the rest of Ecoregion \#134. Table 3.1 summarizes the mean, maximum and minimum temperature and precipitation from Canadian Ecodistrict Climate Normals 1961-1990. The mean annual precipitation is $909 \mathrm{~mm}$, with a mean snowfall of $151.80 \mathrm{~mm}$ and $757 \mathrm{~mm}$ of rain. The mean growing season length is 206 days with 1924 effective growing degree-days ( Ecological Stratification Working Group 1995).

Table 3.1 Temperature and Precipitation for Ecodistrict \#560 from Canadian Ecodistrict Climate Normals 1961-1990. http://sis.agr.gc.cal

\begin{tabular}{|l|r|r|r|r|r|r|}
\cline { 2 - 7 } \multicolumn{1}{c|}{} & \multicolumn{2}{l|}{ Temperature } & \multicolumn{3}{l|}{ Precipitation } \\
\hline Month & Mean & Minimum & Maximum & \multicolumn{1}{c|}{ Total } & \multicolumn{1}{c|}{ Snow } & \multicolumn{1}{c|}{ Rain } \\
\hline January & -7.4 & -11.4 & -3.6 & 59.4 & 39.3 & 19.5 \\
\hline February & -6.8 & -11.2 & -2.6 & 56.5 & 33.0 & 24.1 \\
\hline March & -1.6 & -6.0 & 2.7 & 68.3 & 22.0 & 45.7 \\
\hline April & 5.8 & 0.6 & 10.9 & 72.2 & 7.4 & 64.8 \\
\hline May & 12.3 & 6.5 & 18.1 & 74.9 & 0.3 & 74.6 \\
\hline June & 17.3 & 11.3 & 23.1 & 79.5 & 0.0 & 79.5 \\
\hline July & 20.1 & 14.1 & 26.0 & 81.1 & 0.0 & 81.1 \\
\hline August & 19.0 & 13.3 & 24.7 & 95.9 & 0.0 & 95.9 \\
\hline September & 14.8 & 9.4 & 20.2 & 88.0 & 0.0 & 88.0 \\
\hline October & 8.5 & 3.6 & 13.4 & 72.8 & 1.3 & 71.6 \\
\hline November & 2.6 & -1.0 & 6.1 & 83.2 & 10.8 & 72.8 \\
\hline December & -4.1 & -7.6 & -0.8 & 80.2 & 38.4 & 41.5 \\
\hline Annual & 6.7 & 1.8 & 11.5 & 909.0 & 151.8 & 757.3 \\
\hline
\end{tabular}




\subsubsection{Vegetation}

Ecodistrict \#560, where the Rockwood site is located, has a land cover characterized by $72 \%$ cropland, $24 \%$ mixed forest (canopy $26-75 \%$ conifer and broadleaf trees) and $4 \%$ urban. The mix of crops grown in 1996 is presented in Table 3.2.

Eramosa Township has a total of 11354 ha ( $38 \%$ of the township) in agricultural production with 461 farms, as reported in the 1996 Census of Agriculture (Table 3.2). Soybeans and corn are major crops, both are in the rotation at Sites \#14 and \#44. Alfalfa and alfalfa mixtures also account for a large area of crop production in this township.

Table 3.2 Crop types, number of reporting farms and hectares reported Eramosa Township, Wellington County from the 1996 Census of Agriculture.

\begin{tabular}{|l|r|r|}
\hline Crop Type & Farms Reporting & Hectares \\
\hline Wheat & 41 & 1219 \\
\hline Spring wheat & 6 & 59 \\
\hline Winter wheat & 36 & 1160 \\
\hline Oats & 10 & 57 \\
\hline Barley & 17 & 253 \\
\hline Mixed grains & 41 & 432 \\
\hline Corn for grain & 56 & 2418 \\
\hline Corn for silage & 38 & 452 \\
\hline Alfalfa and mixtures & 119 & 2127 \\
\hline Hay and fodder crops & 40 & 408 \\
\hline Canola & 6 & 49 \\
\hline Soybeans & 51 & 2720 \\
\hline Total & 461 & 11354 \\
\hline
\end{tabular}

\subsubsection{Site Physiography}

The Ecoregion is typically characterized by carbonate-rich, Palaeozoic bedrock, and is dominated by a wide variety of glacial deposits. While level to undulating bedrock outcroppings occur in a few areas, the surficial materials 
are dominated by a glacial till blanket, with glaciofluvial complexes and plains comprising the greatest part of the area. The materials and the predominantly undulating to hummocky to rolling surface form both reflect this glacial history.

Sites \#14 \& \#44 occur in the Guelph Drumlin Field physiographic region (Chapman and Putnam 1966) characterized by drumlinized hills which are broad, oval and moderately steep. The landscape in the vicinity of the Benchmark site is appropriately characterized as a rolling to undulating surface in this drumlinized landscape. The benchmark sites \#14 and \#44 are on a shallow glacial till deposit on the side slope of one of these drumlins. The loamy, calcareous, stony and pale brown glacial tills are derived from the Lockport dolomites exposed along the Niagara escarpment (Chapman and Putnam 1966).

\subsubsection{Soils}

The characteristic soils developed on the tills of Ecodistrict \#560 are dominantly loamy Melanic Brunisolic and Gray Brown Luvisolic soils, with significant inclusions of clayey Gleysolic soils and Organic soils. The soils at Benchmark sites \#14 \& \#44 belong to the Guelph catena ${ }^{1}$ which consists (in sequence from well to poorly drained) of the Guelph, London, Harriston, Listowel and Parkhill soil series. Of the catenary sequence, the Guelph (well drained), London (imperfectly drained) and the Parkhill (poorly drained) soil

\footnotetext{
${ }^{1}$ The catena is defined as is "a nontaxonomic grouping of a sequence of soils of about the same age, derived from similar parent materials, and occurring under similar climatic conditions, but having unlike characteristics because of variations in relief and drainage" (Agriculture Canada 1976, pg. 8).
} 
series are present at the experimental site (Hoffman et al. 1963). The London soils occupy an area too small to be mapped at this site.

The well drained Guelph soil series is classified as a Brunisolic Gray Brown Luvisol and occurs on the upper slope (shoulder to mid slope) positions on slopes that average $4 \%$. The poorly drained Parkhill soil series occupies the lower slope (foot slope to level and depressional) positions and is classified as an Orthic Humic Gleysol. The imperfectly drained London soil series which was not sampled at this site would occupy the lower portion of the mid slope to the upper portion of the lower slope landscape positions. This series is classified as Gleyed Gray Brown Luvisol.

\subsubsection{Guelph Series}

These Guelph soils are among the best agricultural soils in Ontario (Hoffman et al. 1963). At this site they are rated $\mathbf{3 T}$ in the Canada Land Inventory (Ontario) agricultural capability rating system (Wilson 2003). Class 3 soils have moderately severe limitations that reduce the choice of crops or require special conservation practices, with the subclass $T$ denoting limitations due to slope steepness and length. Such limitations may hinder machinery use, decrease the uniformity of crop growth and maturity, and increase water erosion potential. The limitations to cultivation may be the frequency and steepness of slopes, with the erosion hazard being high on steep slopes. There are very few fieldstones or boulders to impede cultivation. The soils are well drained both internally and externally but retain adequate amounts of moisture for the needs of agricultural crops. 
The well drained soil for the no-till site, upper slope position is described in Section 5.1.2 (page 44).

The Guelph soil in the same landscape position for the control site met the criteria for the Orthic Melanic Brunisols (Soil Classification Working Group, 1998). This uncultivated Guelph soil had a $23 \mathrm{~cm}$ very dark brown (10YR 2.5/2) Ah horizon with silt loam texture and a high (6.8\%) organic matter content. The Bm horizon is dark yellowish brown (7.5YR 4/4), loam overlying a fully developed dark yellowish brown (7.5YR 3/4) Bm2 horizon with a loam texture. The depth to the parent material (C horizon) was $53 \mathrm{~cm}$.

\subsubsection{Parkhill Series}

Based on their drainage, the Parkhill series soils at this site would be rated at $\mathbf{5 W}$ (Canada Land Inventory (Ontario) agricultural capability rating system) with the class $\mathbf{5}$ indicating very severe limitations to cultivation and the $\mathbf{W}$ subclass indicating limitation due to excess wetness (Wilson 2003).

These poorly drained soils of the Guelph catena occur in depressions and toe slopes in the lower landscape positions. The Parkhill soil described in the lower landscape position of the no-till site has is described Section 5.1.8 (page 50).

The Parkhill soils have poor internal and external drainage due to their occurrence in depressions and lower slope (water accumulation) locations. In addition these soils usually have significant amounts of fine-grained sediments that have been washed down slope from the water shedding landscapes upslope and deposited in the lower slope and depressional 
positions. If not artificially drained, these Parkhill soils are too wet for regular cultivation. At this site (Benchmark \#14 \& \#44) these soils are drained and are subject to the same land management practices as the associated soils in the field.

\subsection{Site History, Management and Crop Rotation}

Europeans settled this portion of Ontario between 1820 and 1830 and the Guelph soils have been cultivated for as long as 170 years. Site \# 14 has been in the same family for the past 20 years and the portion farmed has been cleared and cultivated for approximately the past 100 years (Davis personal communication 2001). Site \#44 is owned by the Greenspan Corporation and has been leased to several operators during the course of the Benchmark activities. It would be assumed that both sites had similar clearing and cultivation histories up until 1987, when no-till was initiated at site \#14, and conventional tillage was maintained on site \#44 (Davis personal communication 2001).

Hoffman et al. (1963) concluded that erosion had become a significant problem due to long-term intensive cultivation, the removal of fencerows, and cultivation of long-term monoculture crops and the use of larger equipment. This trend has intensified since the early 1960's when this observation was made. Dairying and livestock raising were once the major farm enterprises. The renting of land and the initiation of cash-cropping contributed to the decline of dairy and livestock production. 
The forested road allowance was established by the township, but has never been developed as a road nor been cultivated. The centre of this approximately $25-\mathrm{m}$ strip has been used as a field access road and a light recreational road. Stones cleared from the fields have been deposited along the edges (Davis pers. comm. 2001).

The benchmark sites represent different histories of soil and crop management. Site \# 14 is currently under a conservation (no-till) tillage management system that has been in place since 1987. The other site (\# 44) is under a conventional fall plow management system. The fall plowing was done using a moldboard plow until 1997, when a modified tillage system (no moldboard ploughing and reduced tillage practices) was initiated (Davis pers. comm. 2001). At the time the benchmark sites were established in 1991, the no-till site had had a 12-year corn (Zea mays L.) monoculture system. The conventional tillage section had been in hay forage including alfalfa (Medicago sativa L.). Due to the type of land management, it would be expected that the Ap horizons differed between the no-till and conventional till sites when these Benchmark sitesw were established. The conventional till site should have resembled a no-till cultivation system due to the long term forage copping practices.

During the period 1992-1997, both sites were managed as a rotation of winter wheat (Triticum aestivum L.), soybean (Glycine max (L.) Merr.) and corn (Viger et al. 1999). A similar cop rotation was continued for the period 
1997 to 2001. In 2001 soybeans were planted in both land management systems and corn had been planted the previous year.

The active benchmark study was terminated in 1997, but the crop rotation and land management practices that were in place were maintained for Site \#14 with the exception that the site was ploughed in the spring of 1997 when corn was planted to improve germination (Davis, personal communication, 2002). The most significant change to the no-till (Site \#14) site was the installation of subsurface tile drains running from the top of the slope through the level to depressional lower slope area and emptying into the community drain along the road in the fall of 1997 . The tile drain lines were more or less parallel to the edge of the field and were spaced approximately $15 \mathrm{~m}$ apart (Davis Pers. comm. 2001). Effort was taken to avoid placing experimental sites in areas that may have been disturbed by the installation of these drains. 


\subsection{THE FIELD AND LABORATORY PROGRAM}

Field sampling was performed October 10-12, and November 6-9, 2001 after that year's crop had been harvested and before the land was tilled or seeded. The samples were analyzed during the following winter. The methods of analysis are documented in Appendix sections $8.11-8.14$. The preliminary samples for no-till site \#14 and the conventional till site \#44 had been collected October 29 and 30,1991, as the baseline samples for the establishment of these benchmark sites.

This field-sampling program consisted of the activities described below. Figure 4.1 provides a summary of the solum transect, pedon and grid sample locations.

\subsection{SOIL PEDON DESCRIPTION AND SAMPLING}

Soil pits were dug, one in each major topographic unit (upper, mid and lower slope) of each land management practice system (no-till and conventional tillage) and of the uncultivated control site. A detailed in-situ profile description was completed for each pit, as follows.

- Site data at the pit location were collected. This consisted of geographical position (Trimble Ag-132 differential GPS), \% slope using a Suunto inclinometer, slope complexity, slope length (effective and natural), slope aspect, slope position classes (upper, middle and lower) surface stoniness and surface rockiness determinations (Day 1983; Ontario Institute of Pedology 1995). Digital photographs (Nikon 1250 
Coolpix) of the soil landscape at each location were taken to document the site.

- The soil pit was excavated to the depth of the control section (1 $\mathrm{m})$ (Soil Classification Working Group, 1998), the genetic soil horizons were determined and their thicknesses measured. Determinations of field soil texture, colour, and the presence of redoximorphic features, structure, consistence, coarse fragment content, biopores and rooting depth were made. The depth to carbonates, bedrock, mottles, gley features and water table were measured if applicable.

- Four bulk density cores were obtained from each genetic horizon and bulk soil samples were collected for laboratory preparation and analysis (Appendix 1).

- A digital photograph of the sample face of the soil pit was taken

\subsection{BENCHMARK GRID RESAMPLING}

Twenty (20) locations were resampled on the benchmark monitoring grids (no-till and conventional till) that were used in 1991 and 1997. Forty (40) points were sampled during each sampling program in 1991 and 1997. Figure 4.1 indicates where the sample points were for each grid. In addition a sampling grid was established in the uncultivated road right-of-way separating benchmark site \#14 and benchmark site \#44 (Fig. 4.1).The data collected at each of the sample grid points was based on the sampling protocol established in the original sampling scheme (Viger et al. 1999). 


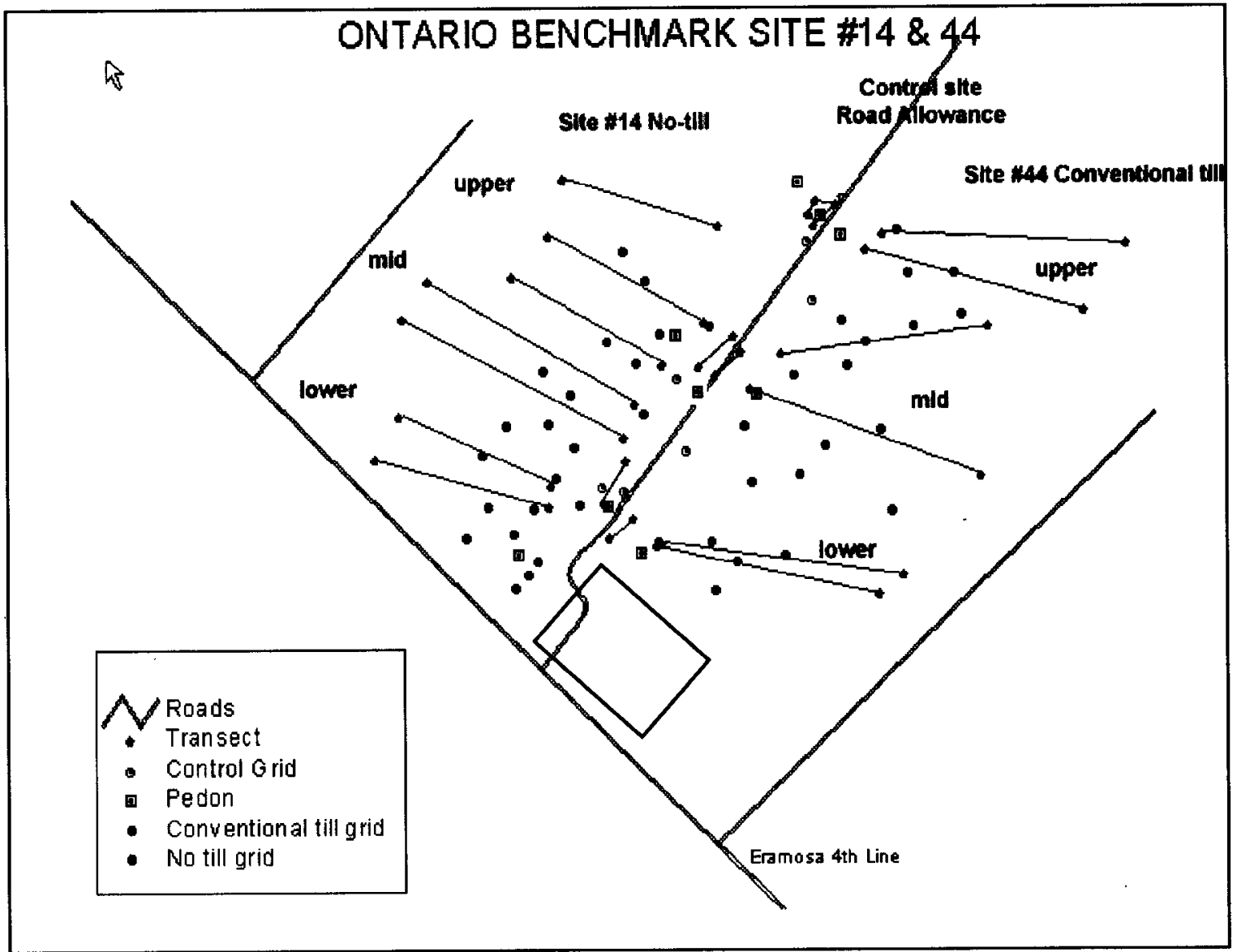

Figure 4.1 Locations of transects, grid point and pedon (detail pit) sampling locations at the Ontario Benchmark Sites \# 14, \#44 and Control (Rockwood, Ontario) 2001.

\subsubsection{Sampling at a Grid Point}

4.2.1.1. For A-horizon sample sites, the depth and colour of the $A$ horizon only was described and a bulk sample and two bulk density cores were collected;

4.2.1.2. For $A+B$ horizon sample sites, the depths and colours of the $A$ horizon and the $B$ horizon were measured and described and a bulk sample and two bulk density cores were collected for each horizon; 
4.2.1.3. For the $A+B+C$ horizon sample sites, the depth of the $A$ and $\mathrm{B}$ horizon and the depth to the $\mathrm{C}$ horizon were measured and colours determined and a bulk sample and two bulk density cores were collected for each horizon.

\subsubsection{Site Location}

Geographic coordinates were determined at each grid site sample point using a TRIMBLE AG230 differential GPS system and a Newton handheld data acquisition system.

\subsubsection{Depth of Solum Transects}

Transects of the soil landscape were conducted in each major topographic unit and measurements of thickness of the $A$ and $B$ horizons (the depth of the solum) were recorded.

On the benchmark sites, two transects were established across the slope in each topographic unit (crest, mid slope and lower slope) of each land management practice system (no-till and conventional tillage). Three transects were sampled in the mid slope position of the no-till site due to the length and steepness of the slope. The depth of solum was determined visually at $10 \mathrm{~m}$ intervals on samples augured with a Dutch auger. The thickness of the solum was measured with a tape measure and verified by applying a $10 \%$ hydrochloric acid solution to the augured sample to detect the depth at which carbonates were first detected. The number of sample points was not the same for each transect, this was due to the different field 
dimension of each site. The number of points in each tillage treatmentlandscape unit is recorded in Table 4.1.

In the narrow uncultivated control site (approx. $25 \mathrm{~m}$ in width) the transects were placed along the slope, parallel to the edge of the fields and solum depth measurements were made at $5 \mathrm{~m}$ intervals from augured samples. The number of sample points is summarized in Table 4.1.

Table 4.1 The number of sample points in the solum transects in each landscape

\begin{tabular}{|c|c|c|c|}
\hline & Site \#14 & Control & Site \#44 \\
\hline Upper & 20 & 10 & 30 \\
\hline Mid & 40 & 10 & 30 \\
\hline Lower & 21 & 10 & 30 \\
\hline
\end{tabular}

The geographical position of each transect was determined by taking GPS readings at the beginning and end of each transect. Sampling intervals were determined using a $100 \mathrm{~m}$ nylon measuring tape. 


\subsection{RESULTS}

This analysis to test the hypothesis that soil properties in a catenary sequence differ with landscape position (slope position) and that these soil properties (solum depth, $\mathrm{pH}$, bulk density and particle size fraction contents (sand, silt, clay)) also change due to land management practice over time will proceed by:

- Presentation of the soil profile descriptions, arranged by landscape position;

- Evaluation (presentation and discussion) of the original data collected in 1991 for the establishment of the Ontario Benchmark sites \#14 and \#44 to determine whether there were significant differences within and between sites at that time.

- Evaluation (presentation and discussion) of the data for the control sites within the never cultivated road allowance, on a property-byproperty basis and for each property a comparison of the no-till and conventional till sites to the control site and to each other using the data collected in 2001. The statistical t-test will be used to determine if there are significant differences for individual soil properties: within an individual land management system across landscape positions; and across land management systems at each landscape position.

- Evaluation (presentation and discussion) of the 1991 and 2001 data statistically compared to assess the degree and significance of soil 
property changes for each landscape position on each site over the 10 year period.

\subsection{PEDON DESCRIPTIONS}

The soil pit (pedon) descriptions were collected to serve as a detailed reference for each landscape position in each land management system. The control pedons represent the best approximation of the natural condition, i.e. pre clearing and cultivation. The pedons in the other landscape positions in the no-till and conventional till land management system represent detailed descriptions of the current condition in each slope position. Pedons were described at the upper and lower positions of the no-till and conventional till sites in 1991, this data is not included.

Analytical data for each pedon described and samples is presented in Appendix Table 8.2.6, Detail Soil Pedon Data -2001, page 128. 


\subsubsection{Control Pit \#1 - Upper Slope Position}

\section{Location: 17T 05660594831256}

Slope: $1 \%$ - simple

Site Position: shoulder slope

Microtopograhy: Micro mounded. Pit and mound with approx. $20 \mathrm{~cm}$ relief Classification: Orthic Melanic Brunisol

Ah $\quad 0-23$ Very dark brown 10YR2.5/2; silt loam; strong, medium and fine subangular blocky; friable; abrupt, smooth boundary; plentiful, medium roots.

Bm 23-40 Dark yellowish brown 7.5 YR 4/4; loam; weak to moderate and fine subangular blocky; very friable; many, fine roots; earthworm and root biopores; clear and smooth boundary.

Btj 40-53 Dark yellowish brown 7.5 YR 4/4; loam; weak to moderate, medium subangular blocky; friable; clay films along root channels and ped surfaces; common to many fine roots; 20 $25 \%$ coarse fragments.

Ck 53-70 Dark yellowish brown 7.5 YR 4/6; fine sandy loam; moderate to coarse angular to subangular blocky; firm to very firm; abrupt, wavy boundary; strongly calcareous; common fine roots

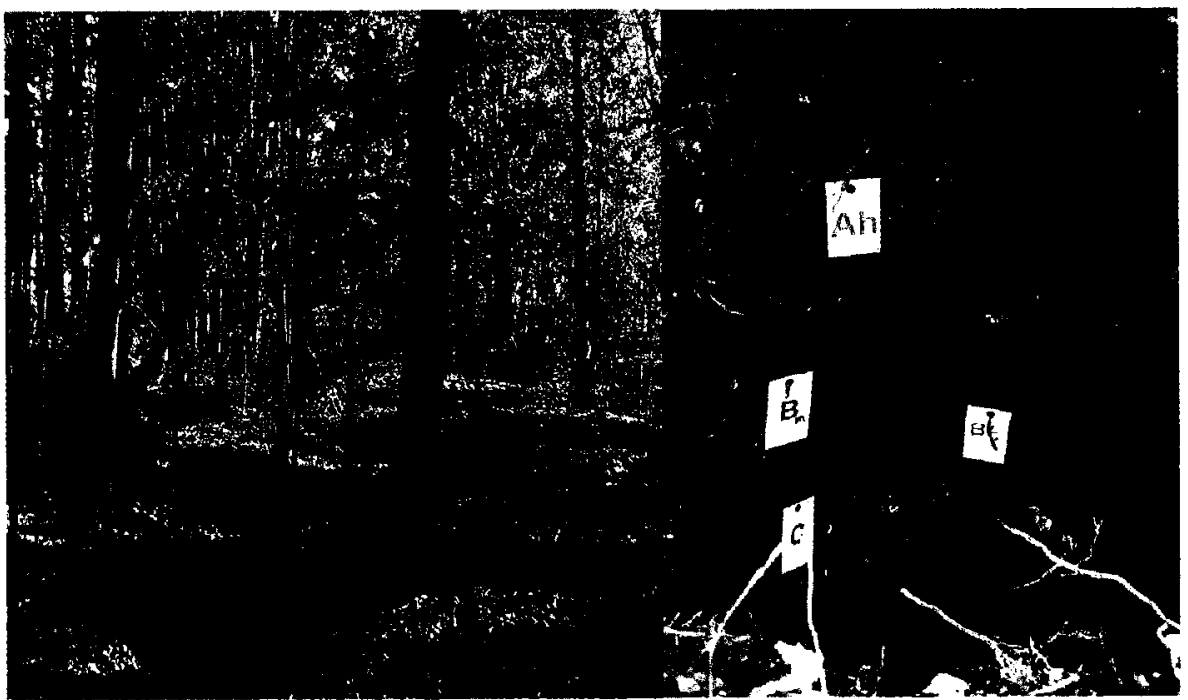

Fig 5.1 Landscape and soil profile photographs for the Control site for the upper slope position (Oct 11, 2001). 
5.1.2 No-till Pit \#1 - Upper Slope Position

Location: 17T 05660474831274

Slope: $2 \%$ - simple, slope length $200 \mathrm{~m}$.

Stoniness: 1. (Slightly stony)

Site Position: Shoulder (crest) slope

Microtopograhy: Level

Classification: Orthic Melanic Brunisol

Ap 0-21 Very dark grayish brown 10YR 3/2; loam; amorphous; friable; abrupt, smooth boundary; many, very fine roots; $5 \%$ coarse fragments.

Bm 21-50 Dark yellowish brown 10 YR 4/4; loam; weak medium to fine subangular blocky; friable; common, very fine roots; many earthworm biopores (3-5 $\mathrm{mm}$. diameter) with dark organic linings; abrupt and wavy boundary; $5 \%$ coarse fragments.

Btj $\quad$ 47-50 Strong brown 7.5 YR 5/6; sandy loam; discontinuous pockets.

Ck 50+ Strong brown 7.5 YR 4/6; gravelly fine sandy loam; weak to medium subangular to angular blocky; firm; few earthworm biopores; no roots; strongly calcareous; $25 \%$ coarse fragments.

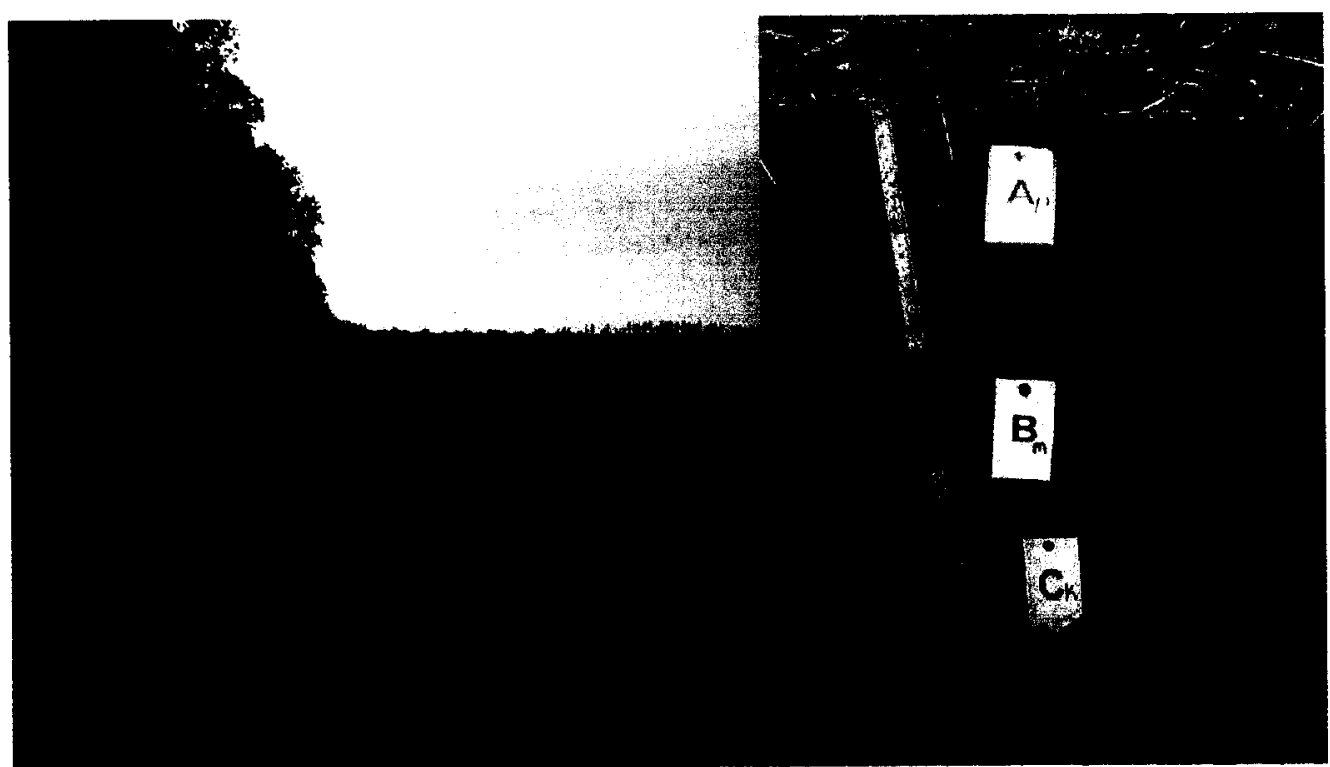

Fig. 5.2 Landscape and soil profile photographs for the No-till site for the upper slope position (Oct. 11, 2001). 


\subsubsection{Conventional Pit \#1 - Upper Slope Position}

Location: 17T 05660714831246

Slope: $2 \%$ - simple, slope length $200 \mathrm{~m}$.

Stoniness: 1 ( 2 in places). Slightly stony to moderately stony.

Site Position: Shoulder slope

Microtopograhy: Level

Classification: Orthic Melanic Brunisol

Ap $\quad 0-20$ Very dark grayish brown 10YR 3/2; loam; amorphous; firm; abrupt, smooth boundary; many, fine roots; common earthworm biopores; $5 \%$ coarse fragments.

Bm 20-32 Dark yellowish brown 7.5 YR 4/4; loam; weak fine subangular blocky; friable; many, fine roots; many earthworm biopores; abrupt and wavy boundary; $5 \%$ coarse fragments. (Note: Horizon thickness ranges from 0 to $17 \mathrm{~cm}$ )

Ck 32+ Brown 10 YR 5.5/3; gravelly fine sandy loam; medium platy breaking to fine angular to weak to moderate subangular blocky; firm; few earthworm biopores; few, fine roots; strongly calcareous; $25 \%$ coarse fragments.

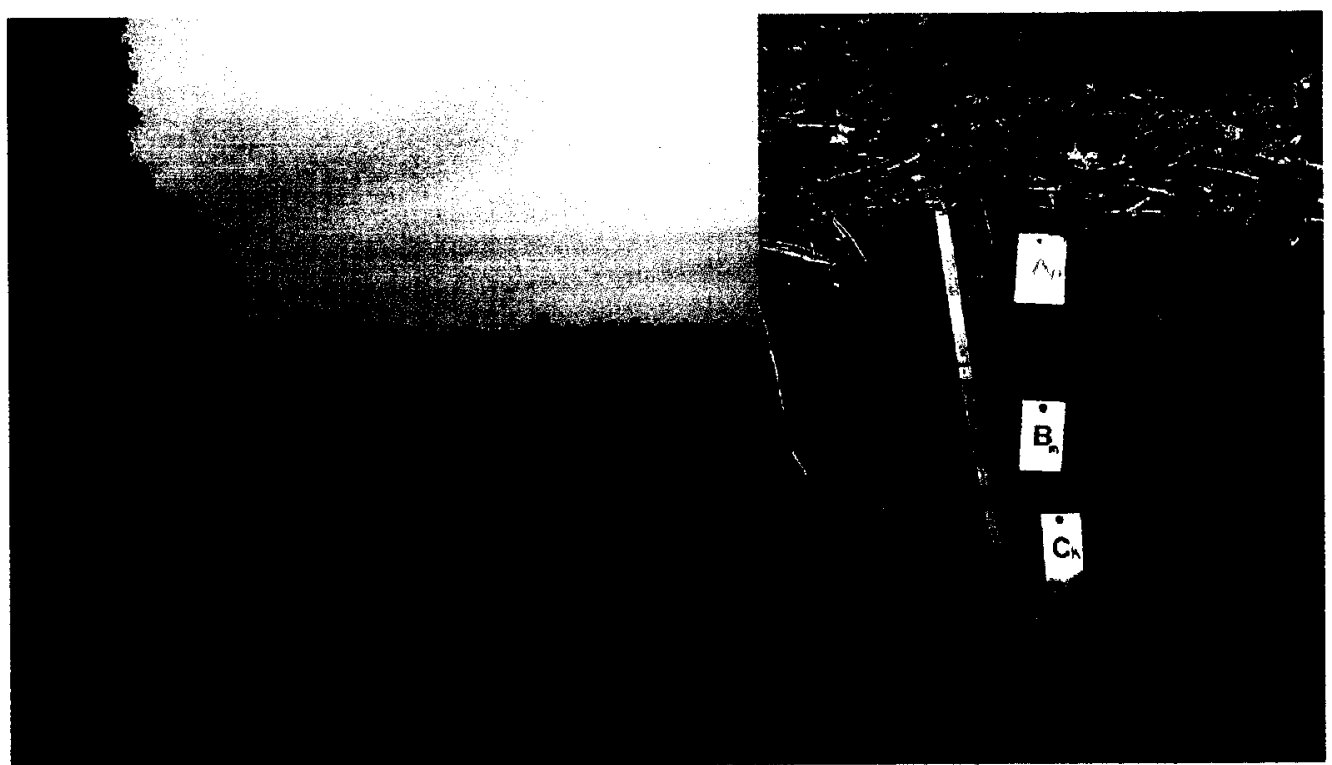

Fig. 5.3 Landscape and soil profile photographs for the Conventional till site for the upper slope position (Oct 11, 2001). 


\subsubsection{Control Pit \#2 - Mid Slope Position}

Location: 17T 05660084831186

Slope: $5 \%$ - simple

Site Position: back slope

Microtopograhy: Micro mounded. Pit and mound with approx. $20 \mathrm{~cm}$ relief

Classification: Orthic Melanic Brunisol

Ah $\quad 0-26$ Very dark brown 10YR2.5/2; sandy loam; strong, medium and fine subangular blocky; friable; abrupt, smooth boundary; plentiful, medium roots.

Bm 26-44 Dark yellowish brown 10 YR 4/4; sandy loam; weak to moderate and fine subangular blocky; very friable; may, fine roots; earthworm and root biopores; clear and smooth boundary.

Btj 44-60 Dark yellowish brown 10 YR 3/4; loam; weak to moderate, medium subangular blocky; friable; clay films along root channels and ped surfaces; common to many fine roots; $20 \%$ coarse fragments.

Ck 60-85 Yellowish brown 10 YR 5/4; very fine sandy loam; moderate to coarse angular to subangular blocky; firm to very firm; abrupt, wavy boundary; strongly calcareous; common fine roots 


\subsubsection{No-till Pit \#2 - Mid Slope Position \\ Location: 17T 05659764831191 \\ Slope: $3 \%$ - simple, slope length $150 \mathrm{~m}$. \\ Stoniness: 0 \\ Site Position: Back slope \\ Microtopograhy: Level \\ Classification: Orthic Melanic Brunisol}

Ap 0-20 Very dark grayish brown 10YR 3/2; loam; moderate, medium, subangular blocky; firm; many, fine roots; common earthworm biopores; wavy, smooth boundary; $2 \%$ coarse fragments.

Bm 20-37 Dark yellowish brown 10 YR 4/6; loam; moderate to medium, subangular blocky; firm; few, fine roots; common to many biopores; clear, smooth boundary; $2 \%$ coarse fragments.

Ckgj 37-58 Grayish Brown 10 YR 5/2; fine sandy loam; moderate to medium subangular blocky; firm; common, earthworm biopores; few, fine roots; weakly calcareous; $2 \%$ coarse fragments.

Ckg 58-79 Light brownish gray 10 YR 6/2; gravelly silt loam; common, coarse and distinct brownish yellow 10YR 6/6 mottles; moderate to medium platy; very firm; common, earthworm biopores; few, fine roots; strongly calcareous; $25 \%$ coarse fragments.

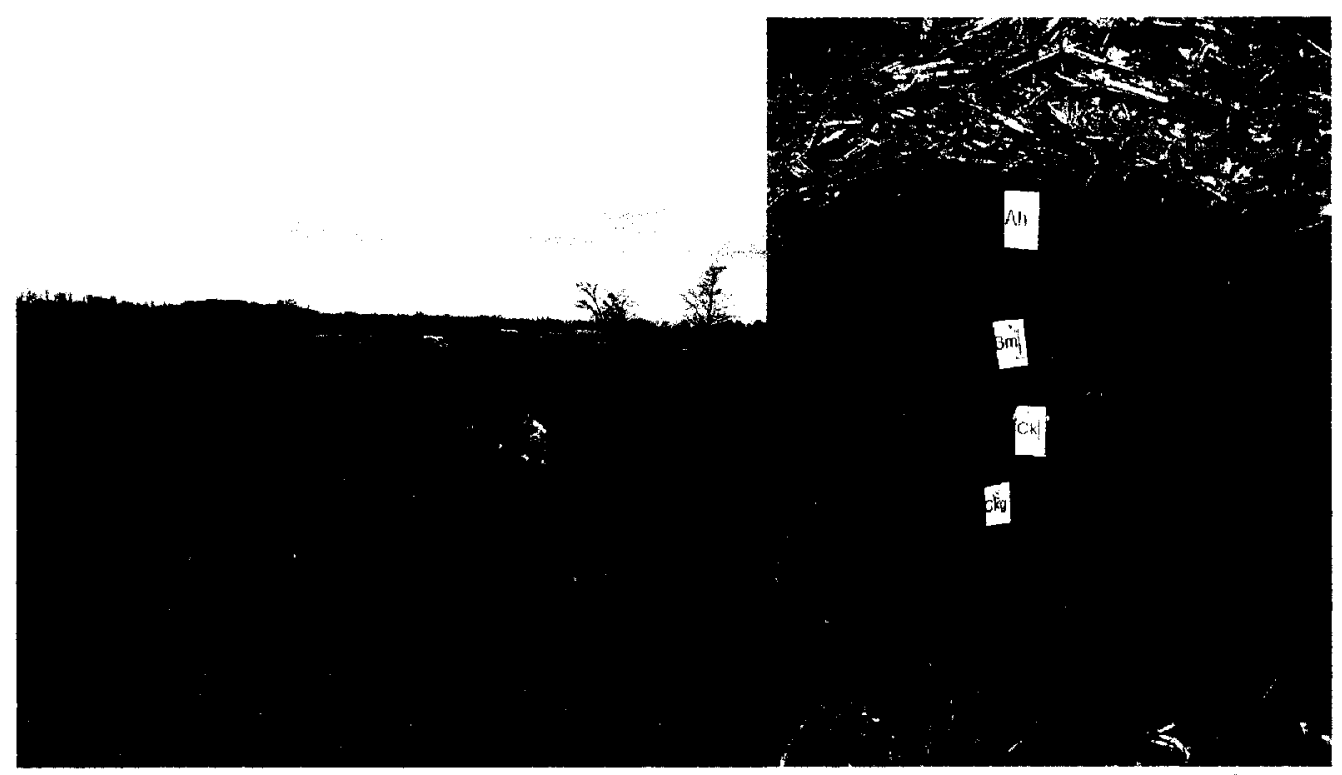

Fig 5.4 Landscape and soil profile photographs for the No-till site for the mid slope position (Oct 1 2001). 
5.1.6 Conventional Pit \#2 - Mid Slope Position

Location: 17T 05660224831160

Slope: $6 \%$ - simple, slope length $125 \mathrm{~m}$.

Stoniness: 1 (2 in places)

Site Position: Back slope

Microtopograhy: Level

Classification: Orthic Melanic Brunisol

Ap $\quad 0-20$ Very dark grayish brown 10YR 3/2; loam; amorphous; firm; many, Fine roots; common earthworm biopores; abrupt, smooth boundary; $5 \%$ coarse fragments.

Bm 20-38 Dark yellowish brown 7.5 YR 4/4; loam; weak to medium fine angular and subangular blocky; friable; many, fine roots; common to many biopores; clear and wavy boundary; $5 \%$ coarse fragments.

Ck 38+ Brown 10 YR 5/3; gravelly fine sandy loam; moderate medium platy breaking to medium to weak moderate angular blocky; firm; common, earthworm biopores; few, fine roots; strongly calcareous; $25 \%$ coarse fragments.

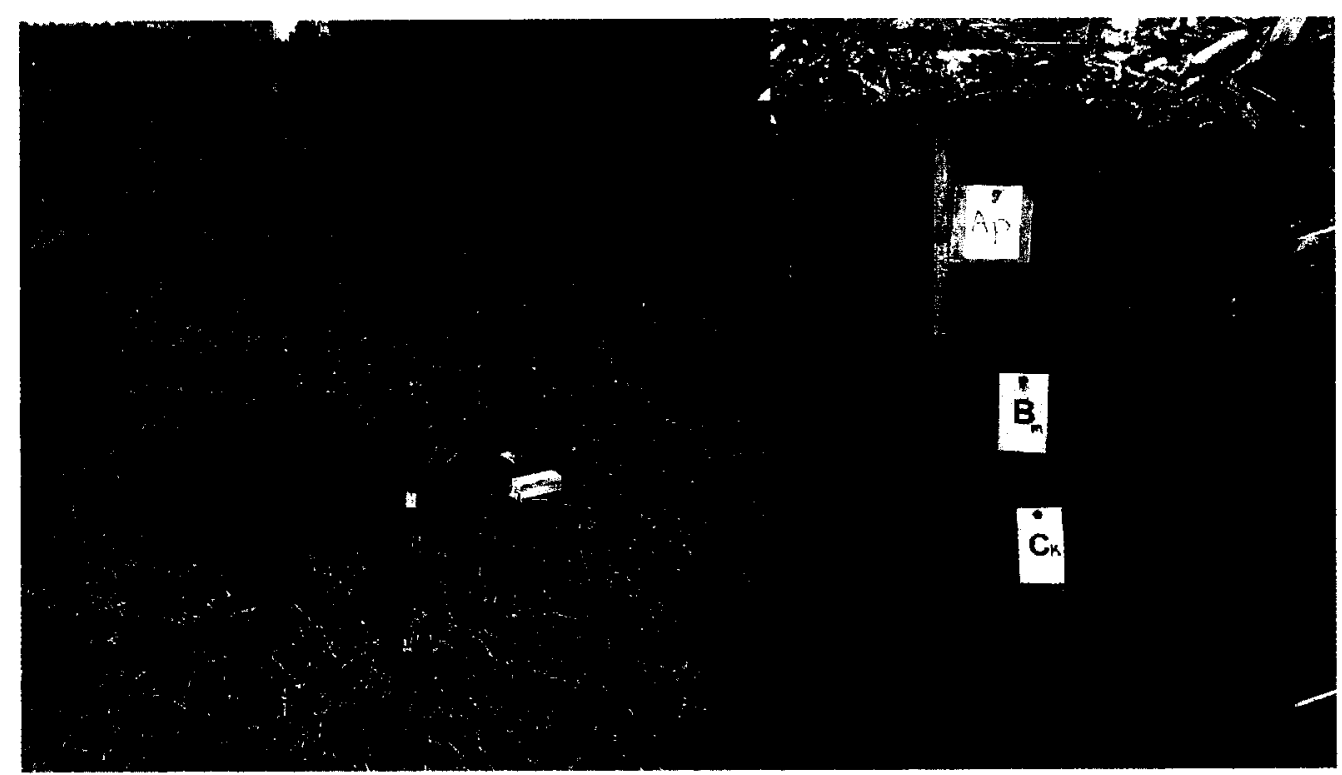

Fig 5.5 Landscape and soil profile photographs for the Conventional till site for the mid slope position (Oct 11, 2001). 


\subsubsection{Control Pit \#3 - Lower Slope Position}

\section{Location: 17T 05659214831077}

Slope: $4 \%$ - simple

Site Position: toe slope

Microtopograhy: Micro mounded. Pit and mound with approx. $15 \mathrm{~cm}$ relief Classification: Orthic Humic Gleysol

Ah $\quad 0-29$ Black 10YR 2/1; silt loam; strong, medium and fine granular; friable; wavy, smooth boundary; numerous, all size roots.

Bm 29-61 Brown 10 YR 5/3; silt loam; moderate, medium subangular blocky; friable; many roots of all sizes; earthworm and root biopores; wavy, discontinuous boundary; $2 \%$ coarse fragments.

Bkg 61-72 Brown 10 YR 5/3; very fine sandy loam; common, medium and prominent yellowish brown (10 YR 5/8) mottles; weak to moderate, medium platy; friable; common fine to medium roots; common biopores; clear, discontinuous horizon boundary; $10 \%$ coarse fragments.

Ckg 72-100 Gray 10 YR 6/1; very fine sandy loam; abundant, medium and prominent yellowish brown (10 YR 5/6) mottles; strong to medium platy; friable; abrupt; fine to medium common roots; wavy boundary; strongly calcareous; $10 \%$ coarse fragments.

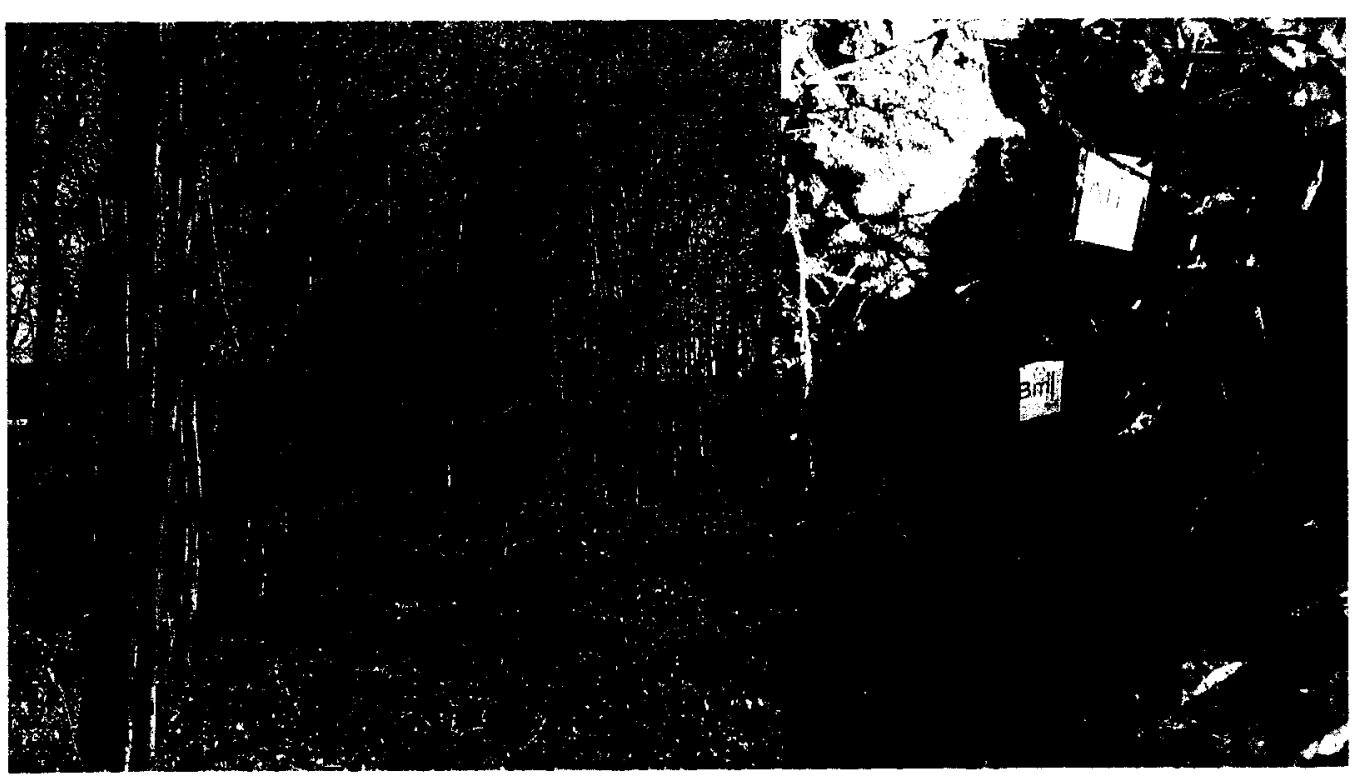

Fig 5.6 Landscape and soil profile photographs for the Control site for the lower slope position (Nov. 7, 2001). 


\subsubsection{No-till Pit \#3 - Lower Slope Position}

Location: 17T 05658854831072

Slope: $5 \%$ - simple, slope length $25 \mathrm{~m}$.

Stoniness: 0

Site Position: Toe slope

Microtopograhy: Level

Water table: $44 \mathrm{~cm}(01 / 11 / 05)$

Classification: Orthic Humic Gleysol

Ap 0-23 Very dark gray 10YR 3/1; silt loam; amorphous, firm; common fine medium roots; common earthworm biopores; clear, smooth boundary; $2 \%$ coarse fragments.

Ahb 23-35 Black 10YR 2/1; silt loam; moderate to medium subangular blocky; friable; few fine roots; common to many earthworm biopores; wavy, smooth boundary; $2 \%$ coarse fragments.

Bg 35-44 Grayish brown 10YR 5/2; loam; abundant, fine and prominent yellowish brown (10 YR 5/6) mottles; moderate to medium subangular blocky; friable; few fine to medium roots; common earthworm biopores; abrupt, smooth boundary; $10 \%$ coarse fragments.

Cgkj 44+ Very Light brownish gray 10YR 6/2; gravelly loam; abundant, medium and prominent (10 YR 5/6) mottles; moderate to medium subangular blocky; friable; few fine roots; common to many earthworm biopores; abrupt smooth boundary; $20 \%$ coarse fragments.

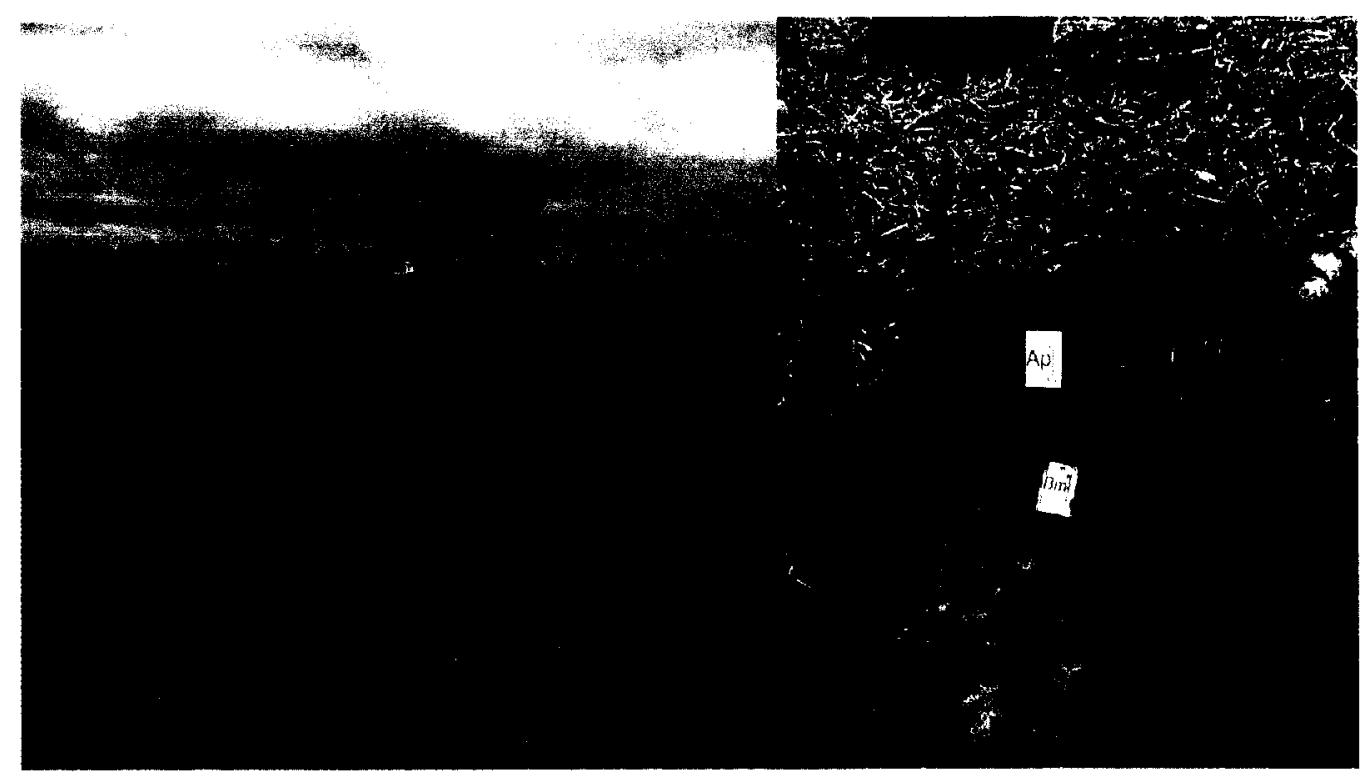

Fig 5.7 Landscape and soil profile photographs for the No-till site for the lower slope position (Nov. 7, 2001). 


\subsubsection{Conventional Pit \#3 - Lower Slope Position}

Location: 17T 05659564831076

Slope: $6 \%$ - simple, slope length $25 \mathrm{~m}$.

Stoniness: 0

Site Position: Toe slope

Microtopograhy: Level

Water table: $82 \mathrm{~cm}(01 / 11 / 05)$

Classification: Orthic Humic Gleysol

Ap 0-23 Very dark grayish brown 10YR 3/2; loam; amorphous, firm; common fine medium roots; common earthworm biopores; clear, smooth boundary; $2 \%$ coarse fragments.

Bm1 23-31 Yellowish brown 10YR 5/6; fine sandy loam; amorphous, firm; few fine roots; common earthworm biopores; wavy, smooth boundary; $2 \%$ coarse fragments.

Bm2 31-36 Brown 10YR 4/3; fine sandy loam; moderate to medium subangular blocky; friable; few fine to medium roots; common earthworm biopores; wavy, discontinuous smooth boundary; $5 \%$ coarse fragments.

Cgk1 36-50 Grayish brown 10YR 5/2; fine sandy loam; moderate to medium subangular blocky; friable; few fine roots; common earthworm biopores; abrupt smooth boundary; $20 \%$ coarse fragments

Cgk2 50-82 Light Brownish Gray 10YR 6/2; gravelly fine sandy loam; abundant, coarse and prominent reddish brown 10YR 5/6 mottles; moderate to medium angular blocky; friable; few fine roots; common earthworm biopores; abrupt smooth boundary; $25 \%$ coarse fragments.

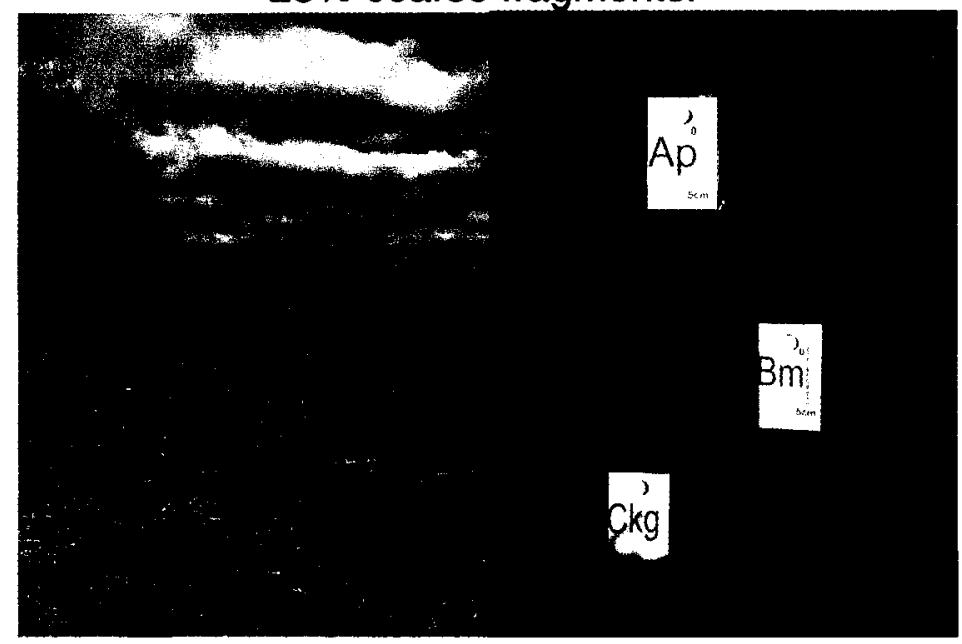

Fig 5.8 Landscape and soil profile photographs for the Control site for the lower slope position (Nov. 4, 2001). 


\subsection{STATISTICAL ANALYSIS OF SOIL PROPERTIES}

The first set of results to be reviewed and statistically compared is for individual soil properties across landscape positions within a land management system. The results will then be compared to determine if there are statistically significant differences for soil properties across land management systems. The Student's $t$-Test for two-samples with unequal variance (heteroscedastic) was used to determine whether two samples are likely to have come from the same underlying populations with the same mean.

The results for the no-till, conventional till and control sampling grids are summarized in Appendix Tables 8.2.3, 8.2.4 and 8.25 respectively.

\subsubsection{Solum Depth}

The solum depth data set (Appendix Table 8.2.7) was collected in 2001 only. The depth of the weathered soil (solum) over the parent material (Fig. 5.9 and Table 5.1), indicates that for the Guelph catena at the control site there is a slight but not significant decrease in the solum depth between the upper slope and mid-slope landscape positions, and a significant increase in mean solum depth between the mid-slope to the lower and the upper to lower slope positions.

The thicknesses of the solum on the no-till site $(\# 14)$ and the conventional tillage site (\#44) (Fig. 5.9 and Table 5.1) display the same trends with landscape position as the control site. 
Table 5.1 Means and t-test results for solum depth for land management systems and slope positions for 2001 data.

\begin{tabular}{|l|l|c|l|c|}
\hline Land Management System & Slope Position & Mean & Variables & t-test \\
\hline CONTROL & Upper & 49.20 & Upper vs. mid & NS \\
\hline & Mid & 46.10 & Mid vs. lower & S \\
\hline & Lower & 62.30 & Upper vs. lower & S \\
\hline \multicolumn{5}{|l|}{} \\
\hline NO-TILL & Upper & 42.60 & Upper vs. mid & NS \\
\hline & Mid & 39.95 & Mid vs. lower & S \\
\hline & Lower & 65.33 & Upper vs. lower & S \\
\hline \multicolumn{5}{|l|}{} \\
\hline CONVENTIONAL TILL & Upper & 40.19 & Upper vs. mid & S \\
\hline & Mid & 30.33 & Mid vs. lower & S \\
\hline & Lower & 46.60 & Upper vs. lower & S \\
\hline
\end{tabular}

Table 5.2 Means and t-test results for solum depth for slope positions between land management systems for 2001 data.

\begin{tabular}{|c|c|c|c|c|}
\hline Slope Position & Land Management System & Mean & Variable & t-test \\
\hline \multirow[t]{3}{*}{ Upper } & NO-TILL & 42.60 & no-till vs. control & $s$ \\
\hline & CONTROL & 49.20 & control vs. conventional till & $s$ \\
\hline & CONVENTIONAL TILL & 40.19 & no-till vs. conventional till & NS \\
\hline \multirow[t]{3}{*}{ Mid } & NO-TILL & 39.95 & no-till vs. control & $s$ \\
\hline & CONTROL & 46.10 & control vs. conventional till & $S$ \\
\hline & CONVENTIONAL TILL & 30.33 & no-till vs. conventional till & $s$ \\
\hline \multirow[t]{3}{*}{ Lower } & NO-TILL & 65.33 & no-till vs. control & NS \\
\hline & CONTROL & 62.30 & control vs. conventional till & $s$ \\
\hline & CONVENTIONAL TILL & 46.60 & no-till vs. conventional till & $s$ \\
\hline
\end{tabular}

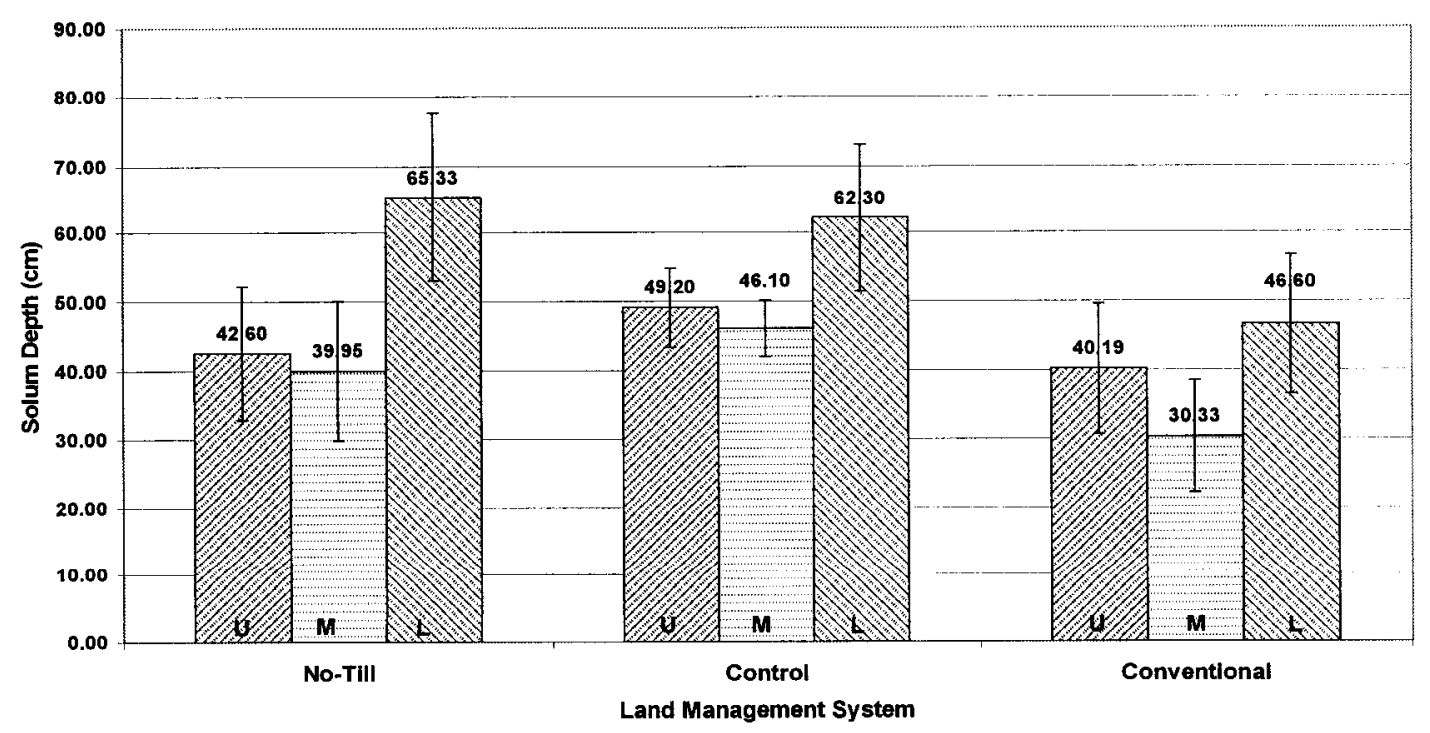

Figure 5.9 Means and standard deviations of solum depth for three land management systems and three slope positions, 2001. 
For both sites there is a decrease in mean solum depth from upper slope to the mid slope position (for the conventional till system the decrease is much larger and statistically significant) and a significant increase in the mean solum depth from the mid to lower slope and from the upper to lower slope positions.

The mean solum depth is significantly greater for the upper and mid slope positions of the control site than for both the no-till and conventional till systems (Table 5.2). The solum depth for the upper and mid slope position of the no-till system is significantly greater than that of the conventional till system, but the difference is not significant for the upper slope position. For the lower slope position the solum depth is slightly greater (but not statistically significant) for the no-till system when compared to the control site. The solum depth for the lower slope position of the conventional till system is significantly less than those of the no-till system and the control site.

There is greater variability in the cultivated sites than the control site (Fig. 5.9) This may be attributable to the greater number of impacts due to cultivation and clearing. The control site may be in steady state with respect to soil loss and formation.

\subsection{2 $\mathrm{pH}$}

Soil $\mathrm{pH}$ is commonly measured in an attempt to assess the level of acidity of natural or modified environmental systems and the impact of land management on an agricultural landscape. 


\subsubsection{1 $\quad \mathrm{pH}-1991$}

For both sites the $\mathrm{pH}$ values increase (statistically significant for the conventional till system) from the upper to the mid landscape position and then decreases significantly to the lower slope position. The $\mathrm{pH}$ values for the no-till system between the upper and the lower landscape positions, are so close that they are not measureably different, (within the error of most $\mathrm{pH}$ meters) and decrease slightly but not significantly for the conventional till system (Fig 5.10 and Table 5.3).

The mean surface $\mathrm{pH}$ values for the conventional till site are greater for all landscape positions when compared to the no-till site. For this position by position comparison of the land management systems, all the $\mathrm{pH}$ differences are statistically significant, with the higher $\mathrm{pH}$ values always being recorded on the conventional till site. 
Table 5.3 Means and t-test results for $\mathrm{pH}$ for land management systems and slope positions for 1991 data.

\begin{tabular}{|c|c|c|c|c|}
\hline & Slope Position & Mean \#14 & Variables & t-test \\
\hline \multicolumn{5}{|c|}{ No-till \#14 } \\
\hline \multirow[t]{3}{*}{ pH } & Upper & 6.94 & upper vs. mid & NS \\
\hline & Mid & 7.03 & mid vs. lower & $s$ \\
\hline & Lower & 6.95 & upper vs. lower & NS \\
\hline \multicolumn{5}{|c|}{ Conventional till \#44 } \\
\hline \multirow[t]{3}{*}{$\mathrm{pH}$} & Upper & 7.19 & upper vs. mid & $\mathrm{s}$ \\
\hline & Mid & 7.29 & mid vs. lower & $s$ \\
\hline & Lower & 7.16 & upper vs. lower & NS \\
\hline
\end{tabular}

Table 5.4 Means and t-test results for $\mathrm{pH}$ for slope positions between land management systems for 1991 data.

\begin{tabular}{|l|l|c|c|l|c|}
\hline Soil Property & Slope Position & Mean \#14 & Mean \#44 & Variables & t-test \\
\hline pH & Upper & 6.94 & 7.19 & Site \#14 vs. Site \#44 & $\mathrm{s}$ \\
\hline & Mid & 7.03 & 7.29 & Site \#14 vs. Site \#44 & $\mathrm{S}$ \\
\hline & Lower & 6.95 & 7.16 & Site \#14 vs. Site \#44 & $\mathrm{S}$ \\
\hline
\end{tabular}

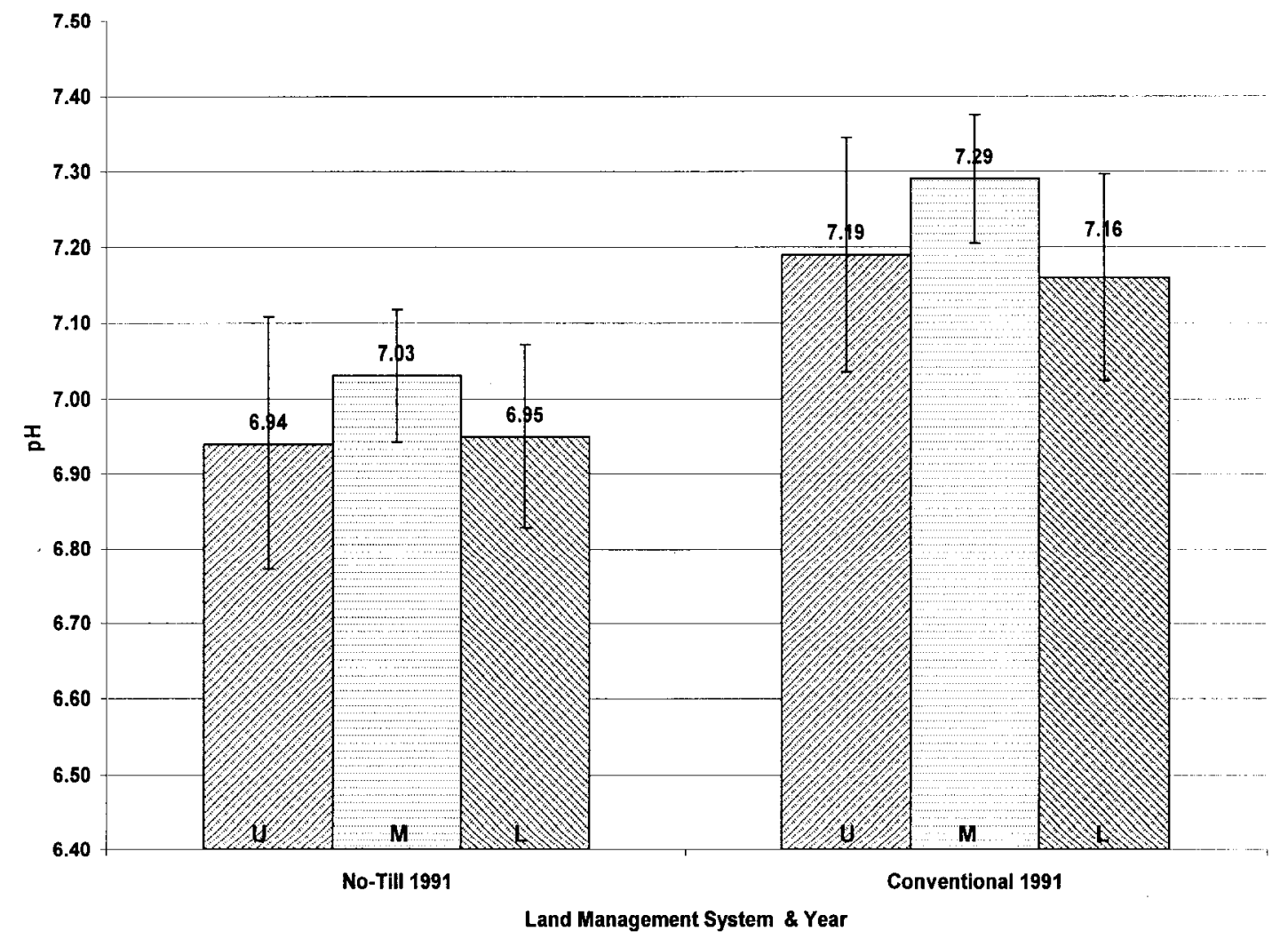

Fig. 5.10 Means and standard deviations of surface (A-horizon) pH for the notill and conventional till land management systems and three slope positions for the 1991 data. 


\subsubsection{2 $\quad \mathrm{pH}-2001$}

Comparisons by $\mathrm{t}$-tests of mean $\mathrm{pH}$ values of $\mathrm{A}$ horizons sampled in 2001 at three slope positions within each land management system show significant difference only between the upper and mid slope, and the lower slope of the no-till site (Fig, 5.11 and Table 5.5).

The $\mathrm{pH}$ values for the no-till and conventional till management systems are significantly higher than those for the control site for all positions (Table 5.6). The no-till mean $\mathrm{pH}$ values are significantly less that those of the conventional till system for upper and lower slope positions, but there is no significant $\mathrm{pH}$ difference for the mid slope positions. 
Table 5.5 Means and t-test results for $\mathrm{pH}$ between slope positions within land management systems for 2001 data.

\begin{tabular}{|l|l|c|l|c|}
\hline Land Management System & Slope Position & Mean & Variables & t-test \\
\hline CONTROL & Upper & 6.55 & Upper vs. mid & NS \\
\hline & Mid & 6.62 & Mid vs. lower & NS \\
\hline & Lower & 6.69 & Upper vs. lower & NS \\
\hline \multicolumn{5}{|l|}{} \\
\hline NO-TILL & Upper & 6.89 & Upper vs. mid & S \\
\hline & Mid & 7.11 & Mid vs. lower & S \\
\hline & Lower & 6.97 & Upper vs. lower & NS \\
\hline CONVENTIONAL TILL & Upper & 7.06 & Upper vs. mid & NS \\
\hline & Mid & 7.10 & Mid vs. lower & NS \\
\hline & Lower & 7.05 & Upper vs. lower & NS \\
\hline
\end{tabular}

Table 5.6 Means and t-test results for $\mathrm{pH}$ between land management systems for all slope positions for 2001 data.

\begin{tabular}{|l|l|c|l|c|}
\hline Slope Position & Land Management System & Mean & Variables & t-test \\
\hline Upper & NO-TILL & 6.89 & no-till vs. control & $\mathrm{s}$ \\
\hline & CONTROL & 6.55 & control vs. conventional till & $\mathrm{S}$ \\
\hline & CONVENTIONAL TILL & 7.06 & no-till vs. conventional till & $\mathrm{s}$ \\
\hline \multicolumn{5}{|l|}{} \\
\hline Mid & NO-TILL & 7.11 & no-till vs. control & $\mathrm{s}$ \\
\hline & CONTROL & 6.62 & control vs. conventional till & $\mathrm{S}$ \\
\hline & CONVENTIONAL TILL & 7.10 & no-till vs. conventional till & $\mathrm{NS}$ \\
\hline \multicolumn{5}{|l|}{} \\
\hline
\end{tabular}

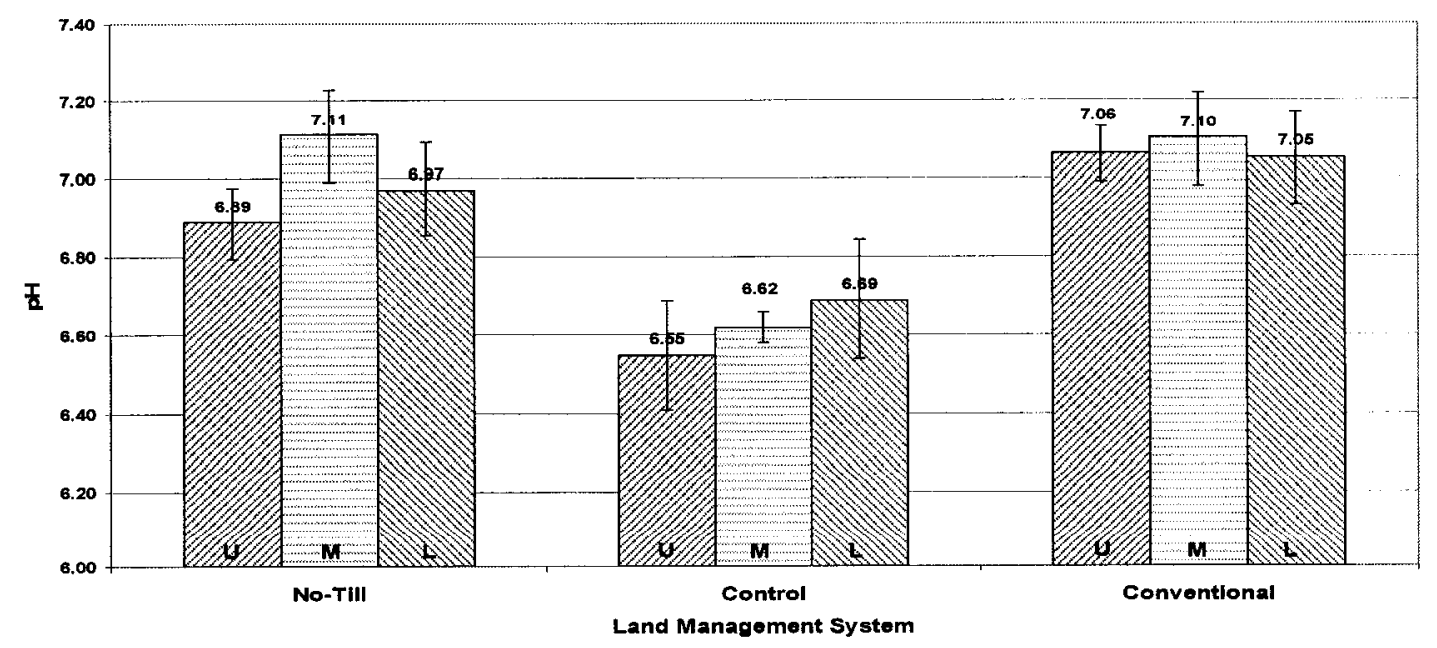

Fig. 5.11 Means and standard deviations of surface (A horizon) $\mathrm{pH}$ for three land management systems and three slope positions for the 2001 data. 


\subsubsection{3 $\quad \mathrm{pH}-$ Change Over Time}

The initial samples for the establishment of the no-till site \#14 and the conventional till site \#44 were collected October 29 and 30, 1991 as the baseline samples for the establishment of this benchmark site. As noted in the methodology section the no-till site \#14 and the conventional till site \#44 were resampled on October $10-14$ and November $6-10,2001$, respectively.

For the no-till site, the mean $\mathrm{pH}$ is less in 2001 for the upper slope position and slightly higher for the mid and lower slope positions, but none of the differences are statistically significant (Fig. 5.12 and Table 5.7). The results for the conventional till system indicate that $\mathrm{pH}$ values are significantly less in 2001 than in 1991 for all landscape positions. 
Table 5.7 Mean surface $\mathrm{pH}$ values and t-test results comparing 1991 and 2001 data for all slope positions for the no-till and conventional till sites.

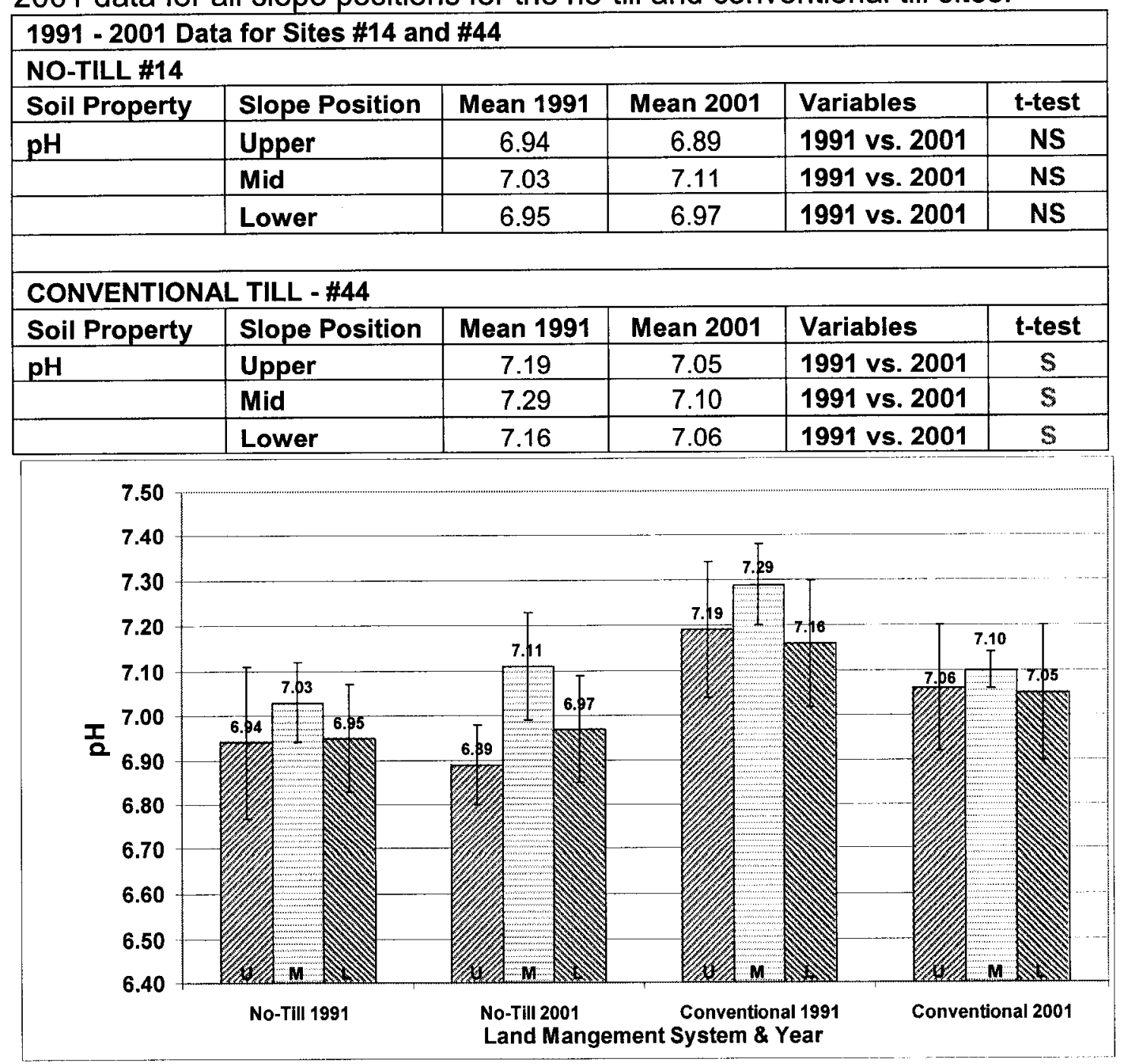

Fig. 5.12 Means and standard deviations of mean surface (A-horizon) $\mathrm{pH}$ for the no-till and conventional till land management systems and three slope positions between the 1991 and 2001 data. 


\subsubsection{Organic Carbon}

\subsubsection{Organic Carbon - 1991}

The trend in mean surface organic carbon content is the same for each land management system: the organic carbon values decrease (not statistically significant) from the upper to the mid slope position and then increase significantly to the lower slope position (Fig.5.13 and Table 5.8). The overall increase from the upper to the lower slope position is statistically significant for the conventional till system.

In Table 5.9 the summary of t-test results for mean organic carbon content between land management systems for each slope position indicate that mean organic carbon contents for all slope positions are greater for the no-till land management system and all the differences are statistically significant. 
Table 5.8 Means and t-test results for surface organic carbon (\%) for land management systems and slope positions for 1991 data.

\begin{tabular}{|l|l|c|l|c|}
\hline No-till \#14 & Slope Position & Mean & Variables & t-test \\
\hline & Upper & 2.48 & upper vs. mid & NS \\
\hline & Mid & 2.22 & mid vs. lower & S \\
\hline & Lower & 2.77 & upper vs. lower & NS \\
\hline \multicolumn{5}{|l}{} \\
\hline Conventional till \#44 & Slope Position & Mean & Variables & t-test \\
\hline & Upper & 1.50 & upper vs. mid & NS \\
\hline & Mid & 1.15 & mid vs. lower & S \\
\hline & Lower & 1.70 & upper vs. lower & S \\
\hline
\end{tabular}

Table 5.9 Means and t-test results for surface organic carbon (\%) for slope positions between land management systems for 1991 data.

\begin{tabular}{|l|l|c|c|l|c|}
\hline \multirow{2}{*}{ Organic Carbon } & Slope & \multicolumn{2}{|c|}{ Mean } & \multirow{2}{*}{ Variables } & t-test \\
\cline { 3 - 6 } & Position & No-till & Conventional till & Vo-till vs. conventional till & $\mathrm{S}$ \\
\hline & Upper & 2.48 & 1.50 & No-till vs. conventional till & $\mathrm{S}$ \\
\hline & Mid & 2.22 & 1.15 & No-till vs. conventional till & $\mathrm{S}$ \\
\hline
\end{tabular}

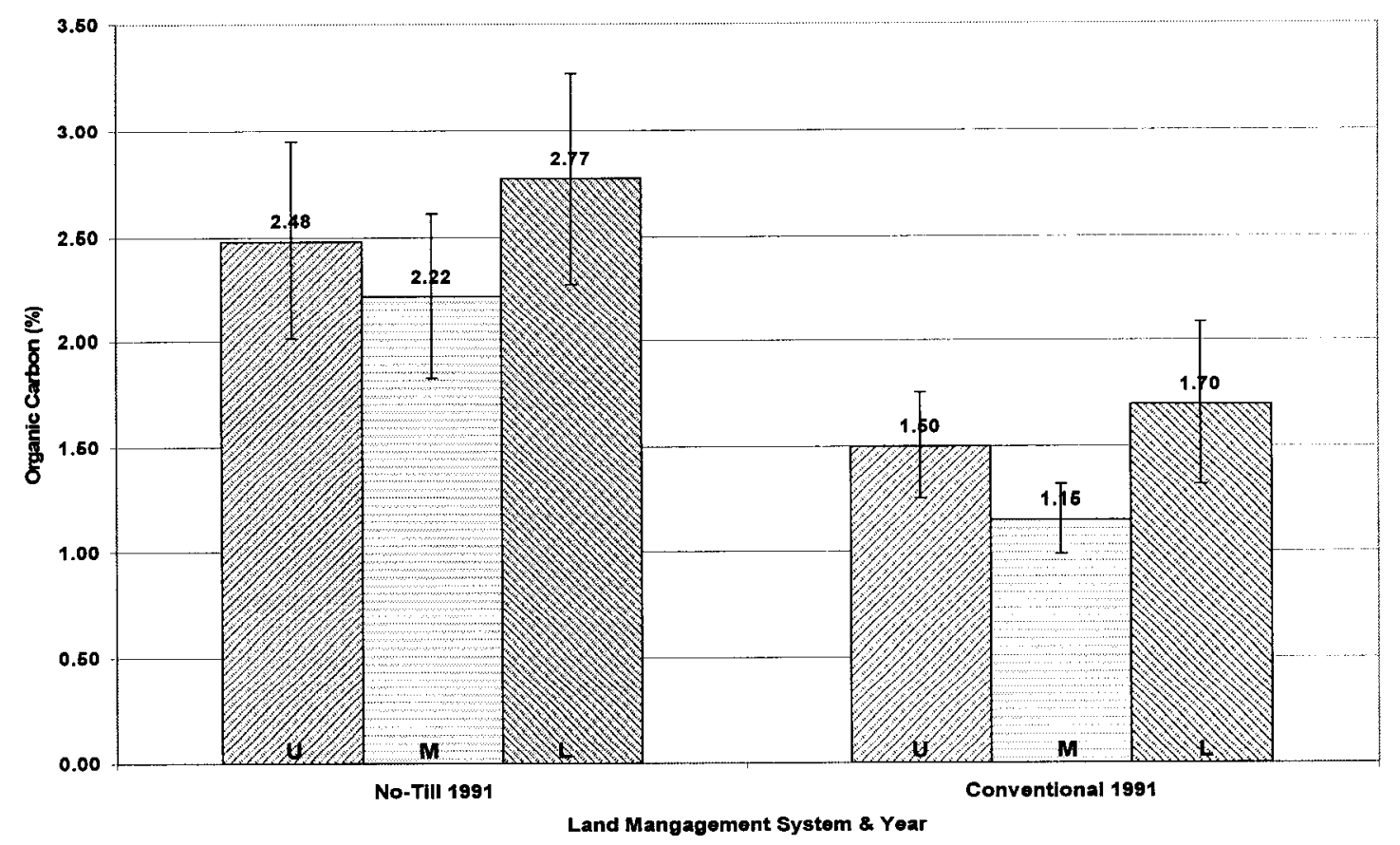

Fig. 5.13 Means and standard deviations of surface (A-horizon) organic carbon (\%) for no-till and conventional till land management systems and three slope positions for the 1991 data. 


\subsubsection{Organic Carbon - 2001}

The 2001 data (Table 5.10) for mean surface organic carbon content by landscape position for the all sites indicates that there is a decrease in organic carbon content from the upper to the mid slope position and then an increase to the lower slope positions. The decrease in organic carbon from the upper to mid slope and landscape position is significant for the conventional till site only. The organic carbon content increases significantly between the lower and mid slope landscape positions for all treatments. The organic carbon content values between the upper and lower landscape positions are statistically significant only for the no-till system.

The comparisons of mean organic carbon contents between the control and the two other management systems in Table 5.11 and Fig. 5.14 demonstrate the overall difference in magnitude of the carbon content characteristic of each system. The control site had the highest organic carbon content for all slope positions, and the conventional till sites had the lowest.

With the exception of differences between the control and the no-till sites for the upper slope landscape position, all of the differences were statistically significant. The reason for the non-statistically significant differences for the upper slope position was probably due to the small number of sample points in the control site (3) and their large standard deviation (0.8). 
Table 5.10 Summary of means and t-tests for surface organic carbon \% results for land management systems and slope positions for 2001 data.

\begin{tabular}{|l|l|c|l|c|}
\hline Land Management System & Slope Position & Mean & Variables & t-test \\
\hline CONTROL & Upper & 3.49 & Upper vs. mid & NS \\
\hline & Mid & 3.14 & Mid vs. lower & S \\
\hline & Lower & 4.31 & Upper vs. lower & NS \\
\hline \multicolumn{5}{|l|}{} \\
\hline NO-TILL & Upper & 2.08 & Upper vs. mid & NS \\
\hline & Mid & 1.79 & Mid vs. lower & S \\
\hline & Lower & 2.66 & Upper vs. lower & S \\
\hline CONVENTIONAL TILL & Upper & 1.44 & Upper vs. mid & S \\
\hline & Mid & 1.11 & Mid vs. lower & S \\
\hline & Lower & 1.69 & Upper vs. lower & NS \\
\hline
\end{tabular}

Table 5.11 Means and t-test results for surface organic carbon \% for slope positions between land management systems for 2001 data.

\begin{tabular}{|c|c|c|c|c|}
\hline $\begin{array}{l}\text { Slope } \\
\text { Position }\end{array}$ & Land Management System & Mean & Variable & t-test \\
\hline \multirow[t]{3}{*}{ Upper } & NO-TILL & 2.08 & no-till vs. control & NS \\
\hline & CONTROL & 3.49 & control vs. conventional till & $s$ \\
\hline & CONVENTIONAL TILL & 1.44 & no-till vs. conventional till & $s$ \\
\hline \multirow[t]{3}{*}{ Mid } & NO-TILL & 1.79 & no-till vs. control & $s$ \\
\hline & CONTROL & 3.14 & control vs. conventional till & 5 \\
\hline & CONVENTIONAL TILL & 1.11 & no-till vs. conventional till & $s$ \\
\hline \multirow[t]{3}{*}{ Lower } & \begin{tabular}{|l} 
NO-TILL \\
\end{tabular} & 2.66 & no-till vs. control & $s$ \\
\hline & CONTROL & 4.31 & control vs. conventional till & $s$ \\
\hline & CONVENTIONAL TILL & 1.69 & no-till vs. conventional till & $s$ \\
\hline
\end{tabular}

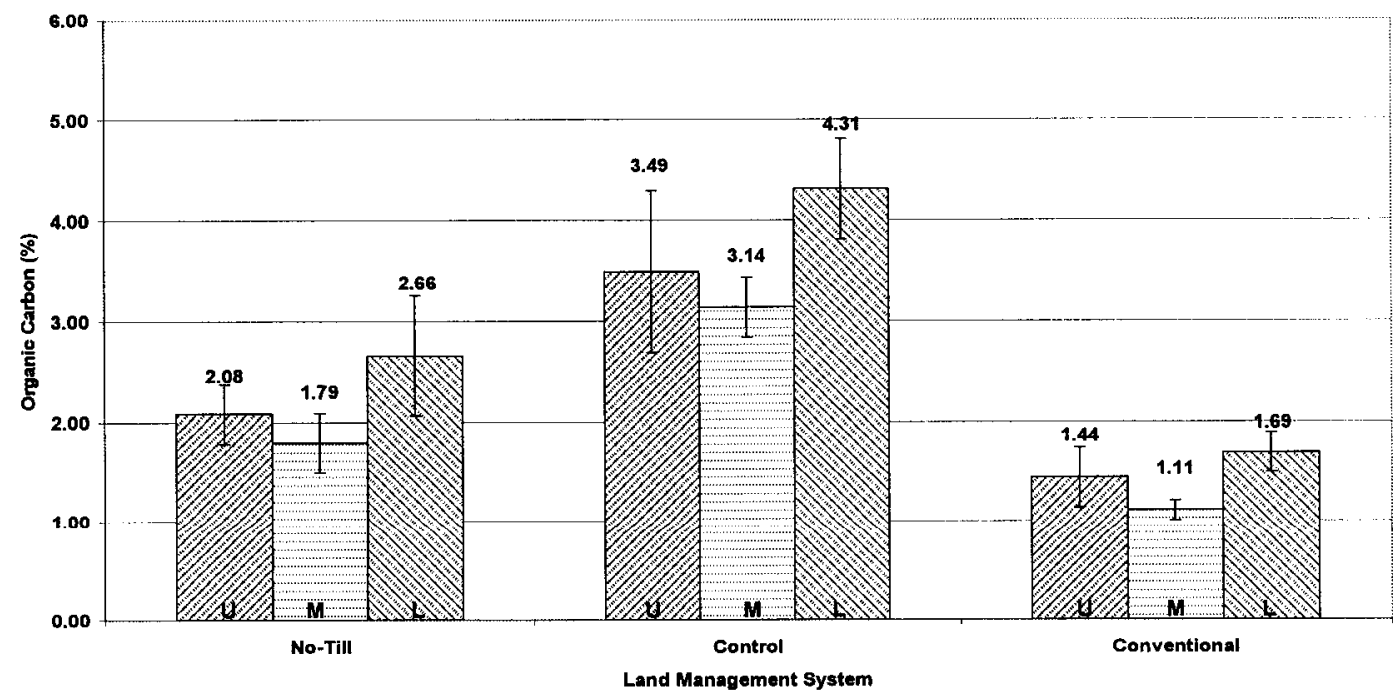

Fig. 5.14 Means and standard deviations of surface (A-horizon) organic carbon (\%) for three land management systems and three slope positions for the 2001 data. 


\subsubsection{Organic Carbon - Change Over Time}

For the conventional till site the mean surface organic carbon values are slightly less in 2001 for all landscape positions (Fig. 5.15 and Table 5.12), but the decrease was never statistically significant. For the no-till site the surface organic carbon values were less for the 2001 data for all landscape positions, and the decrease was statistically significant for the mid slope position. 
Table 5.12 Mean surface organic carbon values (\%) and t-test results comparing 1991 and 2001 data for all slope positions for the no-till and conventional till sites.

\begin{tabular}{|c|c|c|c|c|c|}
\hline \multicolumn{6}{|c|}{1991 - 2001 Data for Sites \#14 and \#44 } \\
\hline Soil Property & Slope Position & Mean 1991 & Mean 2001 & Variables & t-test \\
\hline \multicolumn{6}{|l|}{ NO-TILL \#14 } \\
\hline \multirow[t]{3}{*}{ Organic Carbon } & Upper & 2.48 & 2.08 & 1991vs2001 & NS \\
\hline & Mid & 2.22 & 1.79 & $1991 \mathrm{vs} 2001$ & $S$ \\
\hline & Lower & 2.77 & 2.66 & 1991vs2001 & NS \\
\hline \multicolumn{6}{|c|}{ CONVENTIONAL TILL - \#44 } \\
\hline \multirow[t]{3}{*}{ Organic Carbon } & Upper & 1.50 & 1.44 & 1991vs2001 & NS \\
\hline & Mid & 1.15 & 1.11 & 1991vs2001 & NS \\
\hline & Lower & 1.70 & 1.69 & 1991vs2001 & NS \\
\hline
\end{tabular}

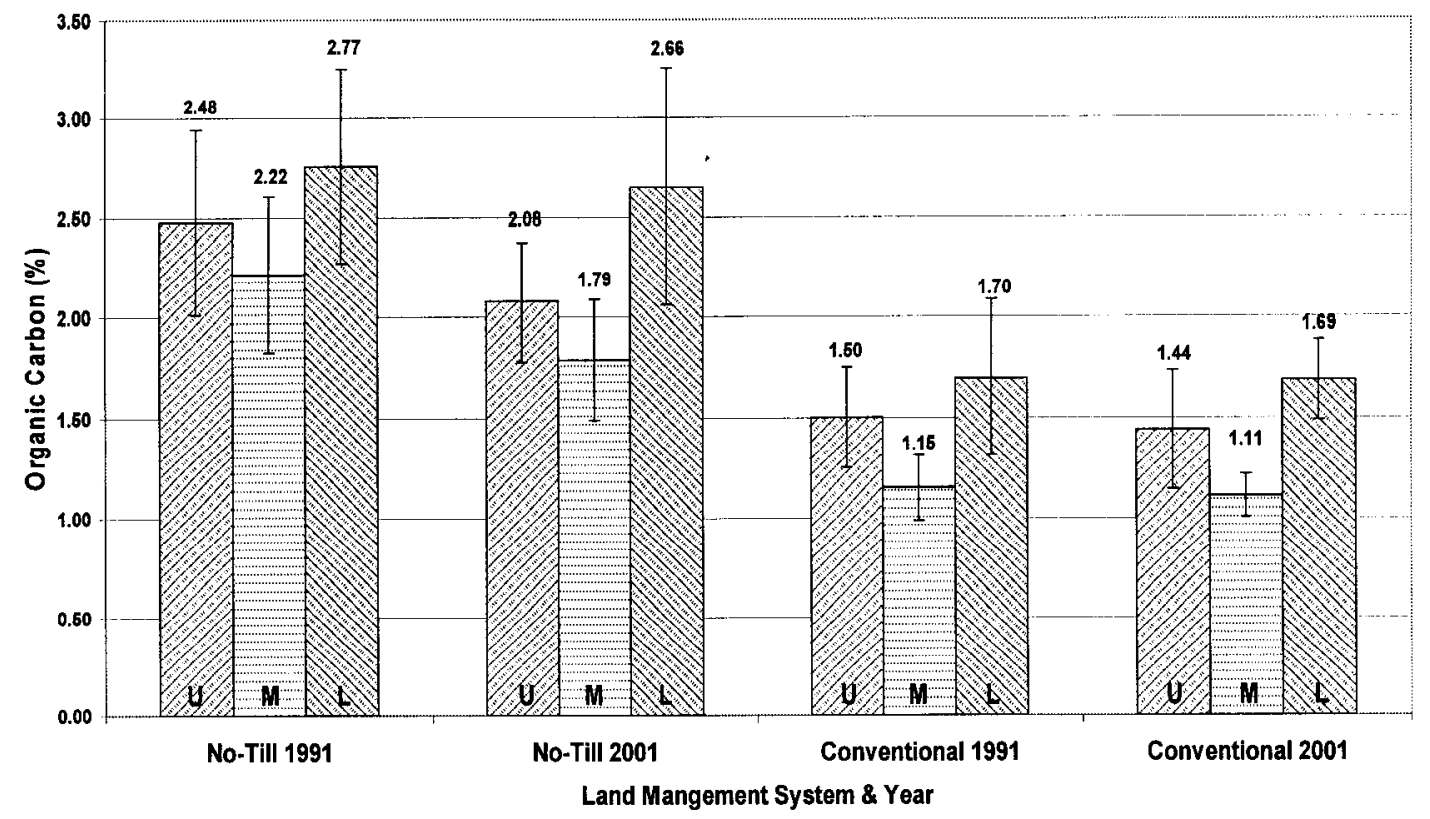

Fig. 5.15 Means and standard deviations of mean surface (A-horizon) organic carbon (\%) for the no-till and conventional till land management systems and three slope positions for the 1991 and 2001 data. 


\subsubsection{Bulk Density}

Bulk density, the mass of dry soil per unit bulk volume $\left(\mathrm{g} \mathrm{cm}^{-3}\right)$, is a dynamic soil property that relates to the proportional volumes of pores and solid materials, and any factor that influences pore space will affect bulk density (Brady \& Weil 1996).

\subsubsection{Bulk Density - 1991}

For the conventional till management system, the mean surface bulk density increases significantly from the upper to the mid slope position and then decreases to the lower slope position. For both sites the bulk densities at different landscape positions are all statistically different, with the exception of the upper and mid slope positions of the no-till site (Fig. 5.16 and Table 5.13).

The mean bulk densities $\left(\mathrm{g} \mathrm{cm}^{-3}\right)$ at each slope position across the land management systems in 1991 (Table 5.14) indicate that values are significantly greater for the no-till site at the upper slope positions, not statistically different at the mid slope positions and significantly less at the lower slope positions when compared to the conventional till site. 
Table 5.13 Means and t-tests for mean bulk density $\left(\mathrm{g} \mathrm{cm}^{-3}\right)$ results for no-till and conventional till land management systems and slope positions for 1991 data.

\begin{tabular}{|l|l|c|l|c|}
\hline No-till \#14 & & & & \\
\hline Soil Property & Slope Position & Mean & Variables & t-test \\
\hline Bulk Density & Upper & 1.37 & Upper vs. mid & NS \\
\hline & Mid & 1.40 & Mid vs. lower & $\mathbf{S}$ \\
\hline & Lower & 1.07 & Upper vs. lower & $\mathbf{S}$ \\
\hline & & & & \\
\hline Conventional till 44 & & & & \\
\hline Soil Property & Slope Position & Mean & Variables & t-test \\
\hline Bulk Density & Upper & 1.29 & Upper vs. mid & $\mathbf{S}$ \\
\hline & Mid & 1.38 & Mid vs. lower & $\mathrm{S}$ \\
\hline & Lower & 1.34 & Upper vs. lower & $\mathrm{S}$ \\
\hline
\end{tabular}

Table 5.14 Means and t-tests for mean bulk density $\left(\mathrm{g} \mathrm{cm}^{-3}\right)$ results for slope positions between the no-till and conventional till land management systems for 1991 data.

\begin{tabular}{|c|c|c|c|c|c|}
\hline Soil Property & Slope Position & \multicolumn{2}{|r|}{ Mean } & Variables & \\
\hline Bulk Density & & No-till & Conventional till & & t-test \\
\hline & Upper & 1.37 & 1.29 & Site \#14 vs. Site \#44 & $s$ \\
\hline & Mid & 1.40 & 1.38 & Site \#14 vs. Site \#44 & NS \\
\hline & Lower & 1.07 & 1.34 & Site \#14 vs. Site \#44 & $\mathrm{s}$ \\
\hline
\end{tabular}

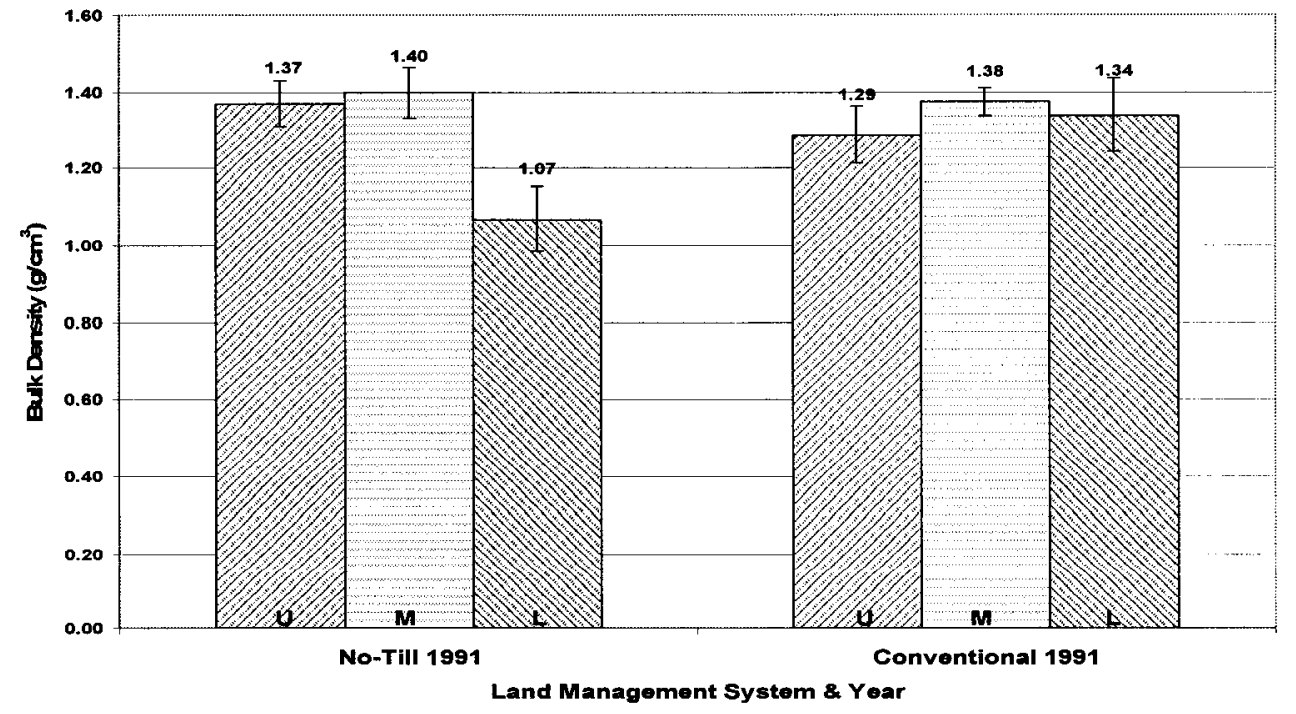

Fig. 5.16 Means and standard deviations of mean surface (A-horizon) Bulk Density $\left(\mathrm{g} \mathrm{cm}^{-3}\right)$ for the no-till and conventional till land management system and three slope positions for the 1991 data. 


\subsubsection{Bulk Density - 2001}

Bulk density is essentially the same in all landscape positions for the control land management system, with no statistically significant differences between landscape positions (Table 5.15, Fig. 5.17).

In both the no-till and conventional till management systems, the trend in mean bulk density increased from the upper to mid landscape position (not significant) and then decreased to the lower landscape position (significant). The bulk densities for the upper to the lower slope positions were statistically significant only for the no-till site.

For all slope positions (Table 5.16, Fig. 5.17), the surface horizons of the control sites always had significantly lower bulk density than that of both the no-till and conventional till sites. The bulk densities at all slope positions for the two management systems were also statistically different at all slope positions, with the no-till system always having the lower bulk density. 
Table 5.15 Means and t-tests for mean bulk density $\left(\mathrm{g} \mathrm{cm}^{-3}\right)$ results for land management systems and slope positions for 2001 data.

\begin{tabular}{|l|l|c|l|c|}
\hline Land Management System & Slope Position & Mean & Variables & t-test \\
\hline CONTROL & Upper & 0.77 & Upper vs. mid & NS \\
\hline & Mid & 0.77 & Mid vs. lower & NS \\
\hline & Lower & 0.78 & Upper vs. lower & NS \\
\hline \multicolumn{5}{|l|}{} \\
\hline NO-TILL & Upper & 1.20 & Upper vs. mid & NS \\
\hline & Mid & 1.24 & Mid vs. lower & S \\
\hline & Lower & 1.08 & Upper vs. lower & S \\
\hline \multicolumn{5}{|l|}{} \\
\hline CONVENTIONAL TILL & Upper & 1.33 & Upper vs. mid & NS \\
\hline & Mid & 1.39 & Mid vs. lower & S \\
\hline & Lower & 1.29 & Upper vs. lower & NS \\
\hline
\end{tabular}

Table 5.16 Means and t-tests for mean bulk density $\left(\mathrm{g} \mathrm{cm}^{-3}\right)$ results for slope positions between land management systems for 2001 data.

\begin{tabular}{|l|l|c|l|c|}
\hline $\begin{array}{l}\text { Slope } \\
\text { Position }\end{array}$ & $\begin{array}{l}\text { Land Management } \\
\text { System }\end{array}$ & Mean & Variable & t-test \\
\hline Upper & NO-TILL & 1.20 & no-till vs. control & S \\
\hline & CONTROL & 0.77 & control vs. conventional till & $\mathrm{S}$ \\
\hline & CONVENTIONAL TILL & 1.33 & no-till vs. conventional till & $\mathrm{S}$ \\
\hline \multicolumn{5}{|l|}{} \\
\hline Mid & NO-TILL & 1.24 & no-till vs. control & $\mathrm{S}$ \\
\hline & 0.77 & control vs. conventional till & $\mathrm{S}$ \\
\hline & CONTROL & 1.39 & no-till vs. conventional till & $\mathrm{S}$ \\
\hline & CONVENTIONAL TILL & \multicolumn{3}{|l|}{} \\
\hline Lower & NO-TILL & 1.08 & no-till vs. control & $\mathrm{S}$ \\
\hline & CONTROL & 0.78 & control vs. conventional till & $\mathrm{S}$ \\
\hline & CONVENTIONAL TILL & 1.29 & no-till vs. conventional till & $\mathrm{S}$ \\
\hline
\end{tabular}

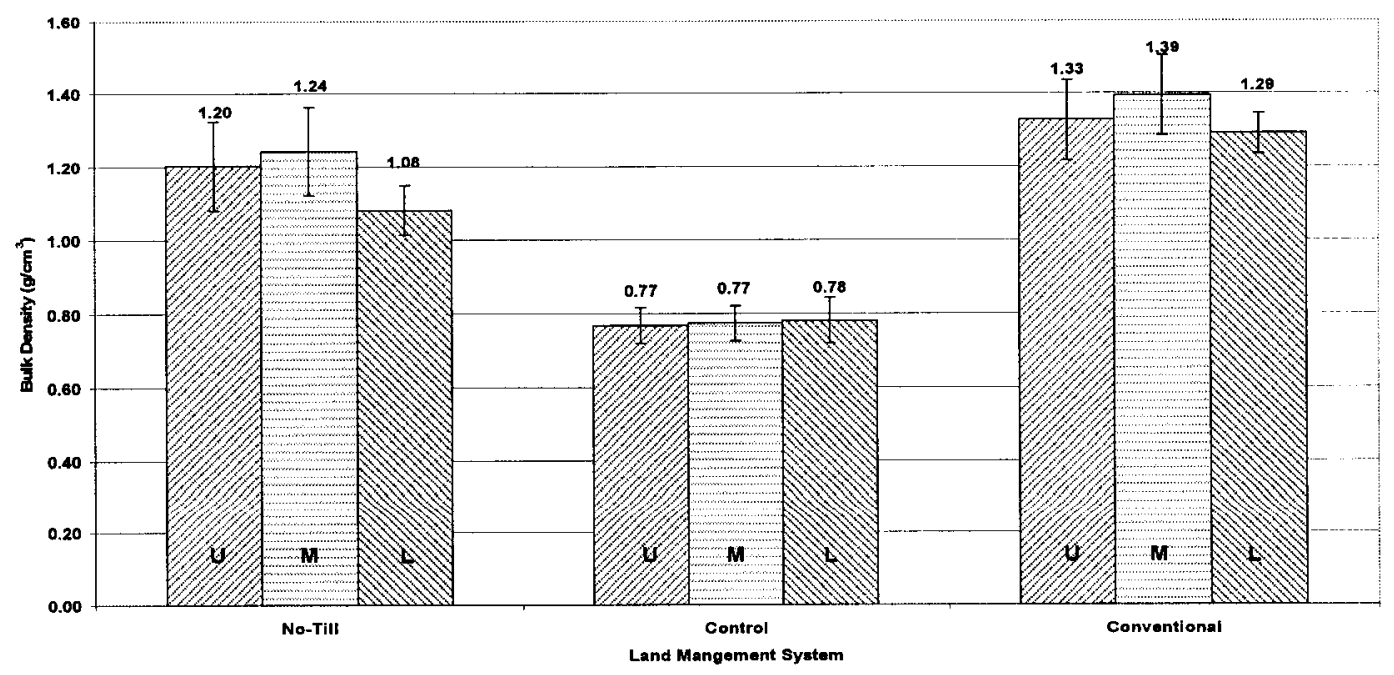

Fig. 5.17 Mean and standard deviations of mean surface (A-horizon) Bulk Density $\left(\mathrm{g} \mathrm{cm}^{-3}\right)$ for three land management systems and three slope positions for the 2001 data. 


\subsubsection{Bulk Density- Change Over Time}

Table 5.17 and Fig 5.18 summarizes the results comparing mean surface bulk density values between 1991 and 2001 for each slope position for each land management system (site). For the no-till site the mean surface bulk density values are all less in 2001 compared to the 1991 data for all landscape positions of the conventional till site. The mean bulk density values were significantly different for the upper and mid landscape positions but not for the lower slope position.

For the conventional till site mean surface bulk density values at the lower landscacpe position were significantly higher in 2001 than 1991 but for the upper and mid slope position values were not statistically different. 
Table 5.17 Mean surface bulk density $\left(\mathrm{g} \mathrm{cm}^{-3}\right)$ values and t-test results comparing 1991 and 2001 data for all slope positions for the no-till and conventional till sites.

\begin{tabular}{|c|c|c|c|c|c|}
\hline \multicolumn{6}{|c|}{1991 - 2001 Data for Sites \#14 and \#44 } \\
\hline Soil Property & Slope Position & Mean 1991 & Mean 2001 & Variables & t-test \\
\hline \multicolumn{6}{|l|}{ NO-TILL \#14 } \\
\hline \multirow[t]{3}{*}{ Bulk Density } & Upper & 1.37 & 1.20 & 1991 vs. 2001 & $\mathrm{~s}$ \\
\hline & Mid & 1.40 & 1.24 & 1991 vs. 2001 & $s$ \\
\hline & Lower & 1.07 & 1.08 & 1991 vs. 2001 & NS \\
\hline \multicolumn{6}{|c|}{ CONVENTIONAL TILL - \#44 } \\
\hline \multirow[t]{3}{*}{ Bulk Density } & Upper & 1.29 & 1.33 & 1991 vs. 2001 & NS \\
\hline & Mid & 1.38 & 1.39 & 1991 vs. 2001 & NS \\
\hline & Lower & 1.34 & 1.29 & 1991 vs. 2001 & $s$ \\
\hline
\end{tabular}

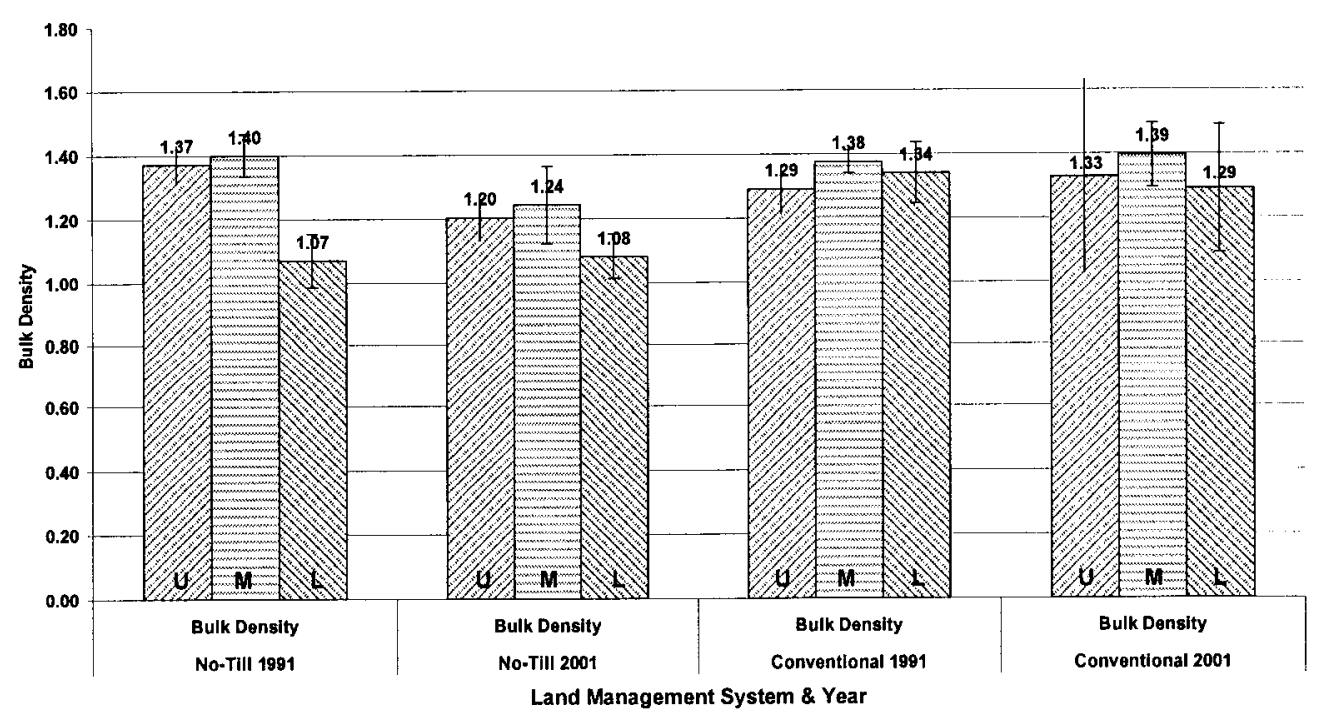

Fig. 5.18 Means and standard deviations of surface (A-horizon) bulk density $\left(\mathrm{g} / \mathrm{cm}^{-3}\right)$ for the no-till and conventional till land management systems and three slope positions for the 1991 and 2001 data.

\subsubsection{Particle Size}

Particle size analysis and the interpretations of soil texture are important determinations made for the purpose of defining properties and functions. Processes operating on slopes can differentially move particles of different 
sizes. As a consequence examination of the various particle size fractions and how they vary in the landscape and under different land management practices may provide additional information for monitoring of soil property change.

\subsubsection{Sand -2001}

The mean and standard deviations of percent sand in the surface horizon for the three land management systems and the three slope positions for the 2001 data are presented in Figure 5.19. Table 5.18 provides the mean percent sand for each slope position by land management systems and the ttest results. For the control site there is a decrease of the mean surface percent sand from the upper to the mid to the lower slope positions. Only the upper and the lower slope positions are significantly different.

For the no-till and conventional till land management systems the increase in mean percent sand from the upper to mid slope positions is not significant, but the decrease from the mid slope to the lower is significant for both. The overall decrease from the upper to the lower slope positions is significant for the no-till site and not significant for the conventional till site. 
Table 5.18 Means and t-test results for mean sand fraction (\%) for land management systems and slope positions for 2001 data.

\begin{tabular}{|l|l|c|l|c|}
\hline Land Management System & Slope Position & Mean & Variables & t-test \\
\hline CONTROL & Upper & 35.9 & Upper vs. mid & NS \\
\hline & Mid & 34.3 & Mid vs. lower & NS \\
\hline & Lower & 29.6 & Upper vs. lower & S \\
\hline \multicolumn{4}{|l|}{} \\
\hline NO-TILL & Upper & 39.2 & Upper vs. mid & NS \\
\hline & Mid & 42.0 & Mid vs. lower & S \\
\hline & Lower & 32.1 & Upper vs. lower & S \\
\hline CONVENTIONAL TILL & Upper & 43.3 & Upper vs. mid & NS \\
\hline & Mid & 49.6 & Mid vs. lower & S \\
\hline & Lower & 40.8 & Upper vs. lower & NS \\
\hline
\end{tabular}

Table 5.19 Means and t-test results for the sand fraction (\%) for slope positions between the land management systems for 2001 data.

\begin{tabular}{|l|l|r|l|c|}
\hline Slope Position & Land Management System & Mean & Variable & t-test \\
\hline Upper & NO-TILL & 39.2 & no-till vs. control & NS \\
\hline & CONTROL & 35.9 & control vs. conventional till & $\mathrm{S}$ \\
\hline & CONVENTIONAL TILL & 43.3 & no-till vs. conventional till & $\mathrm{NS}$ \\
\hline \multicolumn{5}{|l|}{} \\
\hline
\end{tabular}

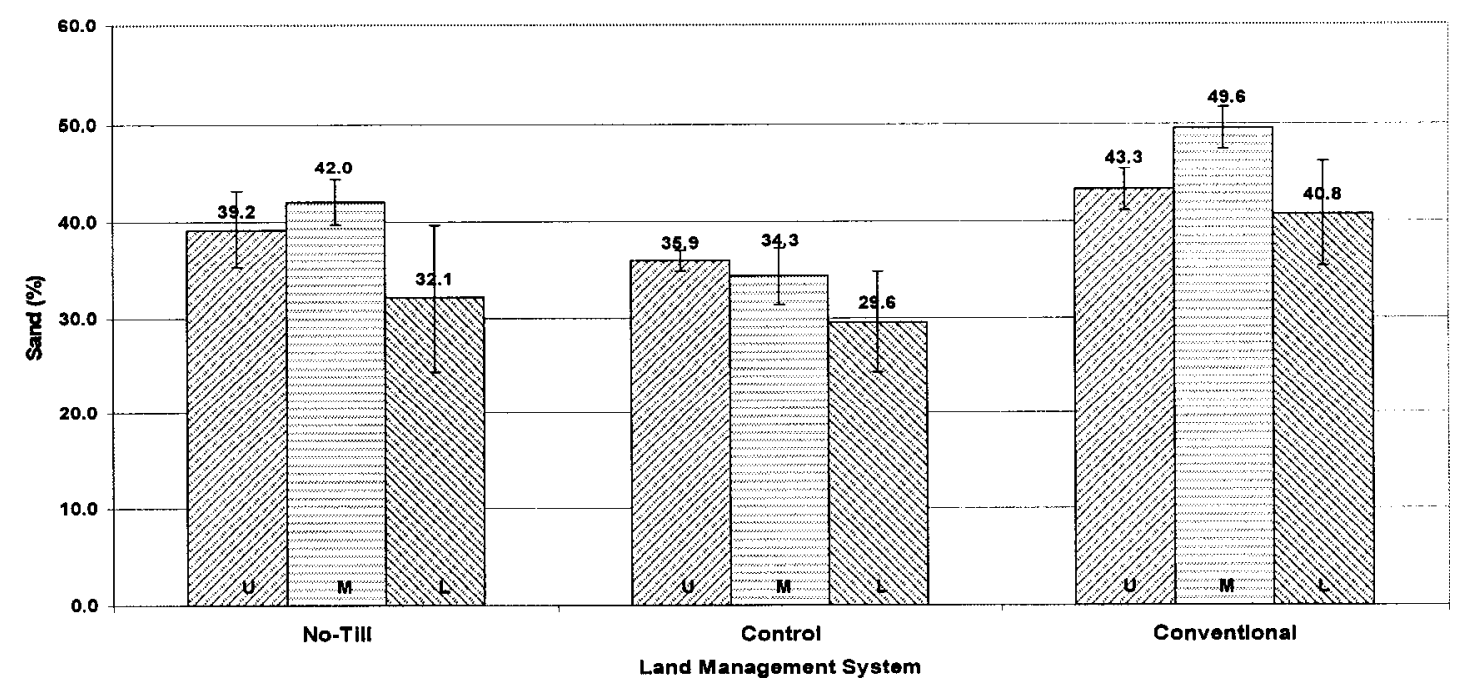


Fig. 5.19 Means and standard deviations of mean surface (A-horizon) sand fraction (\%) for three land management systems and three slope positions for the 2001 data.

Table 5.19 provides a summary of the comparison of mean surface sand content (\%) between land management systems by slope positions. For all landscape positions the mean percent sand is lowest for the control site, in the middle for the no-till site and greatest for the conventional till site. There is no significant difference between the control and the no-till site for any landscape position. The sand contents for the control site are significantly greater than for the conventional till site at all landscape positions. In comparison of the no-till to the conventional till sites, the conventional till has significantly more sand at both the mid and lower slope positions, but not in the upper slope position.

\subsubsection{Silt -2001}

The silt content (the remainder when sand and clay content are subtracted from 100\%) of the control land management system increases from the upper to the mid slope position and from the mid to the lower slope positions but none of the values are statistically different. The no-till and conventional till land management system sites display decreasing percent silt from the upper to the mid slope position which is not significant for the notill site but is significant for the conventional till site. Both show a statistically significant increase in silt from the mid to the lower slope position. The increase in mean percent silt between the upper and lower slope positions is not significant for either management system (Fig. 5.20 and Table 5.20). 
Table 5.20 Means and t-test results for mean silt fraction (\%) by land management systems and slope positions for 2001 data.

\begin{tabular}{|l|l|c|l|c|}
\hline Land Management System & Slope Position & Mean & Variables & t-test \\
\hline CONTROL & Upper & 48.5 & Upper vs. mid & NS \\
\hline & Mid & 53.3 & Mid vs. lower & NS \\
\hline & Lower & 53.7 & Upper vs. lower & NS \\
\hline NO-TILL & Upper & 47.5 & Upper vs. mid & NS \\
\hline & Mid & 44.4 & Mid vs. lower & S \\
\hline & Lower & 50.4 & Upper vs. lower & NS \\
\hline CONVENTIONAL TILL & Upper & 43.7 & Upper vs. mid & S \\
\hline & Mid & 39.0 & Mid vs. lower & S \\
\hline & Lower & 45.6 & Upper vs. lower & NS \\
\hline
\end{tabular}

Table 5.21 Means and t-test results for mean silt fraction (\%) by slope positions between land management systems for 2001 data.

\begin{tabular}{|l|l|c|l|l|}
\hline Slope Position & Land Management System & Mean & Variable & t-test \\
\hline Upper & NO-TILL & 47.5 & no-till vs. control & NS \\
\hline & CONTROL & 48.5 & control vs. conventional till & S \\
\hline \multicolumn{5}{|l|}{} \\
CONVENTIONAL TILL & 43.7 & no-till vs. conventional till & NS \\
\hline Mid & NO-TILL & 44.4 & no-till vs. control & NS \\
\hline & CONTROL & 53.3 & control vs. conventional till & NS \\
\hline \multicolumn{5}{|l|}{} \\
\hline Lower & CONVENTIONAL TILL & 39.0 & no-till vs. conventional till & S \\
\hline & NO-TILL & 50.4 & no-till vs. control & NS \\
\hline & CONTROL & 53.7 & control vs. conventional till & S \\
\hline & CONVENTIONAL TILL & 45.6 & no-till vs. conventional till & NS \\
\hline
\end{tabular}



Fig. 5.20 Means and standard deviations of the mean surface (A-horizon) silt fraction (\%) for three land management systems and three slope positions for the 2001 data. 
The comparison (Table 5.21) between land management systems indicates that for the upper slope position the percent silt of the control and the no-till systems was not significantly different, but the mean percent silt for the conventional till site was significantly less than for the control. The silt content of the conventional till and no-till systems were not significantly different.

For the mid slope position the silt content values decrease from the control, to the no-till, and to the conventional till management systems but only the difference between the no-till and conventional till is significant. .The lack of significance between the control and no-till and the control and the conventional till is probably because of the few samples for the control site.

For the lower slope position the silt content decreased from the control to the no-till site to the conventional till system. Only the difference between the control and the conventional till site is significant. 


\subsection{DISCUSSION AND CONCLUSION}

This study was undertaken to measure the soil property differences that are associated with landscape position and to determine whether measurable differences in soil properties had developed over a ten year period on adjacent cultivated sloping landscapes which were managed in different manners (no-till and conventional tillage). To briefly reiterate, the soils on benchmark sites \#14 and \#44 and the never-cultivated control strip which lies between them are members of the Guelph catena, which have developed on 5-6\% slopes of a drumlin composed of grey and brown loamy and calcareous glacial tills derived from Lockport dolomites (Chapman and Putnam 1966; Hoffman et al 1963). The detailed soil pedon descriptions for the top, middle and lower slope positions at the site indicate a limited range in parent material soil texture (from loam to sandy loam) and that three different soil great groups are present: Gray Brown Luvisols (at the upper and mid slope positions of the control site, and the upper slope of the no-till site), Melanic Brunisols (at the mid slope position of the no-till site and the upper and mid slope positions of the conventional till site) and Humic Gleysols (in the lower slope positions on all sites). Birkeland (1999) states that numerous studies have shown that many soil properties (soil thickness and soil geochemistry) are related to the gradient of the slope as well as the particular position of the soil on the slope. It has been assumed in this study that the soils at all three sites had similar inherent soil properties before clearing and cultivation and therefore differences in the dynamic soil properties among the sites are 
related to differences in agricultural practices, particularly tillage regimes. Changes in these soil properties which were measured in 1991, when the benchmark sites were established, and again in 2001 for this study, allow evaluation of the effects of no-till and conventional till on selected soil properties.

To understand the potential changes to the Guelph catena soil landscape due to clearance and tillage, a conceptual 'model' of how landscape position, tillage system and tillage over time lead to changes in soil properties can be developed. In a hypothetical landscape, the assumption is made that the three sites had similar properties and similar patterns of these properties at the time of clearing. The never cultivated control site is considered to represent the pre-agricultural natural condition of the Guelph catena soils and its soil properties and differences with slope position are assumed to be due to natural pedogenesis. The control site then provides the baseline situation to which the measured soil properties at the cultivated sites can be compared to provide evidence as to which soil properties change with landscape position in the absence of human interference and which properties do not. According to Buol et al (1997) "a soil survives because of: 1) a protective covering in the form of vegetation or of an otherwise resistant surface layer; 2) because in its steady state it forms as it dissipates". Clearing and tillage lead to the removal and alteration of the protective vegetation and disrupt the steady state conditions of the soil. 
Even in native landscapes soil materials move downslope due to the effects of water erosion and in earlier stages of development due to wind if the surface was unvegetated. The soils with the thinnest profiles would be at the top of the slope and the soils with the thickest profiles would be in the foot and lower slope positions where the eroded upslope materials accumulate.

Conventional tillage (moldboard plowing and continuous cultivation with row crops) leads to serious deterioration in soil structure and to soil erosion. This effect is most significant in rolling landscapes, with moderate slopes (Brady and Weil 1996). Conventional tillage represents the most intense management system and the conceptual model would predict erosion and compaction in the upper and mid slope positions, characterized by a decrease in solum thickness and organic matter and an increase in bulk density. In the lower slope position where the redistributed upslope materials are redeposited, an increase in solum thickness and organic matter and decrease in bulk density would be expected.

No-till land management is a conservation tillage practice that attempts to maintain protective crop residues on the soil surface; it also improves the structure and the infiltration rate of the soil (Brady and Weil 1996). As stated by Buol et al. (1997) the maintenance of a protective soil surface aids in the survival of the soil. The protective cover of no-till would be expected to decrease, but not eliminate the effects of the erosive forces of wind and water; consequently the solum depth would be less than similar soils that have not been cleared or cultivated. It would also be expected that the depth 
of solum on the upper and mid slopes for the no-till site would be greater than for conventional till sites on which the crop residues have been incorporated into the soil by plowing. The residue cover of the no-till soils in sloping landscapes will modify the erosion dynamics and stabilize the soil surface. The maintenance of a protective soil surface and no cultivation would enhance the structure of the soil and promote the accumulation and stabilization of organic matter. This should function to decrease the bulk density by incorporation of organic matter into the surface soil as well as reducing the effects of compaction that can be a factor in conventionally tilled soils (Brady and Weil 1996). In summary, the changes that would be expected as a consequence of cultivation are: increased erosion with a decrease in solum thickness and organic matter in the upper and mid landscape positions and an increase in the lower or footslope landscape positions; increase in bulk density in the upper and mid slope position and a decrease in the bulk density in the lower slope position as the redistributed upslope materials are redeposited. The greatest differences from the control situation would occur on the more intensively cultivated site (for most soil properties).

In the results section, location by location, treatment by treatment, property by property comparisons of statistical significance for a series of chemical and physical soil parameters were presented. The results were presented for within treatment (tillage practice across the topographic positions), and between treatments (across tillage treatments for each 
topographic position) comparisons. The complete results will now be discussed to evaluate the overall trends of soil property changes by topographic position, tillage practice and over the ten year time period. Tables $6.1,6.2$ and 6.4 provide summaries of the test of significance for the comparisons. Table 6.3 provides a summary of the trends in soil property change between land management systems by slope position.

The t-test for differences within a site was determined between slope positions. Note that the tests for differences are made for the upper to mid, mid to lower and upper to lower landscape positions. For this study the most important change (difference) comparisons are from the upper to the mid and from the mid to lower slope positions. The comparisons of the upper to the lower slope positions assist in evaluation of the overall process involved.

\subsection{SOIL PROPERTY DIFFERENCES RELATED TO TOPOGRAPHIC POSITION}

\subsubsection{Control Site}

The control site is considered to represent the pre-agricultural, natural condition of the Guelph catena soils and serves as the baseline to which to compare the soils of the no-till and conventional till sites that have been used for agriculture. While removal or deposition of surficial material by natural erosive processes is probably occurring, as is development and deepening of the soil profile into the unweathered parent material, these processes have been occurring since deglaciation and little change would be expected over the short period of time that the adjacent soils have been under agricultural production (approx. 150 years). Organic matter input at the surface and its 
conversion to humus could be roughly balanced by loss due to decomposition (Birkeland, 1999). It is widely agreed that in the natural system, the normal processes of soil formation (additions, removals, translocations and transformations) proceed slowly and are mostly in a state of near equilibrium, barring man-made or natural catastrophic events.

Natural soil forming processes for the control site soils can be inferred by examining the differences in solum thickness with landscape position. The natural erosive forces of wind and water cause the removal and redistribution of surface organic and mineral soil materials resulting in a decreasing solum depth (not significant) from the upper to the mid slope to a significant (large) increase from the mid to the lower slope position (Table 6.1). This accumulation of soil material at lower slope position has also been occurring throughout the soil profiles' development and reflects its natural pedogenic history. The inferred down slope movement and accumulation of material is an example of landform erosion with time in an uncultivated landscape (Birkeland 1999).

The organic carbon results for the control further demonstrate the natural pedogenic process in soils developing on a sloping landscape. There was a significant increase in mean surface organic carbon from the mid to the lower slope position (Table 6.1). The natural processes that contributed to the removal of surface materials in the mid slope position (decreased depth of solum) may also have led to removal of organic matter. The mid slope position represents the most exposed and vulnerable segment of this 
landscape to soil loss to erosive forces. Bergstrom et al. (2001) state that the influence of topography on soil organic matter content has long been recognized. Landscapes with variable topographic relief also influence soil carbon stocks by erosional processes.

The soil properties of solum thickness, organic carbon and sand content demonstrated significant differences with landscape position. These values can be used as baseline data for comparison to data from the cultivated site. The mean surface $\mathrm{pH}$, bulk density and silt content (2001) for the control site were not significantly different for any of the landscape positions (Table 6.1). Differences in these soil properties, if they occur on the cultivated sites, would also serve as important indicators of change in soil properties due to agricultural management.

\subsubsection{No-till Site}

The no-till site represents an agricultural management system which since 1987 has experienced minimal surface disturbance and where crop residues have been left on the soil surface.

For the no-till site, $\mathrm{pH}(2001)$ is the only soil property that shows a significant difference (increase) for the upper to the mid slope position. In contrast, all of the soil properties analyzed (1991 and 2001) for the mid and lower slope positions are significantly different (Table 6.1). Solum depth, organic carbon (1991), bulk density (2001) and silt significantly increase downslope, while pH (1991 and 2001), organic carbon (2001), bulk density (1991), and sand decrease significantly. 


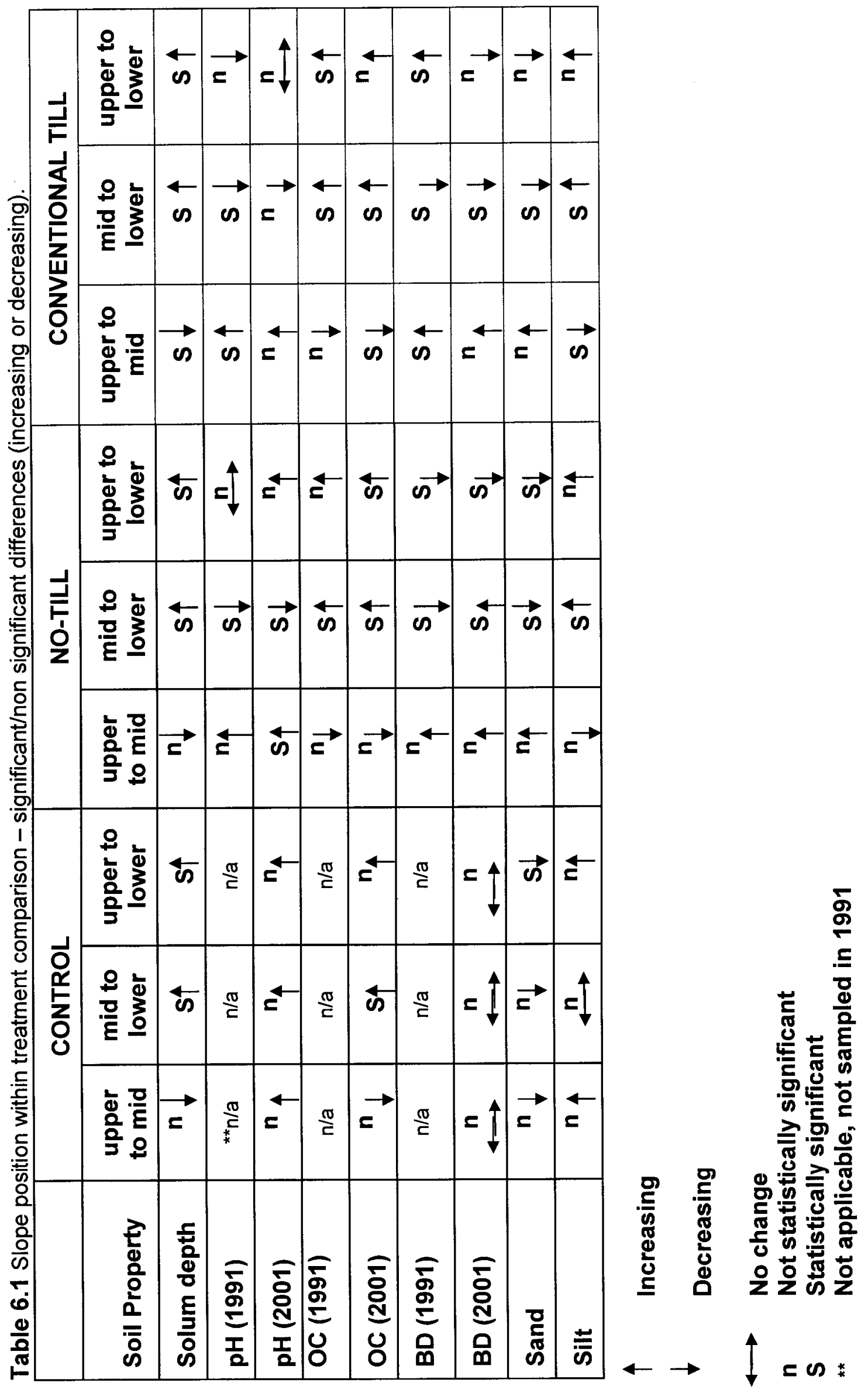


The comparison of the mid to lower slope position demonstrates that this portion of the landscape is significantly affected for all soil properties, most likely by erosion and redistribution due to topographic position. The net result of the erosion and redistribution due to topography is the removal of soil material from the upslope positions and the accumulation of sediments in the lower landscape position. The upslope portion was not as severely eroded as the mid slope due to the lower slope values $(1-2 \%$ for the upper slope versus $5-6 \%$ for the mid slope soils).

\subsubsection{Conventional Till Site}

The conventional till site represents an agricultural management system, which has been annually plowed from 1987 to 1997 and hence has experienced disturbance to the soil surface and almost complete incorporation of crop residues. For the conventional till site, the solum depth, organic carbon (2001) and silt content decrease significantly from the upper to mid slope positions, while the $\mathrm{pH}$ and the bulk density (1991) significantly increase. The decrease in the solum depth, organic carbon content and increase in bulk density indicate that the upper slope segment of the landscape is being eroded and compacted by the effects of conventional tillage. From the mid to lower slope positions, the solum depth, organic carbon (1991 and 2001), bulk density (2001) and silt content significantly increase and the $\mathrm{pH}$ (1991), bulk density (1991) and sand content significantly decrease. The erosion and redistribution of up slope materials by 
wind, water and cultivation result in the accumulation of sediments in the lower slope positions.

Across the slope positions, the soil properties demonstrate significant changes due to topography for the conventional till site. The solum depth decreases from the upper to middle and increases from the mid to lower slope positions. It seems that the soil materials eroded from the upslope positions are transported downslope and accumulate in the footslope (lower) position. The $\mathrm{pH}$ (1991) increased from the upper to the mid slope and decreased from the mid to lower. For the upper and middle slope positions, the removal of surface soil material means that B-horizon material of higher $\mathrm{pH}$ is incorporated into the surface layer by plowing $(\mathrm{pH}$ values increase with depth for most of the soil profiles sampled (Appendix 8.2.6)). For the lower slope position, the $\mathrm{pH}$ decreases significantly as the upslope surface materials that have lower $\mathrm{pH}$ values accumulate there. The organic carbon content decreases from the upper to middle and increases from the mid to the lower slope position as erosion removes the surface materials that are higher in organic carbon and redeposits them in the lower slope positions. The bulk density values increase from the upper to mid and decreases from the mid to the lower. The maximum at the mid slope position may relate to both the loss of the more organic-rich topsoil and to the tendency for bulk densities for all the soils described to increase with depth, which implies that as the surface materials are eroded the materials that remain will be higher in bulk density. The decreasing bulk densities in the lower slope positions are probably a 
result of the redeposition and accumulation of the upper slope surface materials that have higher organic content and lower bulk densities. This is consistent with Boehm and Anderson (1997) who in their study of twenty prairie sites, noted that bulk density values were higher on the divergent backslopes (mid slope) than in convergent footslopes (lower slope) in the conventional till fields compared to no-till fields. They attributed this to the soil surface at the mid slope positions containing less crop residues in various states of decomposition.

\subsubsection{Summation of Topographic Effects}

For all three of the sites, topography is a contributing process in the change of soil properties. All the sites are characterized by long uniform (5$6 \%)$ mid slopes and there is evidence of change in soil properties for all sites due to landscape position. If it is assumed that all other factors remain constant i.e. climate (precipitation and temperature), parent materials, and the effects of organisms (tillage, turbation and decomposition), then the differences in soil properties are dependant on topography (Jenny, 1980). The number of properties that change with landscape position is greater for all the sites that have been cultivated than for the never cultivated control site. The comparison across sites is the subject of the next section.

\subsection{SOIL PROPERTY DIFFERENCES RELATED TO TILLAGE}

The soils of Ontario Benchmark sites \#14 and \#44 have been cleared and cultivated for the past 100 years and under intensive cultivation for approximately the last 50 years. This process of the initial clearing of the land 
and then subsequent cultivation has altered the soils from the natural condition. The soils of the control site (uncultivated road allowance) have never been cleared or cultivated (Davis, personal communication 2002).

In a hypothetical landscape, the assumption is made that everything started out identical at the time of clearing of the sloping agricultural lands. As stated above, the control site is considered to represent the pre-agricultural natural condition of the Guelph catena soils and any changes or lack of changes in soil properties can be assumed to be due to pedogenesis. The control site then provides the baseline situation to which the measured soil properties can be compared to provide evidence as to which soil properties change with tillage practices for comparisons across each landscape position.

Conventional till is the most intense land management system and it could be assumed that the greatest changes in soil properties when compared to the control site would be for this site. The no-till land management system is a conservation tillage practice that attempts to reduce erosion of soil surface materials by maintaining a stable surface cover (crop residue) through confining all tillage and seeding operations to one pass of the planting equipment. It could be assumed that the effects of erosion that initiates the changes in soil properties would be less in the no-till site. Therefore the expected pattern in change would be control $<$ no-till $<$ conventional till.

\subsubsection{Comparison of the Control, No-Till and Conventional Till Sites}

For the comparison of slope positions between the control, no-till and conventional till sites, Table 5.2, 6.2 and 6.3 indicate: that for all slope 
positions solum depth decreased from the control site to the no-till site and decreased further to the conventional till site (except for the lower slope position, the no-till $>$ control $>$ conventional till). The higher percentage change in solum depth for the comparison of the control site to the no-till site and the control site to the conventional till site indicate that the soils on the conventional till site are more severely eroded. Boehm and Anderson (1997) concluded that for their study solum thickness is greater in the no-till system compared to the crop-fallow systems for all landscape positions. They relate these differences to higher rates of soil erosion due to wind, water and tillage in tilled fields than in fields under continuous cropping (no-till).

As summarized in Table $5.6,6.2 \& 6.3$ the surface $\mathrm{pH}$ increased significantly for all slope positions for the control to the no-till site to the conventional till site, (with the exception of the mid slope position of the no-till compared to the conventional till site). This may be a factor of the erosion and compaction of the surface materials from the upper and mid slope positions and the effect of the higher $\mathrm{pH}$ subsoil material brought to the surface by plowing for the conventional till site and for the no-till site before the management was changed. The greater the decrease in the depth of the solum due to removal or compaction (as is the case for the conventional till site) the higher the mean surface $\mathrm{pH}$ values, as the plow incorporates higher $\mathrm{pH}$ subsurface materials into the surface horizon. 


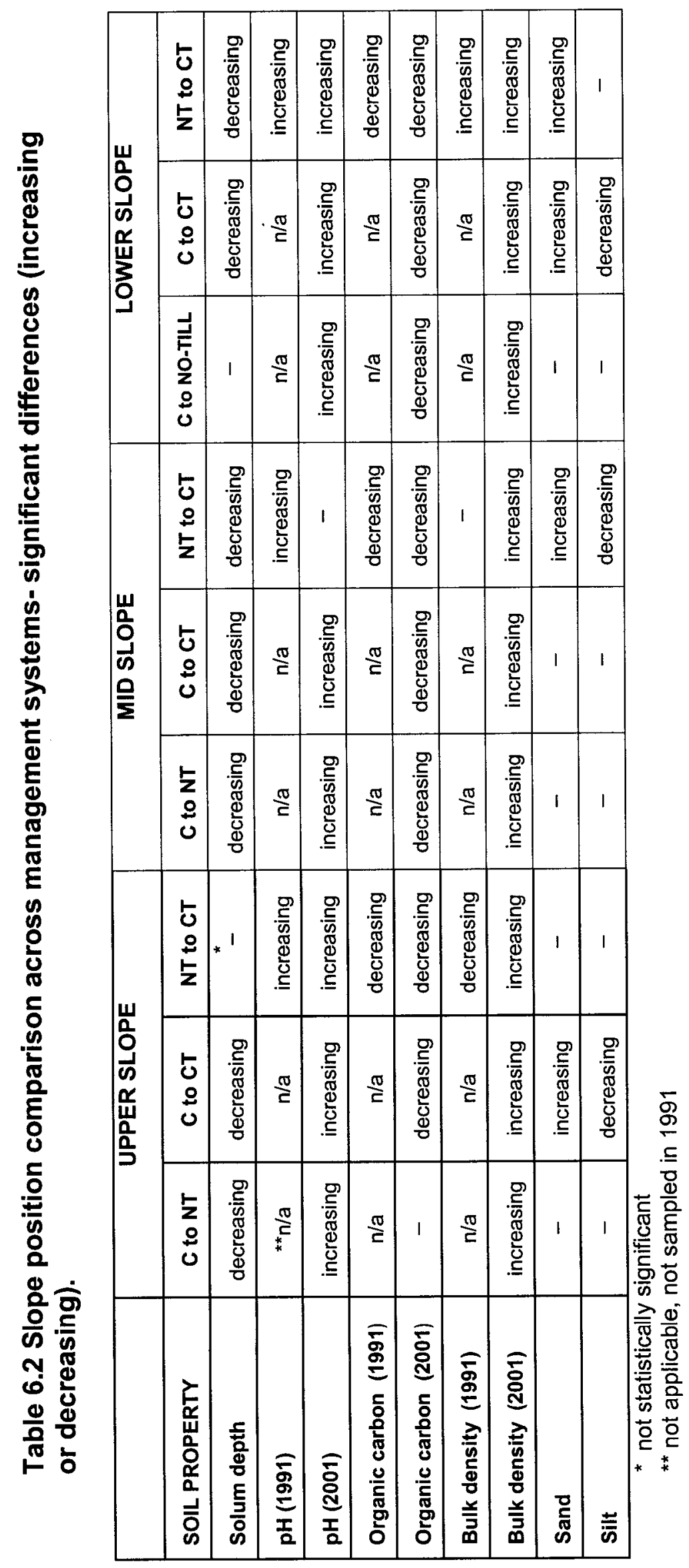


Table 6.3 Trends in soil property change between land management systems (C - NT - CT) by slope position.

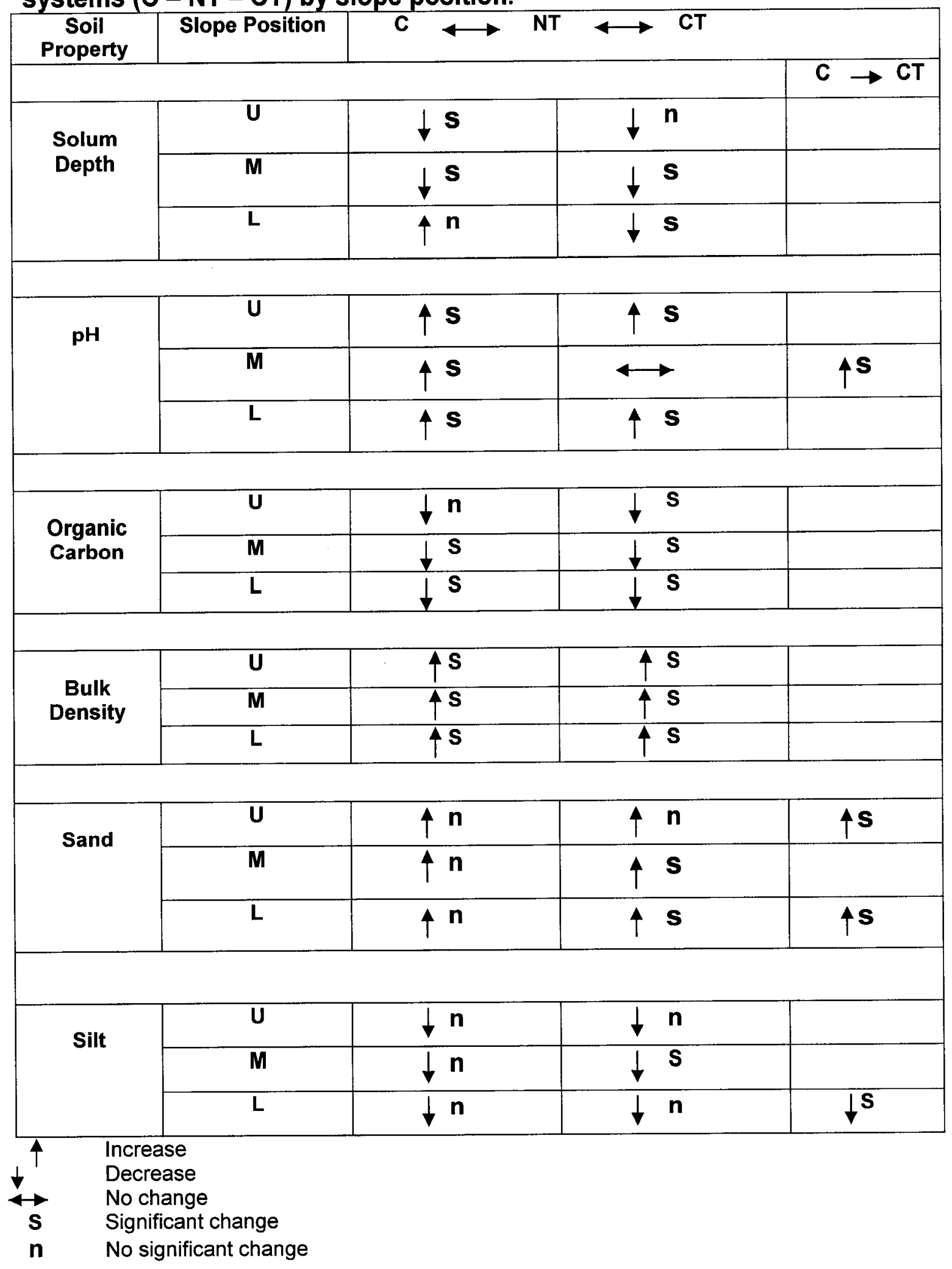


The trend in organic carbon content indicates decreases for all slope positions for the control to no-till to the conventional till site (Table 5.11, 6.2\& 6.3). All of the decreases were significant with the exception of the upper slope position comparison of the control to the no-till site. This is consistent with the findings of Boehm and Anderson (1997) that soils of continuous cropping, minimum tillage or no-till farming practices generally have more Ap horizon organic matter than conventional tillage farming systems. This difference is attributed to higher annual additions of crop residue to the soil surface and differences in the assimilation and decomposition of soil organic matter.

Bulk density of surface horizons increased significantly for all slope positions from the control to the no-till site and from the no-till to the conventional till site (Table 5.16, $6.2 \& 6.3$ ). Brady and Weil (1996), note that the long term effects of conventional tillage, especially plowing, are generally undesirable. Some of the negative effects are: rapid breakdown of organic matter and hence a reduction of the organic matter content, decrease in aggregate stability; and soil compaction due to frequent passage of tractors and other heavy equipment.

From the comparisons of the particle size results for all landscape positions (Table 6.2) the sand content increases (trend) for all slope positions for the control to the no-till site and for the no-till to the conventional till site, with only the mid and lower slope comparison for the no-till to conventional till site being significant. The silt content demonstrates the opposite trend 
decreasing for all slope positions in the comparison of control to no-till and no-till to conventional till sites, with only the decrease for the mid slope position of the no-till to the conventional till site being significantly different. The control site has the lowest mean percent sand and the highest silt fraction while the conventional till site has the opposite trend. The conventional till site is the most affected or eroded landscape The overall amount of sand is greater and the mid slope position has the highest mean surface sand content and the lowest silt content. The silt sized particles apparently have been eroded from the conventional till site and a larger proportion of sand size fraction particles remain, with the lowest mean silt content in the mid slope position. The control site, characteristic of the preagricultural soil condition for the sites on this soil catena, exhibits the lowest sand and highest silt content in all landscape positions.

\subsubsection{Summation of tillage effects}

The results of the analysis of these dynamic soil properties would indicate that for all three sites with the mid slope positions indicate the impact of erosion. The degree of change for the mid slope position is dependant on the type of treatment, with the control $<$ no-till $<$ conventional till.

The change in soil properties for the no-till and conventional till sites according to slope position when evaluated against a control site indicate: for solum depth for all slope positions the control site had the deepest depth of solum, next the no-till site and finally the conventional till site (except for the lower slope position - the no-till > control); the mean surface pH is lowest in all 
landscape positions of the control site and increases to the no-till and further increases to the conventional till site (except for the mid slope position of the no-till site which is not significantly different from the conventional till site); the mean surface organic carbon content is highest for all slope positions of the control site less for the no-till and least for the conventional till site; and the mean surface bulk density is significantly lower for the control site, increases significantly for the no-till and is highest (significant) for the conventional till sites for all landscape positions.

The analyses of sand and silt contents also demonstrate that clearing and cultivation of these sloping sites affect these soil properties. In every situation where there is significance, sand content increases and silt content decreases. This suggests that there is preferential removal of silt from each slope position even the lower slope, and some of the eroded silt at this site is not held at the lower slope position, but moves onward and the eroded sand is held. For surface sand content, control $<$ no-till $<$ conventional till and for the surface silt content, control > no-till > conventional till, for all landscape positions. As the severity of erosion and soil redistribution increases from the control to the no-till to the conventional till systems, more silt size particles (which are more easily eroded and moved down slope when the soils have been cleared and cultivated) will remain in the control system relative to the sand particles. The conventional till site has the lowest silt content in all landscape positions, which may be indicative of the most severely eroded landscape. 
The processes of land clearing and the successive years of cultivation, accentuate the process of regressive pedogenesis and become major factors in the alteration of the dynamic soil properties. The data fits with the theory (Simonson 1980) that cultivation changes the direction of pedogenesis by altering soil properties and horizonation, and by the removal of soil material. Not only tillage but the type of tillage system has a significant impact on the alteration of the natural process of pedogenesis and increasing the rate and the magnitude of the change in some measured soil properties. The dynamic chemical soil properties of $\mathrm{pH}$, organic carbon and the physical property of bulk density were measured and the comparison of the differences between the no-till, conventional till and the control site indicate that cultivation has had an effect on these soil properties at these sites. In addition, solum depth and particle size fraction for the soil surface were also determined and exhibit characteristics of dynamic soil properties, properties that change due to disturbance (clearing and cultivation) for these sites.

\subsection{SOIL PROPERTY DIFFERENCES RELATED TO TILLAGE OVER TIME}

The dynamic soil properties of $\mathrm{pH}$, organic carbon and bulk density were measured in both 1991 and 2001, which allows analysis and evaluation of changes in these properties over the 10 year period.

\subsubsection{No-till Site}

For the no-till site there was a slight, non-significant decrease in $\mathrm{pH}$ for the upper and a slight, non-significant increase for the mid and lower slope 
positions (Table 5.7, Table 6.4). This might be indicative of a trend developing which might continue to develop over time.

The organic carbon data indicates that there is a significant loss at the mid slope position, and a slight, non-significant loss at the upper and lower slope positions (Table 5.12, Table 6.4). There was a net loss in organic carbon in the 10 years of no-till land management. This would tend to suggest that the no-till management has not led to improvements at this site, most notably for the mid slope position.

The bulk density has decreased significantly for the upper and mid slope positions; there was no significant difference for the lower slope position between the sampling periods (Table 5.17, Table 6.4). This would suggest that no-till land management has led to improvements for the most affected portion of this landscape. Bulk density is a dynamic physical soil property that relates to the proportional volumes of pores and solid materials.

The no-till management practices may have improved the soils at this site, presumably by reducing the number of passes of planting/tillage equipment and hence resulting in decreasing bulk density values for the upper and mid slope positions.

The net result of no-till land management has been:

- $\mathrm{pH}$ - no significant change, with decreasing (upper) and increasing (mid and lower) trends

- Organic carbon -(decreasing) trend toward regressive pedogenesis

- Bulk density - trend toward progressive pedogenesis. 
Table 6.4 Comparison across time (1991- 2001), within treatment differences (significant/not significant - increasing/decreasing).

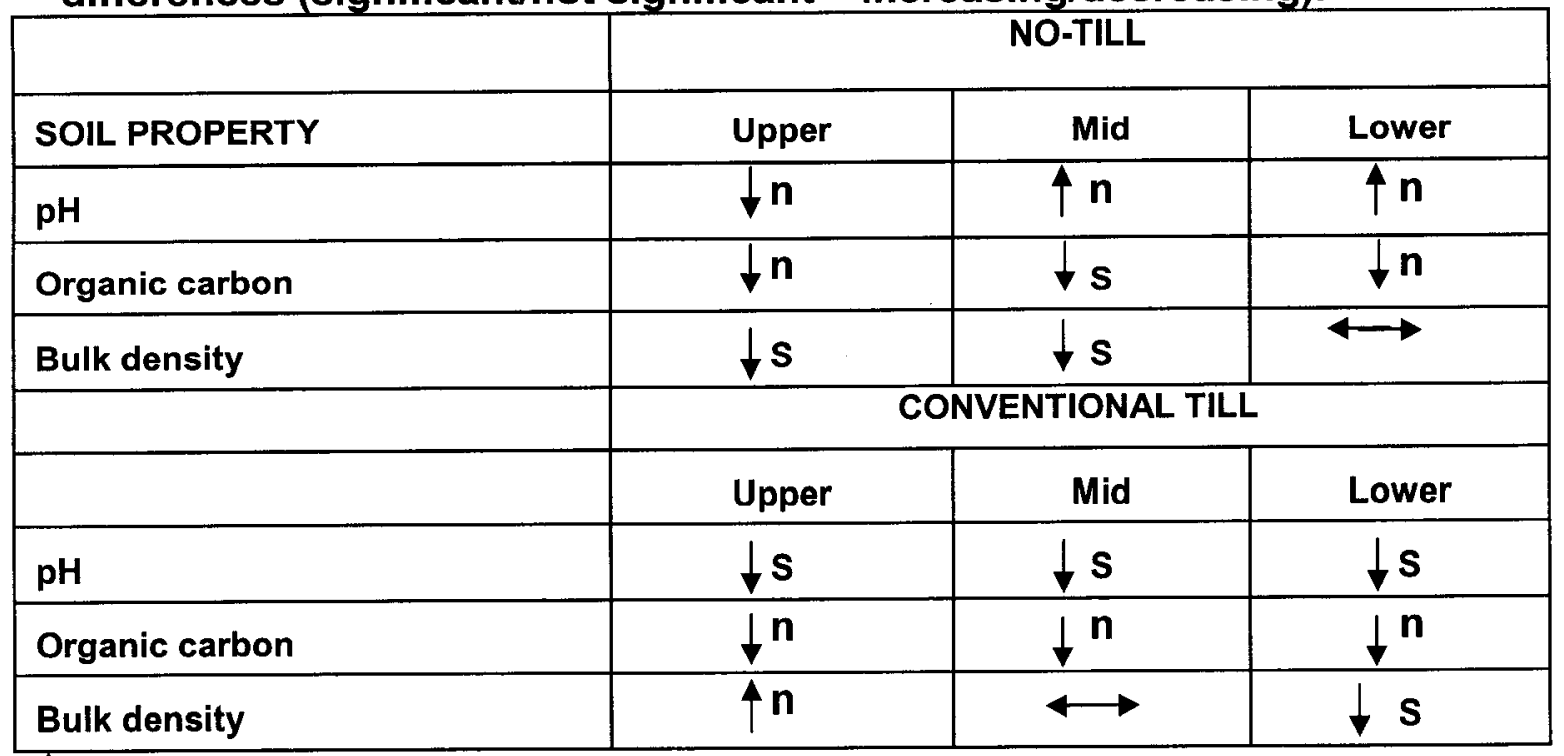

$\begin{array}{ll}\stackrel{\text { Increasing }}{+} & \text { Decreasing } \\ \longleftrightarrow & \text { No change } \\ & \text { Statistically significant } \\ \mathbf{S} & \text { Not statistically significant }\end{array}$

The maintenance of a conservation land management systems for a significant period of time may change the direction of pedogenesis and favour horizon formation due to accumulation (Birkeland 1999), the rate and quantity of accumulation would vary with the type and magnitude of the slope. Further measurements after several years would be necessary to determine the direction of pedogenesis within this site.

\subsubsection{Conventional Till Site}

For the conventional till site, the $\mathrm{pH}$ decreased significantly for the upper, mid and the lower slope positions. There was a slight non-significant decrease in organic carbon content between the sampling periods for all slope positions. Bulk density showed a slight, non-significant increase for the 
upper slope position, no change at the middle slope position and a significant decrease for the comparison of the lower landscape position between the two sampling periods (Table 6.4).

The net result of conventional till land management has been:

- $\mathrm{pH}$ - decreases significantly, trend toward progressive pedogenesis

- Organic carbon - decreasing trend, but not significant differences, trend toward regressive pedogenesis

- Bulk density - increasing at upper and middle and significant decrease in lower slope position, trend to regressive pedogenesis, the decrease at the lower slope may be related to the erosional effects upslope.

The conventional till site appears to be slightly further along in regressive pedogenesis than the no-till site as compared to the control site. As was noted in the methodology section, the conventional till site has been managed under a reduced tillage system since 1997.

\subsection{Summation of Tillage Effects Over Time}

The $\mathrm{pH}$ values show no significant differences between 1991 and 2001 for all slope positions for the no-till site. The lack of change for the no-till site may be an indication of steady state conditions being reached. Some of the free carbonates have been removed by leaching and no additional carbonates have been incorporated from the subsoil by cultivation. The $\mathrm{pH}$ values for the conventional till site, as expected, have shown a minor but significant decrease for all landscape positions for the same time period comparison. A contributing factor to explain this observation may be the 
change to a modified land management practice beginning in 1997, with reduced tillage, less incorporation of surface residue and less subsurface material transported to the surface through plowing. In addition the reduced tillage will promote better soil structure and increase infiltration, enabling more leaching of bases by the increased downward movement of water.

According to Ontario Ministry of Agriculture and Food guidelines the target $\mathrm{pH}$ for coarse and medium-textured mineral soils (sand, sandy loams, loams and silt loams) is $\mathrm{pH} 6.0$ for corn and soybeans. Although the mean surface $\mathrm{pH}$ values for the conventional till site are greater (statistically significant) than the no-till site these values are within the recommended $\mathrm{pH}$ ranges $(\mathrm{pH} 6.0-8.0)$ for the crops grown throughout the period. http://www.gov.on.cal

The slight decrease in organic carbon content (not significant) (Table 6.4) for all slope positions between 1991 and 2001 could indicate that the maintenance of conventional till practices for this time continued to reduce the amount of organic carbon due to its incorporation increasing the decomposition rate of organic matter. The evaluation of organic carbon content over time indicates, that while the amount of carbon stored in the notill site is greater than the conventional till site (statistically significant for both the 1991 and 2001 data), there has been an overall decrease in the amount of carbon in both systems between the two sampling periods.

The lower bulk density values for the no-till site compared to the conventional till site may be related to decreased disturbance and compaction due to no-till management. 


\subsection{EFFECTS ON SOIL TAXONOMY RELATED TO TILLAGE}

Soil classification is an interpreted soil property based on diagnostic soil properties and criteria (Olson et al. 1994; Norfleet et al. 2003). The detailed pit descriptions in this study (pages 43-51) allow the determination of whether the changes that have occurred under the different tillage systems have changed the horizonation sufficiently to affect the taxonomy of the soil (Table 6.5). The soil profile descriptions for each landscape position integrate the effects of landscape position, clearing, cultivation, and tillage systems on soil properties and horizon characteristics and allow evaluation of whether these are indicative of normal or regressive pedogenesis having occurred.

Table 6.5 Summary of the soil classifications by management system and slope position.

\begin{tabular}{|l|l|c|c|}
\hline & Control & No-till & Conventional till \\
\hline Upper & Orthic Melanic Brunisol & $\begin{array}{c}\text { Orthic Melanic Brunisol } \\
\text { (eroded phase) }\end{array}$ & $\begin{array}{c}\text { Orthic Melanic Brunisol } \\
\text { (eroded phase) }\end{array}$ \\
\hline Middle & Orthic Melanic Brunisol & $\begin{array}{c}\text { Orthic Melanic Brunisol } \\
\text { (eroded phase) }\end{array}$ & $\begin{array}{c}\text { Orthic Melanic Brunisol } \\
\text { (eroded phase) }\end{array}$ \\
\hline Lower & Orthic Humic Gleysol & Orthic Humic Gleysol & Orthic Humic Gleysol \\
\hline
\end{tabular}

The historical data for the Guelph series (The Ontario Soil Names File and the Soil Survey of Wellington County) indicates that the classifications for the 'native' pedons of the Guelph series soil are Brunisolic Gray Brown Luvisols. The agricultural pedons are described as Orthic Gray Brown Luvisols, (the cultivation practices have incorporated the Ae and/or Bm/Bf horizons into the Ah horizon to form an Ap horizon, which changes the 
classification of this soil from the Brunisolic Gray Brown Luvisol of a native profile (Agriculture Canada, 1978)).

It was assumed that by comparing the classifications of the control pedons against the no-till and conventional till pedons that evidence of erosion could be found. The assumption was that due to erosion and compaction the diagnostic criteria that defines Luvisolic soils (thickness and clay content of a Bt horizon) may have been modified and these pedons would no longer be classified as Luvisols but rather as Brunisols.

The pedon descriptions (page 43-51) however indicate that the classifications for all the upper and mid slope positions of the control, no-till and conventional till sites are Orthic Melanic Brunisols, lacking the diagnostic Luvisolic criteria. Therefore we are unable to use the interpreted property of classification for these study sites to provide evidence of erosion or regressive pedogenesis. The soil pedons of the lower slope positions are classified as an Orthic Humic Gleysol with characteristic Ah horizon greater than $10 \mathrm{~cm}$ and a B horizon greater than $10 \mathrm{~cm}$.

The analyses in the previous section (6.2.2) demonstrate, by comparison to the 'native' pedons of the control site for the upper and mid slope positions, that the solum depth and organic carbon decreases and the bulk densities increase from the control to the no-till to the conventional till sites. From this comparison it could be concluded that the upper and mid slope position of the no-till site and the conventional till site are 'eroded phases' of the Guelph loam soils. Olson et al. (1994) indicate that a major problem in soil 
classification is determining the effects of rapid erosion on diagnostic surface horizons or shallow subsurface horizons. Simonson's $(1957,1980)$ concept of additions, removals, translocations and transformations can be applied to this situation, and the analysis yields results that indicate that the process of development of soil horizons has been altered in a direction that decreases the horizon differentiation and results in the change in the classification to reflect the less mature state. This analysis fits the Johnson and WatsonStegner (1987) model of regressive pedogenesis. Birkeland (1999) states that regressive pedogenesis can follow progressive pedogenesis resulting in several possibilities: the soil morphology no longer changes; properties and constituents that no longer increase with time (steady state); or the soil reverses its morphological evolution or pathway by losses of properties or constituents. A negative feedback may operate in the soil with the soil returning to a previous stage in the developmental sequence (Birkeland 1999). The loss of surface materials and horizons at the Guelph catena sites, due to clearing and cultivation, has led to increased erosion on the sloping landscapes and compaction due to cultivation, which has led to changes in dynamic soil properties, changes in the horizon characteristics and, at some slope positions, could alter the classification. If the erosional processes continue, the diagnostic horizons of the Orthic Melanic Brunisols could be eroded and if the thickness of the Bm horizon decreases to less than $5 \mathrm{~cm}$ or is absent these soils would be classified as Orthic Regosols. For one mid 
slope grid sample point for the conventional till site the thickness of the $\mathrm{Bm}$ horizon was $4 \mathrm{~cm}$.

The use of soil taxonomic units (catena and series) in this study may allow the extension of results of the tillage comparisons to comparable sites within similar landscapes for which detailed soil taxonomic information is available (Bergstrom et al. 2001). Caution would have to be used if region specific interpretations from this site were to be extrapolated to other locations where the Guelph soils are present but have different topographic and climatic conditions. The interpretations developed for the soils at this site may provide insights that could be applied to other soils developed on till within the same Ecoregion or for other soils in the same soil order or a closely related order. This possibility derives from the Ecoregions being determined on the basis of similar climate and physiography (Jarvis et al. 1996; Ecological Stratification Working Group 1995). Since the soils at this site, as described in the pedon descriptions, are Brunisols (mapped as Luvisols), then it would be appropriate to use these interpretations for Luvisol and Brunisol soils developed on similar landscapes and parent materials. The methodology of using the analysis of soil properties and interpreted soil classifications as indicators of change or trends would have a fairly wide applicability.

\subsection{SUMMARY}

Each soil profile results from one or more combinations of processes, which have endured for a period of time (Simonson 1978). For this study, the expression of soil profile characteristics and soil formation for each site and 
slope position is a result of the integration of the natural soil forming processes and the effects of clearing and tillage. The combined effects of the human-driven and human-influenced processes of: the addition to the soil of crop residues, soil amendments and redistributed sediments; the transformation of soil aggregates due to tillage (or lack of tillage) and compaction; the redistribution of soil particles and carbonates due to erosion and cultivation; and the removal of soil particles due to erosion by wind, water and cultivation, combine to control soil profile development, soil formation and soil properties at each position of each site. The combination of these processes affects both the matter and energy and provides for build-up as well as break-down of the soil profile (Jenny 1980).

The soil properties selected to assess change with topography, tillage and tillage over time for different management systems, detected change in the dynamic soil properties. The findings of this study agree with the general statement by Bergstrom et al. (2001) that the use of the depth of solum is among the best indicators of change. It is better than the thickness of the Ahorizon for this landscape because the contact with the unweathered parent material can be determined readily and reliably by testing with dilute hydrochloric acid, whereas the thickness of the A-horizon may be a function of the tillage system. Parent material (C-horizon materials) may be incorporated into the A-horizon on eroded landscapes. The depth of the solum is an easily measured property when the change from absence to 
presence of $\mathrm{CaCO}_{3}$ differentiates the $\mathrm{B} / \mathrm{C}$ horizon boundary. In addition large numbers of tests can be made quickly in a systematic and standard fashion.

From the comparisons of the descriptions and analysis of the detailed soil pits for each landscape position in each site, complete in situ representations of the soil development characteristics of each site and slope can be developed. The use of the soil classification for each position (derived and interpreted information) allows comparison between sites for each landscape position and assists with the identification of eroded phases of the soil series when compared against the classification and description of the 'benchmark' control site. This information was effectively used by Olson et al. (1994) in a study to quantify soil loss from eroded soil phases, in which it was determined that a major problem in soil classification is determining the effects of rapid erosion on diagnostic surface horizons or shallow subsurface horizons. The recognition of eroded phases and the potential changes in the soil classification provide a means to make qualitative and quantitative estimates of erosion at similar sites on similar materials. This study demonstrated the link between changes in soil properties and the resultant changes in soil classification which supports the utility of detailed soil profile descriptions pits in all landscape positions and in all treatments to provide 'context' for the interpretation and evaluation of statistical data. For this site it would be useful to examine additional pedons in the control site to determine if any of these can be classified as Luvisolic soils. 
The use of long-term 'benchmark' data allowed the evaluation of trends in soil property change. The systematic data collection and standard analysis of the initial data set in 1991 provided a reference point for monitoring changes of dynamic soil properties for the no-till and conventional till sites at this location. The resampling of the sites in 2001 , using the same methodologies and at the same sample (grid) points, allowed the comparison of data within the sites and for each landscape position between the sites. The sampling and analysis of data for the control site in 2001 allowed the characterization of pre-agricultural soil properties for the soils of the Guelph catena and allowed a baseline for comparison of the two tillage systems.

A recommendation to improve the monitoring potential of this site would be a more comprehensive and complete sampling of the control site which would increase the number of samples, almost certainly decrease standard deviation, and improve the determination of statistical significance. The addition of the control site to the Benchmark sites will improve the utility of the site for future monitoring, but more data is required for this site.

Additional suggestions to improve the information for monitoring and evaluation for this site would be to use organic carbon mass within the complete solum as a means of comparison of stored carbon in the soil profile (Webb et al. 2000). Similarly the use of soil aggregate size distribution and the volume of water-stable aggregates could be a valuable parameter to sample and evaluate. Boehm and Anderson (1997) determined that the proportion of the different size classes of water-stable aggregates relates well 
to the amount of organic carbon and bulk density of the soil, with more waterstable aggregates being present in the no-till continuously cropped soils on all slopes when compared to the conventional till systems.

Despite the relatively large variability within these site, some attributable to topography and some random, systematic changes in soil properties resulting from tillage practices were detectable, indicating that the selected soil properties were sufficiently sensitive to management to be useful indicators of dynamic soil property change in the sloping landscape of the Guelph catena soils.

This study detected changes in some soil properties between 1991 and 2001. Similar studies (Webb et al. 2000) were able to detect changes in soil properties due to topography and tillage after analyzing data collected 5 years apart. For this site resampling in 10 years (2011) would probably be the most effective, to maintain the same schedule and also to enable the sites to equilibrate to perturbations such as the installation of subsurface drainage and changes in management practices. From this study the suggested properties that should be resampled to monitor change and detect differences would be solum depth, organic carbon and bulk density. These properties yielded the most consistent results and are easy to measure and reproduce. 


\subsection{REFERENCES}

Agriculture Canada. 1976. Glossary of terms in soil science. Agriculture Canada Publication 1459, Ottawa, Ont. 44 pp.

Acton, D.F. and Gregorich, L.J. 1995. The health of our soils-toward sustainable agriculture in Canada. Centre for Land and Biological Resources Research, Agriculture and Agri-Food Canada, Ottawa, ON. xiv+138pp.

Bergstrom, D.W., Monreal, C.M. and St. Jaques, E. 2001. Spatial dependence of soil organic carbon mass and its relationship to soil soil series and soil topography. Can. J. Soil Sci. 81:53-62.

Bergstrom, D.W., Monreal, C.M. and St. Jaques, E. 2001. Influence of tillage practice on carbon sequestration is scale-dependant. Can. J. Soil Sci. 81:6370.

Boehm, M.M. and Anderson, D.W. 1997. A landscape-scale study of soil quality in three prairie farming systems. Soil Sci. Soc. Am. J. 61:1147-1159.

Buol, S.W., Hole, F.D., McCracken, R.J. and Southard, R.J. 1997. Soil Genesis and Classification, Fourth Edition. Iowa State University Press, Ames. 527 pp.

Brady, N.C. and Weil, R.R. 1996. The Nature and Property of Soils, Eleventh Edition. Prentice Hall, New Jersey. 739 pp.

Chapman, L.J. and Putnam, D.F. 1966, The Physiography of Southern Ontario, second edition. Ontario Research Foundation, University of Toronto Press. $386 \mathrm{pp}$.

Ecological Stratification Working Group. 1995. A National Ecological Framework for Canada. Agriculture and Agri-Food Canada, Research Branch, Centre for land and Biological Resources Research and Environment Canada, State of the Environment Directorate, Ecozone Analysis Branch, Ottawa/Hull. Report and national map at 1:7500 000 scale.

Elliot, J.A. and Efetha, A.A. 1999. Influence of tillage and cropping on soil organic matter, structure and infiltration in a rolling landscape. Can. J. Soil Sci. 79:457-463.

Hoffman, D.W., Matthews, B.C. and Wicklund, R.E. 1963. Soil Survey of Wellington County Ontario. Report No. 35 of the Ontario Soil Survey. Research Branch, Canada, Department of Agriculture and the Ontario Agricultural College. Guelph, ON. 69 pp. + map. 
http://sis.agr.gc.ca/cansis/nsdb/ecostrat/climate normals 1961-90.htm|\#temperature http://www.gov.on.ca/OMAFRA/english/crops/pub811/2limeph.htm\#table210

http://www.gov.on.ca/OMAFRA/english/crops/pub811/2tillsys. htm\#convention

http://www.gov.on.ca/OMAFRA/english/crops/pub811/2limeph.htm\#table210

http://www.soils.org/sssagloss/search.html

http://soils.usda.gov/sqi/soil quality/what is/glossary.html

Jarvis, I., MacDonald, K.B., Wang, F. and Denholm, K. 1996. Ontario Soil Landscape Attribute Project, Working Paper. Ontario Land Resource Unit, Agriculture and Agri-Food Canada, Guelph, ON. 220pp.

Jenny, H. 1980. The Soil Resource Origin and Behavior. Ecological Studies 37. Springer-Verlag, New York. 367 pp.

Johnson, D.L. and Watson-Stegner, D. 1987. Evolution model of pedogenesis. Soil Science. 143. No. 5. $349-366$.

Manning, G., Fuller, L.G., Eilers, R.G. and Florinsky, I. 2001. Topographic influence on the variability of soil properties within an undulating Manitoba landscape. Can. J. Soil Sci. 81:439-447.

Norfleet, M.L., Ditzler, C.A., Puckett, W.E., Grossman, R.B. and Shaw, J.N. 2003. Soil quality and its relationship to pedology. Soil Science 168, 149-155.

Olson, K.R.; Norton, L.D.; Fenton, T.E.; Lai, R. 1994. Quantification of soil loss from eroded soil phases. J. Soil and Water Cons. 49, 591-596.

Simonson, R.W. 1957. Modern concepts of soil genesis - a symposium. Proceedings of Soil Sci. Soc. Am. Atlanta GA. Pp152-156.

Simonson, R.W. 1978. A multiple-process model of soil genesis. In W.C. Mahaney ed. Quaternary Soils, p. 1-25. Geo. Abstracts, University of East Anglia, England.

Viger, B., Gregorich, E.G., Kroetsch, D.J. and King, D. 1999. Benchmark Site Documentation: 14\&44-ON) Rockwood, Ontario). Eastern Cereal and Oilseed Research Centre, Research Branch, Agriculture and Agri-Food Canada, Ottawa, ON. 54 pp.. ECORC Technical Bulletin No. 991445.

Wang, C., Walker, B.D., Rees, H.W., Kozak, L., Nolin, M.C., Michalyna, W., Webb, K.T., Holmstrom, D.A., King, D., Kenney, E.A. and Woodrow, E.F. 1994. Benchmark sites for monitoring soil quality in Canada. Soil Quality 
Evaluation Program Technical Report 1. Centre for Land and Biological Resources Research, Agriculture and Agri-Food Canada , Ottawa, ON. 76pp.

Webb, K.T., Wang, C., Astatkie, T. and Langille, D.R. 2000. Spatial and temporal trends in soil properties at a soil quality benchmark site in central Nova Scotia. Can. J. Soil Sci. 80:567-575.

Wilson, E. (in press). Classifying Prime and Marginal Agricultural Soils and Landscapes: Guidelines for Application of the Canada Land Inventory in Ontario. Ontario Ministry of Agriculture and Food, Guelph. 


\subsection{APPENDICES}

Particle size and $\mathrm{pH}$ analyses were performed by the Soil and Nutrient Laboratory of the University of Guelph. This is a modern, state of the art laboratory with a very high level of quality control and quality assurance. Reference samples were used by the laboratory as part of their standard analysis.

Bulk density and Carbon analysis (LECO) were performed in the Carbon laboratory of Dr. Ed Gregorich by a trained technician. Comprehensive quality control and assurance practices were used as well as reference samples for calibration.

\subsection{ANALYTICAL METHODS}

\subsubsection{Bulk Density (Core Method)}

1. Application

1.1 Soil bulk density is the ratio of the oven-dried mass of soil to its volume either at time of sampling or at a specified moisture content.

It is usually expressed in terms of grams per cubic centimeter $\left(\mathrm{g} / \mathrm{cm}^{3}\right)$ or SI units of megagram per cubic meter $\left(\mathrm{Mg} / \mathrm{m}^{3}\right)$.

Measurement of bulk density generally requires cores or clods in their natural structure.

1.2 To obtain core samples is relatively simple if no stones are present however; it is more difficult to obtain good quality cores. The core sampler is pushed or driven (gently hammered) into the soil to the desired depth and then removed. Many samplers are available which are provided with a metal casing to hold the core and permit easy removal and handling of the sample during weighing, wetting and 
drying. If the soil sampler is assumed to be full its volume may be used as the volume of soil.

\section{Apparatus}

2.1 Core sampler - (7.62 cm dia. $\times 7.62 \mathrm{~cm}$ length $)$.

2.2 Sharp, rigid knife or spatula.

2.3 Balance sensitivity $0.01 \mathrm{gms}$.

2.4 Oven capable of 1050C.

2.5 Plastic bags - large enough to hold sample.

2.6 Weighing tins $-32 \mathrm{oz}$ or large enough to hold soil sample.

2.7 Tape - (masking).

3. Procedure

3.1 Prepare a smooth undisturbed' vertical soil surface at the depth to be sampled.

3.2 Drive or press the sampler into the soil far enough to fill the inner cylinder but not so far as to compress the soil. Do not rock the sampler, as this ends to disturb the soil.

3.3 Carefully remove the sampler so as to preserve the sample retaining the "undisturbed" soil in the cylinder.

3.4 Carefully trim the soil sample flush with each end of the cylinder.

3.5 If only bulk density and water content are to be determined and assuming the sample fills the cylinder completely the soil can be pushed out of the cylinder into a plastic bag. The bag should be closed and labeled. The sample should be transported to the laboratory with a minimum of disturbance.

3.8.1 The full cylinder or the soil from the cylinder is placed in a weighing tin and weighed. The weight of the wet soil plus tin plus cylinder is recorded as WI. Record the weight of the tin as W2 and the weight of the cylinder as W3.

3.8.2 These weights (W2 and $\mathrm{W} 3$ ) may be measured before sampling or after drying. The samples are then dried in an oven at 1050C. The time required to dry the sample vary with the amount of soil present. For cores, $7.62 \mathrm{~cm}$ diameter $X 7.62 \mathrm{~cm}$ long, we used $72 \mathrm{hrs}$ to dry; for smaller samples less time is required.

Record the weight of the oven dry sample, tin and cylinder as W4. The wet weight (WI) is used to calculate the moisture content at time of sampling.

3.9 Calculate the bulk density

$\mathrm{Db}=\mathrm{W} 4-\mathrm{W} 2-\mathrm{W} 3 / \mathrm{Nol}$. of cylinder

Calculate the moisture content

$\theta \mathrm{V}=(\mathrm{W} 1-(\mathrm{W} 4-\mathrm{W} 2-\mathrm{W} 3) / \mathrm{W} 4-\mathrm{W} 2-\mathrm{W} 3) \times \mathrm{Db}$ 


\subsection{2 pH}

1. Application

1.1 The two main methods of measuring soil $\mathrm{pH}$ are outlined in this procedure. They are 1:I soil:water ratio and $1: 2$ soil:0.01M CaCl 2 ratio. The measurement of soil $\mathrm{pH}$ in $0.01 \mathrm{M} \mathrm{CaCl}_{2}$ is the preferred method for most purposes because of advantages pointed out by Peech (1965).

1. The $\mathrm{pH}$ is almost independent of dilution over a wide range.

2. The $\mathrm{pH}$ measured is almost independent of the concentration of soluble salt present in non-saline soils.

3. It provides a good approximation of the $\mathrm{pH}$ of the soil solution under field conditions.

4. Errors due to the liquid junction potential are minimized because the soil suspensions are flocculated.

Measurement of the $\mathrm{pH}$ of a saturated soil is not recommended because of theoretical (junction potential) and practical (difficulty of obtaining reproducible results) disadvantages. There is no point in measuring the $\mathrm{pH}$ of most soils containing free carbonates of $\mathrm{Ca}$ and $\mathrm{Mg}$ as the value obtained depends upon the partial pressure of $\mathrm{CO}_{2}$ which is generally uncontrolled during $\mathrm{pH}$ measurements (Turner and Clark, 1956).

It is, however, useful to measure the $\mathrm{pH}$ of saline, calcareous soils as $\mathrm{pH}$ values above about 8.5 indicate sodium carbonate (Richards, 1954).

\section{Apparatus}

$2.150 \mathrm{~mL}$ disposable paper cups or beakers.

$2.2 \mathrm{pH}$ meter and electrodes.

\section{Reagents}

3.1 $0.01 \mathrm{M}$ Calcium chloride $\left(\mathrm{CaCl}_{2}\right)$ : Dilute $\mathrm{l}$.lg of calcium chloride to 1 liter in a volumetric flask with distilled water. Alternatively, if large volumes are required make a stock solution of $3.6 \mathrm{M} \mathrm{CaCl}\left(\mathrm{CaCl}_{2} . \mathrm{H}_{2} \mathrm{O}\right.$ $1059 \mathrm{~g} / 2 \mathrm{~L}$ ). Dilute $50 \mathrm{~mL}$ of this stock solution to 18 liters with distilled water. Check the $\mathrm{pH}$ of this solution; it should be between 5.0 and 6.5. If it is not, adjust by adding $\mathrm{Ca}(\mathrm{OH})_{2}$ or $\mathrm{HCl}$. To check the concentration of the solution, measure its conductivity; the specific conductivity should be $2.32+0.08$ millisiemens per $\mathrm{cm}(\mathrm{mS} / \mathrm{cm})$ at $250 C$.

4. Procedure

4.1 $\mathrm{pH}$ in $0.01 \mathrm{M} \mathrm{CaCl}_{2}$ (1:2, soil: solution ratio) 
4.1.1 Weigh about $10 \mathrm{~g}$ of $2 \mathrm{~mm}$ soil into a $50 \mathrm{~mL}$ disposable paper cup or beaker.

4.1.2 Add about $20 \mathrm{~mL}$ of $0.01 \mathrm{M} \mathrm{CaCl}_{2}$ solution and stir the suspension several times during the next 30 minutes. For organic soils that absorb all of the solution use a 1:4 soil: solution ratio.

NOTE: Weight and volume measurements are not critical as $+/-1 \mathrm{gm}$ will not affect $\mathrm{pH}$ in $0.01 \mathrm{M} \mathrm{CaCl}$.

4.1.3 Let the suspension stand for 30 minutes to allow most of the sediment to settle.

4.1.4 Measure the $\mathrm{pH}$ by immersing the glass electrode into the partly settled suspension (do not immerse it to the bottom of the container) and placing the calomel electrode in the clear supernatant solution. If a combination electrode is used immerse it in the supernatant solution. The $\mathrm{pH}$ meter is adjusted by setting it to the $\mathrm{pH}$ of buffer solutions at the same temperature as the soil suspension. The meter should be checked against two buffers one of which has a $\mathrm{pH}$ at the lower end and the other at the upper end of the range of the expected $\mathrm{pH}$ of the soils being measured.

4.1.5 Record the $\mathrm{pH}$ in $0.01 \mathrm{M} \mathrm{CaCl}_{2}$ to one decimal place.

$7 \%$ and $1.7 \%$ respectively.

\subsubsection{Total Carbon, Leco Induction Furnace}

1. Application

1.1 Several quantitative methods are available for the determination of total $C$ in soils. The use of a LECO induction furnace provides an accurate, fast and convenient method of analyzing for total $\mathrm{C}$. For samples containing carbonates, organic $\mathrm{C}$ can be determined by subtracting carbonate $\mathrm{C}$ from total $\mathrm{C}$. The procedures differ depending on the age and model of the instrument and the $\mathrm{CO}_{2}$ measuring system involved. The following method is suitable for the model 577100-carbon analyzer and requires approximately five minutes per sample. The newer models permit more rapid determinations of total C.

2. Apparatus

2.1 Leco induction furnace equipped with purifying train, and carbon determinator.

2.2 A supply of spare parts that require replacement on a regular basis (combustion tubes, filter cloths, etc)

2.3 Crucibles

3. Reagents 
3.1 Red leveling solution - Dissolve $0.4 \mathrm{~g}$ of methyl orange in $200 \mathrm{~mL}$ distilled water, boil, cool to room temperature, and filter. Dilute this solution to $800 \mathrm{~mL}$ and add $40 \mathrm{~mL}$ concentrated $\mathrm{H}_{2} \mathrm{SO}_{4}$. To this solution add $2 \mathrm{~mL}$ LECONAL wetting agent. This solution will last indefinitely and need be changed only when dirty or for some other obvious reason. This solution is poured into the leveling bottle and the bottom of the meniscus in the calibrated stem is adjusted to the zero point by either adding or removing red solution.

3.2 Caustic solution - Dissolve $450 \mathrm{~g}$ of $\mathrm{KOH}$ in $900 \mathrm{~mL}$ distilled water. Allow solution to cool to room temperature and pour all of the solution into the absorption vessel.

3.3 Manganese dioxide is used in the sulphur trap to absorb sulphur gases, which interfere with the determination.

3.4 Concentrated sulphuric acid, drierite, ascarite, and glass wool are required to prepare the purifying train.

3.5 Iron chip and tin metal accelerators.

\section{Procedure}

4.1 Blanking the apparatus and testing for leaks

4.1.1 Plug in the furnace 15 minutes or so before analyzing a sample. This allows the catalyst furnace, which converts $\mathrm{CO}$ to $\mathrm{CO}_{2}$, to warm up.

Turn on the filament switch (green pilot light) 5 minutes before blanking the apparatus.

4.1.2 Turn on the $\mathrm{O}_{2}$ tank to about $4 \mathrm{psi}$ and close the needle valve on the purifying train. DO NOT apply too much force to the needle valve. Turn the buret stopcock to the exhaust position (down) and raise the levelling bottle to the upper cup until the red solution fills the buret and seats the float valve. Seat the valve SLOWLY BY PINCHING the tubing BEFORE the liquid reaches the valve. This keeps the solution out of the stopcock.

4.1.3 Turn the buret stopcock to the furnace position (left) and place a crucible on the pedestal of the raising mechanism. The crucible should contain $1 / 2$ scoop of tin accelerator and one scoop of iron chip accelerator.

4.1.4 Open the needle valve and adjust the $\mathrm{O}_{2}$ flow to 0.5 liters/minute. Close the raising mechanism on the furnace and set the levelling bottle on the base. Lay the tubing on the bench.

4.1.5 When the red solution is about $1 / 3$ of the way down the calibrated stem of the buret, open the raising mechanism and turn the stopcock to the exhaust position (down).

4.1.6 Allow the buret to drain (about 30 seconds, use a stopwatch). Check the drainage time periodically by turning the stopcock to the lock position (right) and noting if the red fluid rises above zero. If the red liquid is not at zero after drainage, add or remove some red solution from the levelling bottle.

4.1.7 Turn the buret stopcock to the caustic position (up) BEFORE (to avoid loss of $\mathrm{CO}_{2}$ ) raising the levelling bottle to the upper cup and above to 
remove all the gas from the buret. Lower the levelling bottle below the table level until the $\mathrm{KOH}$ solution in the absorption vessel rises and seats the float valve (this can be seen through the window).

4.1.8 Turn the buret stopcock to the lock position (right) and then place the levelling bottle on the base and lay the tubing on the bench. Allow the buret to drain for 60 seconds and read. It should be 0 . Frequently there is a blank reading of .04 or so after the first flushing with $\mathrm{O}_{2}$. If this occurs, repeat the blanking procedure.

4.1.9 Test for leaks by filling the buret with the red solution and letting $\mathrm{O}_{2}$ enter until the red solution reaches some level on the calibrated stem of the buret. Turn off the needle valve. If the solution continues to fall, a leak is indicated. Progressively pinch off sections of tubing between the needle valve and the carbon determinator to find at what point the solution stops falling. The leak is then BEHIND the last pinched off point.

\subsection{Selection of sample weight}

4.2.1 Sample weight is based upon an estimate of the $C$ present in the soil. The maximum $C$ that can be determined by this model is $15 \mathrm{mg}$. The samples should be ground to 35 mesh or finer prior to analysis.

4.2.2 A guideline to weight (nearest $\mathrm{mg}$ ) for estimated $\mathrm{C}$ is:
C $1 \%$
Weigh $500 \mathrm{mg}$
C $1-4 \%$
Weigh $250 \mathrm{mg}$
C $4-8 \%$
Weigh $125 \mathrm{mg}$
C $8-20 \% 1$
Weigh $50 \mathrm{mg}$
C $20-50 \%$
Weigh $25 \mathrm{mg}$

\subsection{Analyzing a sample}

4.3.1 Add one scoop of iron chip accelerator, $1 / 2$ scoop of tin accelerator. Include standards and blanks with each set of samples. MAKE SURE THAT THE ACCELERATOR COVERS THE ENTIRE SAMPLE. The amount of accelerator required may vary depending upon the furnace.

4.3.2 Repeat steps 4.1.2 to 4.1.8 inclusive. The $\mathrm{O}_{2}$ flow rate should be 0.5 $\mathrm{L} / \mathrm{min}$. The meter above the filament switch should read over 300 milliampers at the hottest stage of combustion and it should read this level before the red solution is half way down the bulb of the burette. If this does not occur, the results will be low as combustion and sweeping will be incomplete. It is important to lower the raising mechanism before the red fluid reaches the bottom of the burette.

4.3.3 Read the burette by raising the leveling bottle until the liquid in the side arm reading tube is at exactly the same level as the liquid in the burette. Read the right scale of the burette. The right scale is calibrated in $\% \mathrm{C}$ for $0.250 \mathrm{~g}$ samples; the left scale for $1.00 \mathrm{~g}$ samples. By weighing the above recommended amounts, calculations of \% $\mathrm{C}$ are simplified.

4.3.4 When the instrument is not in use, pull out the furnace plug. Fill the burette with red solution to just below the valve. DO NOT SEAT the 
valve. Turn the stopcock to the lock position (right) and place the leveling bottle on the base.

\section{NOTES:}

1. The combustion tube must be cleaned about four times each day. A brass brush is supplied and the vacuum cleaner is quite helpful. TURN OFF the filament switch before cleaning. A partly plugged tube will result in low temperature and incomplete combustion.

2. Replace dust filter cloth periodically. Clean it with a vacuum cleaner at least twice each day.

3. Replace $\mathrm{MnO}_{2}$ periodically when samples high in $\mathrm{S}$ are being run.

4. The temperature in the tube during combustion is directly related to the amount of accelerator added and the $\mathrm{O}_{2}$ flow rate. If the previously mentioned values are used, one will seldom have any trouble using this instrument. If the meter above the filament switch should reach 500 milliamps and hold for more than three seconds, IMMEDIATELY lower the raising mechanism. Repeat the sample using less accelerator.

\section{Calculations}

5.1 Corrections are made for temperature and pressure by reading the thermometer in the burette and reading a barometer (once a day is usually sufficient). The correction is made with the aid of the factor chart supplied.

5.2 For the following conditions: sample weight $0.200 \mathrm{~g}$, correction factor 0.950 and a final reading of 2.40

$\% \mathrm{C}=0.250 \times 0.950 \times 2.40 / 0.200=2.85$

6. References

6.1 Bremner, J.M. and Tabatabai, M.A. 1971. Use of automated combustion technilques for total carbon, total nitrogen and total sulphur analysis of soils. In Instrumental methods for analysis of soils and plant tissue. 71 -16. L.M. Walsh, ed. Soil Sci. Sot. Am. Proc., Madison, Wisconsin.

6.2 Tabatabai, M.A. and Bremner, J.M. 1970. Use of the Leco automatic 70-second carbon analyzer for total carbon analysis of soils. Soil Sci. Sot. Am. Proc. 34, 608-610.

\section{Removal of Inorganic C (Carbonates) from Soil Samples}

\subsection{Apparatus}

$10 \% \mathrm{Hcl}$

$150 \mathrm{ml}$ beakers

Whatman \#2 Qualitative filters

Buchner funnels and $500 \mathrm{ml}$ Erlynmeyer flasks 
Weighing tins

Deionized $\mathrm{H} 2 \mathrm{O}$

\subsection{Method}

1. Weigh approximately $10 \mathrm{~g}$ of $2 \mathrm{~mm}$ soil into beaker.

2. Treat soil with $50 \mathrm{ml}$ of $10 \% \mathrm{Hcl}$.

3. Stir solution frequently (6 times/30 $\mathrm{min}$ ) then allow to sit $18 \mathrm{~h}$.

4. Decant solution into buchner filter/funnels which are set up to a vacuum.

5. Wash sample with de-ionized $\mathrm{H} 2 \mathrm{O}$, allowing soil to dessicate between washings.

6. Repeat until at least $200 \mathrm{ml}$ of $\mathrm{H} 2 \mathrm{O}$ has passed through sample.

7. Dry sample for $12-24 \mathrm{~h}$ with vacuum on.

8. Transfer remaining sample from filter to weighing tin and place in oven for $12-18 \mathrm{~h}$ at $105 \mathrm{C}$.

9. If necessary, grind samples.

10. Place in vials for laboratory analysis.

\subsection{Reference:}

Harris,D.; van Kessel, C.; Horwath, W.R. 2000. Removing Carbonates from the Soil: Effects on Estimates of Soil C Sequestration by the Stable Isotope Method. University of California, Davis.

\subsubsection{Particle Size Distribution}

\section{Application}

1.1 Particle-size analysis is the measurement of the proportions of the various sizes of primary soil particles as determined usually either by their capacities to pass through sieves or various mesh size or by their rates of settling in water. The proportions are usually represented by the relative weights of particles within stated size classes. The limits of these size classes differ in various commonly used systems of soil particle-size classification (Fig. 12). In this Manual the CSSC system is used. For engineering interpretations, the AASHO and the Unified systems are used.

There is no general 'best' method of doing particle-size analysis. The best method in a particular case depends upon the nature of the soil being analyzed, the purpose of the analysis, time constraints, and the equipment available. The following method was adapted from the U.S. soil survey Lincoln, Nebraska and reduces the time required to do the analysis by replacing the numerous centrifuge washing steps with a filter candle system. The data determined using the filter candle system corresponds well with the data from the pipette method and centrifuge washing. 


\section{Apparatus}

2.1 Fleakers $-300 \mathrm{~mL}$ plus plastic caps.

2.2 Filter candles - FP-88-02

2.3 Shakers 1. end-over-end (40-60 rpm)

2. sieve shaker ( 500 oscillations per minute).

2.4 Cylinder - soil suspension $(1205 \mathrm{~mL})$ marked at $1000 \mathrm{~mL}$.

2.5 Racks 1. Custom built metal frame to hold 4 motor driven stirrers equipped with propeller type stirrer and teflon guard.

2. Shaw pipette rack modified to hold four $25 \mathrm{~mL}$ Lowy pipettes.

3. Custom built wood frame to support fleakers, filter candles, and vacuum system.

2.6 Styrofoam pipe insulating cover.

$2.7 \quad 100 \mathrm{~mL}$ beakers or wide mouth glass pill bottles.

2.8 Balance (0.1 mg sensitivity).

2.9 Sieves 1.300 mesh 6".

2. Set of sieves brass $2 \mathrm{l} / 2^{\prime \prime}$. U.S. series and Tyler screen scale equivalent designations as follows:

\section{Opening mm}

1.00

0.50

0.25

0.105

0.046

3.

3.1 Hydrogen peroxide ( 30 or $50 \%$ ).

3.2 Hydrochloric acid $1 \mathrm{~N}$.

3.3 Citrate-bicarbonate buffer. Prepare a $0.3 \mathrm{M}$ solution of sodium citrate

$(88.4$

$\mathrm{g} / \mathrm{L}$ ) and add $125 \mathrm{~mL}$ of $1 \mathrm{M}$ sodium bicarbonate (84 $\mathrm{g} / \mathrm{L})$ to each liter of citrate solution.

3.4 Sodium hydrosulphite (dithionite).

3.5 Saturated sodium chloride solution.

3.6 Prepare a solution of sodium metaphosphate with enough sodium carbonate added to bring the $\mathrm{pH}$ to $10\left(\mathrm{Na} \mathrm{PO}_{3}\right) 35.7 \mathrm{~g} / \mathrm{L}+\mathrm{Na} 2 \mathrm{CO}_{3} 7.9$ $\mathrm{g} / \mathrm{L}$ is suitable.

\section{Procedure}

\subsection{Removal of Carbonates}

4.1.1 Weigh $10 \mathrm{~g}$ of $2 \mathrm{~mm}$ air dry soil into a $300 \mathrm{~mL}$ fleaker (tared to $1 \mathrm{mg}$ ). If the sample appears to be sandy, weigh a larger sample (e.g. $30 \mathrm{gL}$

4.1.2 Add $50 \mathrm{~mL}$ of water, mix and add $1 \mathrm{~N} \mathrm{HCl}$ slowly until the $\mathrm{pH}$ falls between 3.5 and 4.0 and remains there for 10 minutes. Stronger $\mathrm{HCl}$ can be used to avoid having a large volume of solution in soils high in carbonate content. Soils requiring a large amount of $\mathrm{HCl}$ to adjust the 
$\mathrm{pH}$ are washed several times with water to remove excess acid by using the filter candle system.

\subsection{Removal of Organic Matter}

4.2.1 Add $10 \mathrm{~mL}$ of hydrogen peroxide ( $\mathrm{H} 20230$ or $50 \%$ ) to the fleakers, cover and allow to stand. If a violent reaction occurs, repeat the cold $\mathrm{H}_{2} \mathrm{O}_{2}$ treatment until no more frothing occurs.

4.3.2 When frothing subsides heat to about $90^{\circ} \mathrm{C}$. Continue adding $\mathrm{H}_{2} \mathrm{O}_{2}$ and heating until most of the organic matter is destroyed (as observed by the color and the rate of reaction of the sample).

4.2.3 Rinse down the sides of the reaction vessel occasionally. Continue heating the sample for about 45 minutes after the final addition of hydrogen peroxide to remove excess hydrogen peroxide.

NOTE: $\quad$ 1. It may be necessary to transfer samples containing high amounts of organic matter (>5\%) to large beakers (e.g. $1000 \mathrm{~mL}$ tall form).

2. If excessive frothing occurs cool the container either with cold water or by the addition of methyl alcohol to avoid sample loss.

\subsection{Removal of Soluble Salts.}

4.3.1 Place the fleakers in a rack and filter the remaining peroxide and water off from step 4.23 using a filter candle system.

4.3.2 Add $150 \mathrm{~mL}$ water in a jet strong enough to stir the sample and filter the suspension through a filter candle ( -88-02) system. Five such washings and filterings are usually enough except for soils containing much coarse gypsum. To test for salts check with silver nitrate $\left(\mathrm{AgNO}_{3}\right)$ for $\mathrm{Cl}$ and barium chloride for $\mathrm{SO}_{4}{ }^{-2}$.

4.3.3 Remove soil adhering to the filter candle by applying back pressure gently, and using a rubber tipped finger as a policeman.

NOTE: If iron oxides are to be removed DO NOT complete step 4.34 at this time.

4.3.4 Place the sample in an oven overnight at $105^{\circ} \mathrm{C}$, cool in a dessicator, and weigh to the nearest milligram. Use the weight of the oven-dry treated sample as the base weight for calculating percentages of the various fractions.

\subsection{Removal of Iron Oxides (Optional)}

NOTE: Iron oxides should be removed from samples to permit the determination of phyllosilicate minerals by $x$-ray diffraction but this is not necessary for most samples. However, if the interest is in iron oxides in the clay fraction, pretreatments with dithionite-citrate-bicarbonate must be avoided. 
4.4.1 Add $150 \mathrm{~mL}$ of citrate-bicarbonate buffer to the samples in the fleakers. Stir and add $3 \mathrm{~g}$ of sodium hydrosulfite $\left(\mathrm{Na}_{2} \mathrm{~S}_{2} \mathrm{O}_{4}\right)$ gradually as some samples may froth.

4.4.2 Put the fleakers in a water bath at 800 and stir intermittently for 20 minutes.

4.4.3 Remove the fleakers from the bath, place in the holding rack and filter the suspension through the filter candle system. If a brownish color remains repeat steps 4.4.1 to 4.4.3 inclusive. If the samples are completely gleyed (gray) proceed to step 4.4.4.

4.4.4 Wash five times with a jet of water strong enough to stir the sample and filter the suspension through the filter candle system.

4.4.5 Do step 4.3.4 to determine the oven dry weight.

4.5 Dispersion of Sample.

4.5.1 Add $10 \mathrm{~mL}$ of sodium metaphosphate dispersing agent to the fleakers containing the oven dry treated samples. Make the volume to $200 \mathrm{~mL}$ with distilled water.

4.5.2 Stopper tightly and shake end-over-end (50-60 rpm) overnight.

4.6 Separation of Sand Fractions.

4.6.1 Pour the suspensions through a 300 mesh $(47 \mathrm{pm})$ sieve into a sedimentation cylinder marked at one liter. The 300 mesh sieve of about $14 \mathrm{~cm}$ diameter is placed in a large funnel held above the cylinder (2.4) by a retort stand.

4.6.2 Wash the sand retained on the sieve thoroughly with a fine jet of water and collect the washings in the cylinder until the volume in the cylinder is about $950 \mathrm{~mL}$. Remove sieve and make final volume to $1000 \mathrm{~mL}$.

4.6.3 Transfer the sand to a $100 \mathrm{~mL}$ beaker and oven dry at $105^{\circ} \mathrm{C}$. Weigh the sand and record weight at this time if only total sand is being determined. Otherwise proceed with sand fractionation.

4.6.4 Transfer the dried sand to a set of sieves $(6 \mathrm{~cm}$ diameter) arranged as follows from top to bottom: $1 \mathrm{~mm}, 0.5 \mathrm{~mm}, 0.25 \mathrm{~mm}$ (60 mesh), 0.105 (140 mesh), 0.047 (300 mesh) and pan. Pour sand on the top sieve, put the cover in place and shake the sieves on a sieve shaker. The time of shaking depends on the type of shaker and volume of sand (usually 5 to 10 minutes is sufficient). Weigh each sand fraction and record weight.

\subsection{Determination of Clay $(0-2 \mu \mathrm{m})$}

4.7.1 Before placing cylinders in sedimentation room (any vibration free area equipped with Shaw pipette rack), stir the material in the sedimentation cylinders for 4 minutes with a motor driven stirrer ( 8 minutes if suspension has stood for longer than 16 hours).

4.7.2 Remove from stirrer; slip a length of Styrofoam pipe-insulating cover over sedimentation cylinder. Stir the suspension for 30 seconds with a hand stirrer, using an up and down motion. Note the time at the completion of stirring. 
4.7.3 Sample the $2 \mathrm{pm}$ fraction after a predetermined settling time (usually 4.5 to $6.5 \mathrm{hrs}$ ), varying depth according to time and temperature. About 1 minute before sedimentation is complete, lower the tip of a closed Lowy $25 \mathrm{~mL}$ pipet slowly into the suspension to the proper depth with a pre-calibrated shaw pipet rack. Regulate the filling time of the pipet to about 12 seconds. Fill the pipet and empty it into a tared $90 \mathrm{~mL}$ wide mouth bottle (or $100 \mathrm{~mL}$ beaker) and rinse the pipet into the bottle once.

4.7.4 Evaporate the water and dry in an oven at $105^{\circ} \mathrm{C}$ for at least 24 hours. Cool in a desiccator containing phosphorus pentoxide $\left(\mathrm{P}_{2} \mathrm{O}_{5}\right)$ as a desiccant. Weigh and record the weight.

\subsection{Determination of Clay $0.2 \mu \mathrm{m}$ (optional)}

4.8.1 Pour about $200 \mathrm{~mL}$ of suspension from the sedimentation cylinders into $250 \mathrm{~mL}$ centrifuge bottles. Shake the suspensions, and centrifuge at the appropriate speed for the time necessary to sediment particles coarser than $0.2 \mathrm{~mm}$ to a depth of $5 \mathrm{~cm}$ (54 minutes at 1500 RPM on an IEC Model V Centrifuge). The formula to use is based on Stokes' law:

$t=63.0 \times 1 \& n \log R / S$ where NLDLAs

$\mathrm{n}=$ viscocity in poises at the existing temperature

$R=$ radius of rotation $(\mathrm{cm})$ of the top of the sediment in the tube

$\mathrm{s}=$ radius of rotation $(\mathrm{cm})$ of the surface of the suspension in the tube

$\mathrm{N}=$ revolutions per minute

$\mathrm{D}=$ particle diameter in urn

As = difference in specific gravity between the solvated particle and the suspending liquid (usually uses q 1.65)

$\mathrm{t}=$ time in minutes

(see Jackson, 1956 for tables of centrifuging times and speeds)

4.8.2 Withdraw a $25 \mathrm{~mL}$ aliquot from a depth of $5 \mathrm{~cm}$. Discharge the sample into a tared weighing bottle or beaker, rinse the pipette, add the rinsing to the weighing bottle, dry at $105^{\circ} \mathrm{C}, \mathrm{cool}$ in a desiccator and weigh.

\section{Calculations}

5.1 $A=$ weight $(\mathrm{g})$ of pipetted fraction (2 $\mathrm{pm}$ or $0.2 \mathrm{urn})$

$\mathrm{B}=$ weight correction for dispersing agent $(\mathrm{g})$

NOTE: $\quad$ To determine the correction factor, add $10 \mathrm{~mL}$ of the Sodium metaphosphate solution (3.6) to a 1 liter cylinder, make to volume, stir thoroughly, withdraw duplicate 25

$K=\underline{1000}$ $\mathrm{mL}$ samples, dry and weigh (about $0.012 \mathrm{~g}$ ).

$\mathrm{D}=\underline{100}$

$\mathrm{H}_{2} \mathrm{O}_{2}$ treated oven dry total sample $(\mathrm{g})$

5.2 Sand fraction(s):

Percentage of sand fraction $(\mathrm{s})=$ weight $(\mathrm{g})$ of fraction on sieve times D. 
Pipetted fraction(s): Percentage of pipetted fraction(s) $=(A-B) K D$. Silt fraction: Percentage of silt $=100-(\mathrm{O}-2 \mathrm{u}$ clay + sand $)$.

6. References

6.1 McKeague, J.A. Ed. 1978. Manual on soil sampling and methods of analysis. 2nd Edition. Can. Sot. Soil Sci. Suite 907, 151 Slater st., Ottawa, Ont. 


\subsection{SITE ANALYTICAL DATA}

Table 8.2.1 Site \# 14 (No-till) - 1991 DATA

\begin{tabular}{|c|c|c|c|c|c|}
\hline FIELD ID & DEPTH & HORIZON & pH 91 & OC 91 & BD 91 \\
\hline \multicolumn{6}{|l|}{ LOWER } \\
\hline E10N10 & $0-25$ & $A p$ & 7.2 & 2.86 & 1.35 \\
\hline E10N30 & $0-27$ & $A p$ & 7.0 & 3.55 & 1.30 \\
\hline E10N50 & $0-24$ & $A p$ & 7.1 & 3.47 & 1.34 \\
\hline E10N70 & $0-31$ & $A p$ & 7.0 & 4.20 & 1.22 \\
\hline E30N10 & $0-34$ & $A p$ & 6.7 & 3.58 & 1.12 \\
\hline E30N10 & $\mathrm{Na}$ & B & 6.9 & 0.54 & 0.00 \\
\hline E30N30 & $0-25$ & $A p$ & 6.8 & 3.73 & 1.20 \\
\hline E30N50 & $0-29$ & $A p$ & 6.9 & 3.41 & 1.26 \\
\hline E30N50 & $50-60$ & $B$ & 7.4 & 0.34 & 0.00 \\
\hline E30N50 & $85-95$ & $\mathrm{C}$ & 7.5 & 0.32 & 0.00 \\
\hline E30N70 & $0-22$ & $A p$ & 7.0 & 3.56 & 1.19 \\
\hline E50N10 & $0-31$ & $A p$ & 6.8 & 2.92 & 0.00 \\
\hline E50N30 & $0-23$ & $A p$ & 6.9 & 3.21 & 1.19 \\
\hline E50N50 & $0-27$ & $A p$ & 7.0 & 3.03 & 1.27 \\
\hline E50N70 & $0-36$ & $A p$ & 7.0 & 2.97 & 1.32 \\
\hline E70N10 & $0-23$ & $A p$ & 6.9 & 2.85 & 1.41 \\
\hline E70N30 & $0-22$ & $A p$ & 6.9 & 2.63 & 1.31 \\
\hline E70N30 & $50-60$ & B & 7.7 & 0.12 & 0.00 \\
\hline E70N30 & $90-100$ & C & 7.8 & 0.39 & 0.00 \\
\hline E70N50 & $0-24$ & $A p$ & 7.0 & 2.35 & 1.35 \\
\hline E70N70 & $0-25$ & $\mathrm{Ap}$ & 7.0 & 2.60 & 1.40 \\
\hline E70N70 & $\mathrm{Na}$ & $\mathrm{B}$ & 7.7 & 0.29 & 0.00 \\
\hline \multicolumn{6}{|l|}{ MID } \\
\hline E90N10 & $0-18$ & Ap & 6.9 & 2.61 & 1.33 \\
\hline E90N30 & $0-22$ & Ap & 6.9 & 2.82 & 1.30 \\
\hline E90N50 & $0-25$ & Ap & 7.0 & 2.57 & 1.34 \\
\hline E90N70 & $0-25$ & $A p$ & 7.0 & 2.54 & 1.34 \\
\hline E110N10 & $0-19$ & $A p$ & 7.0 & 2.59 & 1.44 \\
\hline E110N10 & $\mathrm{Na}$ & $\mathrm{B}$ & 7.7 & 0.00 & 0.00 \\
\hline E110N10 & $80-90$ & C & 7.7 & 0.24 & 0.00 \\
\hline E110N30 & $0-20$ & Ap & 7.1 & 2.64 & 1.32 \\
\hline E110N50 & $0-25$ & Ap & 7.2 & 2.08 & 1.43 \\
\hline E110N50 & $\mathrm{Na}$ & $\mathrm{B}$ & 7.8 & 0.00 & 0.00 \\
\hline E110N70 & $0-24$ & $\mathrm{Ap}$ & 7.1 & 2.33 & 1.42 \\
\hline E130N10 & $0-17$ & $\mathrm{Ap}$ & 6.9 & 2.23 & 1.31 \\
\hline E130N30 & $0-16$ & $\mathrm{Ap}$ & 7.0 & 2.04 & 1.51 \\
\hline E130N50 & $0-23$ & $\mathrm{Ap}$ & 7.1 & 1.52 & 1.48 \\
\hline E130N70 & $0-19$ & $\mathrm{Ap}$ & 7.1 & 1.74 & 1.44 \\
\hline \multicolumn{6}{|l|}{ LOWER } \\
\hline E150N10 & $0-17$ & $A p$ & 7.0 & 2.04 & 1.44 \\
\hline E150N30 & $0-17$ & $A p$ & 7.1 & 1.95 & 0.00 \\
\hline E150N30 & $\mathrm{Na}$ & $\mathrm{B}$ & 7.7 & 0.47 & 1.45 \\
\hline E150N50 & $0-18$ & $A p$ & 7.1 & 1.90 & 1.40 \\
\hline E150N70 & $0-22$ & $\mathrm{Ap}$ & 7.0 & 1.93 & 1.45 \\
\hline E150N70 & $\mathrm{Na}$ & $\mathrm{B}$ & 7.7 & 0.31 & 0.00 \\
\hline E150N70 & $80-100$ & $\mathrm{C}$ & 7.7 & 0.37 & 0.00 \\
\hline E170N10 & $0-20$ & $\mathrm{Ap}$ & 7.2 & 2.13 & 1.36 \\
\hline E170N30 & $0-23$ & $A p$ & 7.0 & 2.10 & 1.32 \\
\hline E170N50 & $0-22$ & $\mathrm{Ap}$ & 7.1 & 2.01 & 1.39 \\
\hline E170N70 & $0-20$ & $A p$ & 7.0 & 2.33 & 1.40 \\
\hline E190N10 & $0-36$ & $A p$ & 6.8 & 2.50 & 1.46 \\
\hline E190N10 & $\mathrm{Na}$ & $\mathrm{B}$ & 7.6 & 0.69 & 0.00 \\
\hline E190N30 & $0-22$ & $A p$ & 6.7 & 2.95 & 1.30 \\
\hline E190N050 & $0-29$ & Ap & 6.8 & 2.74 & 1.31 \\
\hline E190N050 & 29-51 & Btj & 6.8 & 1.09 & 0.00 \\
\hline E190N050 & $51-62$ & Btk & 7.0 & 0.71 & 0.00 \\
\hline E190N050 & $62-75$ & 2Bck & 7.6 & 0.19 & 0.00 \\
\hline E190N050 & $75+$ & $2 \mathrm{Cca}$ & 7.7 & 0.17 & 0.00 \\
\hline E190N70 & $0-22$ & $\mathrm{Ap}$ & 6.9 & 3.10 & 1.43 \\
\hline
\end{tabular}


Table 8.2.2 Site \#44 (Conventional till) - 1991 Data

\begin{tabular}{|c|c|c|c|c|c|}
\hline FIELD_ID & HORIZON & DEPTH_SLCH & pH & OC_91 & BD-91 \\
\hline \multicolumn{6}{|l|}{ LOWER } \\
\hline 010E010S & $A p$ & $0-25$ & 7.0 & 2.26 & 1.28 \\
\hline 010E010S & $\mathrm{B}$ & $25-45$ & & & 1.34 \\
\hline 010E030S & $A p$ & $0-30$ & 7.1 & 2.44 & 1.23 \\
\hline O10E050S & $\mathrm{Ap}$ & $0-28$ & 7.4 & 1.97 & 1.35 \\
\hline 010E050S & Ckg & na & & & 1.21 \\
\hline 010E070S & $\mathrm{Ap}$ & $0-30$ & 7.1 & 2.47 & 1.39 \\
\hline 030E070S & $A p$ & $0-26$ & 7.2 & 1.33 & 1.31 \\
\hline O30E050S & $A p$ & $0-28$ & 7.4 & 1.61 & 1.15 \\
\hline 030E030S & Ap & $0-35$ & 7.3 & 1.68 & 1.15 \\
\hline 030E010S & $A p$ & $0-30$ & 7.1 & 1.99 & 1.21 \\
\hline O50E010S & $\mathrm{Ap}$ & $0-29$ & 6.9 & 1.88 & 1.24 \\
\hline 050E010S & $\mathrm{B}$ & $29-53$ & & & 1.28 \\
\hline O50E010S & $\mathrm{C}$ & na & & & 1.34 \\
\hline 050E030S & $\mathrm{Ap}$ & $0-25$ & 7.1 & 1.87 & 1.49 \\
\hline O50E050S & $A p$ & $0-38$ & 7.2 & 1.92 & 1.39 \\
\hline 050E050S & $\mathrm{C}$ & na & & & 1.18 \\
\hline 050E070S & $\mathrm{Ap}$ & $0-25$ & 7.2 & 1.72 & \\
\hline 070E070S & $\mathrm{Ap}$ & $0-27$ & 7.3 & 1.44 & \\
\hline O70E050S & $A p$ & $0-35$ & 7.1 & 1.21 & \\
\hline O70E030S & $\mathrm{Ap}$ & $0-30$ & 7.1 & 1.22 & \\
\hline O70E010S & Ap & $0-25$ & 7.1 & 1.79 & \\
\hline \multicolumn{6}{|l|}{ MID } \\
\hline 090E010S & $A p$ & $0-30$ & 7.1 & 1.11 & 1.41 \\
\hline O90E030S & $A p$ & $0-30$ & 7.3 & 1.01 & 1.38 \\
\hline 090E050S & $A p$ & $0-33$ & 7.2 & 1.18 & 1.33 \\
\hline 090E070S & $\mathrm{Ap}$ & $0-27$ & 7.3 & 1.54 & 1.33 \\
\hline 110E070S & Ap & $0-30$ & 7.2 & 1.21 & 1.39 \\
\hline 110E050S & $A p$ & $0-25$ & 7.3 & 1.16 & 1.38 \\
\hline 110E050S & $\mathrm{C}$ & na & & & 1.44 \\
\hline $110 \mathrm{E} 030 \mathrm{~S}$ & $A p$ & $0-32$ & 7.3 & 1.13 & 1.39 \\
\hline $110 \mathrm{E} 010 \mathrm{~S}$ & $\mathrm{Ap}$ & $0-32$ & 7.2 & 1.39 & 1.36 \\
\hline $110 \mathrm{E} 010 \mathrm{~S}$ & $B$ & $32-60$ & & & 1.37 \\
\hline 130E010S & $\mathrm{Ap}$ & $0-27$ & 7.3 & 1.21 & 1.37 \\
\hline 130E030S & $A p$ & $0-28$ & 7.4 & 0.86 & 1.39 \\
\hline 130E050S & $A p$ & $0-27$ & 7.3 & 1.12 & 1.42 \\
\hline $130 \mathrm{E} 070 \mathrm{~S}$ & $\mathrm{Ap}$ & $0-27$ & 7.3 & 1.08 & 1.41 \\
\hline 150E070S & $\mathrm{Ap}$ & $0-25$ & 7.4 & 1.27 & 1.33 \\
\hline 150E070S & $\mathrm{C}$ & na & & & 1.31 \\
\hline 150E050S & $A p$ & $0-30$ & 7.4 & 1.05 & \\
\hline 150E030S & $A p$ & $0-29$ & 7.4 & 0.94 & \\
\hline 150E030S & C & na & & & \\
\hline 150E010S & $A p$ & $0-30$ & 7.3 & 1.14 & \\
\hline \multicolumn{6}{|l|}{ UPPER } \\
\hline 170E010S & $A p$ & $0-27$ & 7.3 & 1.26 & 1.40 \\
\hline 170E030S & $A p$ & $0-28$ & 7.3 & 1.21 & 1.42 \\
\hline 170E050S & $A p$ & $0-28$ & 7.3 & 1.39 & 1.22 \\
\hline 170E070S & $A p$ & $0-27$ & 7.2 & 1.26 & 1.34 \\
\hline 190E070S & $A p$ & $0-27$ & 7.3 & 1.22 & 1.28 \\
\hline 190E050S & $A p$ & $0-30$ & 7.3 & 1.59 & 1.20 \\
\hline 190E030S & $A p$ & $0-27$ & 7.2 & 1.46 & 1.26 \\
\hline 190E010S & $A p$ & $0-27$ & 7.4 & 1.25 & 1.38 \\
\hline $210 \mathrm{E} 010 \mathrm{~S}$ & $A p$ & $0-26$ & 7.0 & 1.63 & 1.17 \\
\hline 210E030S & $A p$ & $0-31$ & 7.1 & 1.41 & 1.32 \\
\hline 210 E030S & C & na & 7.7 & 0.03 & 1.30 \\
\hline 210E050S & $A p$ & $0-33$ & 7.1 & 1.81 & 1.30 \\
\hline 210E070S & $A p$ & $0-23$ & 7.4 & 1.27 & 1.30 \\
\hline $210 \mathrm{E} 070 \mathrm{~S}$ & C & na & 7.7 & 0.11 & 1.22 \\
\hline 230E070S & $A p$ & $0-24$ & 7.2 & 1.76 & 1.19 \\
\hline 230E050S & Ap & $0-28$ & 7.0 & 1.91 & 1.32 \\
\hline $230 \mathrm{E} 030 \mathrm{~S}$ & $A p$ & $0-26$ & 6.9 & 1.76 & \\
\hline 230E010S & $A p$ & $0-30$ & 7.0 & 1.85 & \\
\hline
\end{tabular}




\begin{tabular}{|c|c|c|c|c|c|c|c|c|c|c|c|c|c|c|c|c|c|c|c|c|c|c|c|c|c|c|c|c|c|c|}
\hline & $\bar{c}$ & 5 & ?ִ. & & & & $\frac{7}{7}$ & $=$ & O & & $\stackrel{\infty}{\check{\infty}}$ & $\mid$\begin{tabular}{l}
$\mathbf{J}$ \\
\hdashline
\end{tabular} & & & & & & & & & & & & & & & & & 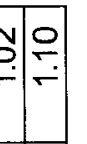 \\
\hline & דִ & & & & & & & & & & & $\stackrel{+}{-}$ & & & & & & & & & & & $-\sigma$ & & & & & & & \\
\hline & 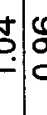 & & & & & & & & & & & $\stackrel{\substack{\infty \\
\hdashline}}{-}$ & $\stackrel{\cong}{\mp}$ & & & & & & & & 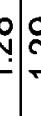 & 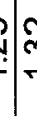 & $\stackrel{\sim}{\sim}$ & & & & & 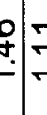 & & \\
\hline 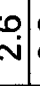 & \begin{tabular}{r|l}
$n$ \\
$n$ \\
$n$
\end{tabular} & & 80 & $\vec{S}$ & & & & jo & $\approx$ & 2 & Oִ & 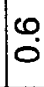 & N & & & $N$ & $\mathrm{~N}$ & & & & ro & 10 & & & & $\stackrel{\infty}{\leftarrow}$ & $\stackrel{0}{\circ}$ & & $\infty$ & $m$ \\
\hline $0 \mid$ & 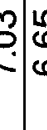 & & 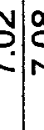 & 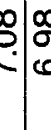 & & & & & & & & $\frac{n}{\pi}$ & & & & & $\underbrace{2}$ & I & & & 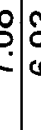 & & & & & & & & & ? \\
\hline & $\begin{array}{c}\text { s. } \\
\end{array}$ & & 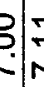 & $=\left[\begin{array}{lll}\sigma \\
\end{array}\right.$ & 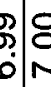 & & & & & o & 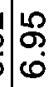 & i & $\frac{0}{i}$ & & & 6 & co. & $\stackrel{s}{*}$ & & के & co & $\stackrel{0}{8}$ & ת & & 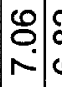 & $\begin{array}{c}N \\
\infty \\
0 \\
0\end{array}$ & & B. & & 6 \\
\hline & & & & & \begin{tabular}{c|c}
8 \\
\hdashline \\
\hdashline
\end{tabular} & & $\frac{7}{7}$ & & & $\begin{array}{l}\alpha \\
\sigma \\
c\end{array}$ & $\mid \begin{array}{l}\infty \\
\sigma \\
0\end{array}$ & $\stackrel{N}{N}$ & $\begin{array}{l}\mathbf{O} \\
\dot{0}\end{array}$ & & & (ל.) & \begin{tabular}{c}
$\mathscr{8}$ \\
\hdashline \\
\end{tabular} & \pm & \pm & & $=$ & צִ & $\frac{\pi}{2}$ & & $\left(\begin{array}{c}8 \\
\\
\sim\end{array}\right.$ & $\begin{array}{c}\hat{0} \\
\dot{0}\end{array}$ & & & & $\mid \begin{array}{l}- \\
\infty \\
0\end{array}$ \\
\hline $\bar{c}$ & $\vec{n}$ & $\frac{1}{n}$ & & $1-$ & - & & $1-$ & - & - & - & $\vec{\sigma}$ & $\frac{\vec{w}}{\mathbb{W}}$ & 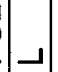 & & & - & . & . & & & - ــ & - נل & - & & $|-|$ & - & ـإــ & $\mid \overline{\bar{o}}$ & & $5 \bar{\omega}$ \\
\hline \begin{tabular}{l}
+ \\
\hdashline \\
\hdashline
\end{tabular} & \begin{tabular}{l}
$\int$ \\
\hdashline
\end{tabular} & 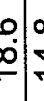 & 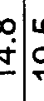 & 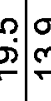 & $\begin{array}{l}\qquad \\
\dot{p}\end{array}$ & & $\begin{array}{lll}0 \\
\end{array}$ & & & & $\stackrel{8}{5}$ & & $\begin{array}{l}\infty \\
\stackrel{0}{\sim}\end{array}$ & $\dot{\nabla}$ & & $\underline{0}$ & $\dot{I}$ & $\bar{v}$ & $\stackrel{\sim}{=}$ & $\dot{ \pm}$ & 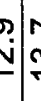 & & $\begin{array}{l}0 \\
3 \\
3\end{array}$ & & $\begin{array}{c}\stackrel{\sim}{\sim} \\
\stackrel{2}{*}\end{array}$ & 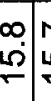 & $\stackrel{s}{\Omega}$ & & & \\
\hline $\begin{array}{c}\infty \\
\vdots \\
\vdots \\
\vdots\end{array}$ & 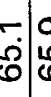 & ל. & $\frac{9}{6}$ & gִ & 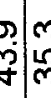 & & 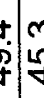 & 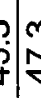 & $\left\{\begin{array}{l}\infty \\
5 \\
5\end{array}\right.$ & $\stackrel{p}{\alpha}$ & 要 & 歺 & $\begin{array}{l}0 \\
\frac{8}{8}\end{array}$ & $\begin{array}{l}\infty \\
\text { in } \\
\text { m. }\end{array}$ & & 与ी & : & | & $\vec{q}$ & $\frac{7}{4}$ & $\begin{array}{l}0 \\
\dot{y} \\
\end{array}$ & $f$ & $\dot{F}$ & & $\left(\begin{array}{l}\vec{m} \\
⿱ 亠 乂\end{array}\right.$ & $\stackrel{9}{8}$ & & 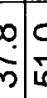 & & S: \\
\hline $\begin{array}{c}\infty \\
\text { लि. } \\
\text { ले. }\end{array}$ & 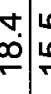 & مُ & רִ & 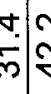 & $\begin{array}{lll}N & 15 \\
y & 15 \\
\end{array}$ & & & & & N & $\begin{array}{l}\infty \\
\stackrel{\infty}{N}\end{array}$ & 号 & $\begin{array}{l}1 \\
1 \\
0 \\
8\end{array}$ & $\begin{array}{l}\infty \\
\\
\end{array}$ & & ల్ల & : & $\begin{array}{c}\forall \\
\dot{y} \\
\end{array}$ & & & 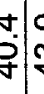 & $\dot{i}$ & 8 & & $\begin{array}{l}\infty \\
\tilde{v}\end{array}$ & & & & & 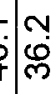 \\
\hline$\underline{c}$ & $\tilde{\sigma}$ & סִ & v & \begin{tabular}{l|l}
0 \\
0 \\
0
\end{tabular} & $\begin{array}{ll}\infty \\
\dot{v} \\
\dot{v}\end{array}$ & : & $\begin{array}{c}\mathbf{v} \\
\mathbf{v}\end{array}$ & 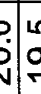 & $\mid \begin{array}{l}15 \\
c \\
c\end{array}$ & $\vec{v}$ & $\frac{0}{2}$ & & $\begin{array}{l}S \\
\stackrel{2}{ } \\
\end{array}$ & ָั & & ㅇ. & $\overrightarrow{\mathrm{N}}$ & N & $\overrightarrow{\mathrm{d}}$ & & & $\dot{c}$ & 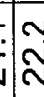 & & $\stackrel{\bar{N}}{\bar{N}}$ & 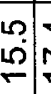 & $F$ & 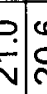 & & $=-$ \\
\hline 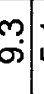 & $\dot{s}$ & $\vec{m}$ & $\sigma^{\circ}$ & ح: & $\begin{array}{l}\infty \\
\\
\end{array}$ & : & $?$ & $\checkmark$ & Fis & רֶ? & $\infty$ & 沜 & O. & ִָ & & . & $\vec{\sim}$ & $\dot{0}$ & 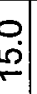 & y & $?:$ & 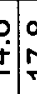 & {$\left[\begin{array}{l}\infty \\
m\end{array}\right.$} & & m & $\underset{ \pm}{ \pm}$ & \pm & $7^{\circ}$ & & 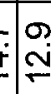 \\
\hline$\sigma$ & i & $\underbrace{.}$ & $\mu^{\circ}$ & مُ & $\dot{s}$ & s. & $\stackrel{8}{\circ}$ & $\underset{5}{5}$ & s. & 8 & i & 10 & $\stackrel{7}{8}$ & | & & $\dot{y}$ & $\nabla$ & & & + & 10 & 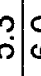 & in & & $\mid \begin{array}{c}N \\
\text { in }\end{array}$ & $\begin{array}{l}O \\
\dot{\tau}\end{array}$ & S & S: & \begin{tabular}{l|l}
$\mathbf{y}$ & 0 \\
$\vdots$ &
\end{tabular} & $5^{\circ} \mid \Omega^{\circ}$ \\
\hline ๙ & 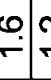 & - & - & 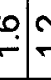 & $\because 7$ & 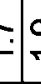 & 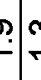 & : & $=0$ & $q^{\circ}$ & 0 & i & 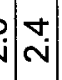 & $\stackrel{0}{-}$ & & 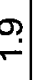 & & & $\stackrel{\circ}{\circ}$ & & & & $j \mid \sim$ & & & $\stackrel{0}{-}$ & & & & 17 \\
\hline r & $\dot{0}: \dot{c}$ & $\check{s}$ & $\stackrel{0}{0}$ & $\begin{array}{c}0 \\
\vdots\end{array}$ & $\dot{0}$ & s. & 8 & $\dot{b}$ & 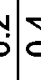 & $\vdots$ & 0 & ?ִ & $\begin{array}{l}0 \\
0\end{array}$ & $\begin{array}{l}0 \\
0 \\
0\end{array}$ & & & & & & & & & & & & $\dot{0}$ & مُ & & : & \\
\hline & בิ & مُ & o. & 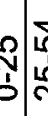 & $\begin{array}{l}S \\
S\end{array}$ & $\begin{array}{l}y_{0}^{\prime} \\
\vdots \\
\end{array}$ & & & 5 & 2 & 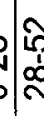 & $\mid$\begin{tabular}{|}
+ \\
t
\end{tabular} & & 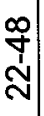 & & & & & & & & & $\vec{c}$ & & & 0 & 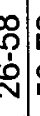 & & & 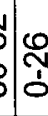 \\
\hline 8 & & & 足 & ธ & $\bar{c}$ & S? & & & & & $\infty$ & 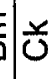 & & (⿳亠口冋. & & & & & & & & & a|ব & & & . & ณ. & 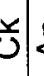 & ç & $\bar{a}$ \\
\hline$\frac{5}{6}$ & 응 & 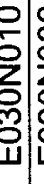 & 象 & క్రక & žn & ל̧: & 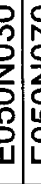 & & & & & 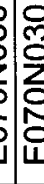 & : & 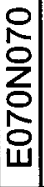 & & & & & & & & & 2 & $\frac{\frac{\alpha}{\omega}}{\frac{\alpha}{\alpha}}$ & 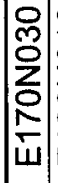 & $\begin{array}{l}\text { 응 } \\
\text { 잉 } \\
\frac{0}{5}\end{array}$ & క & 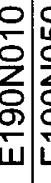 & $\frac{1}{4}$ & ?. \\
\hline
\end{tabular}




\begin{tabular}{|c|c|c|c|c|c|c|c|c|c|c|c|c|c|c|c|c|c|c|c|c|c|c|c|c|}
\hline $\begin{array}{l}z \\
z \\
z \\
0\end{array}$ & & $\stackrel{\grave{r}}{\stackrel{m}{r}}$ & & & & & & & & & 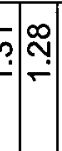 & $\stackrel{m}{-}$ & & $\stackrel{m}{\stackrel{m}{*}}$ & $\mid \begin{array}{l}\infty \\
\stackrel{\infty}{-}\end{array}$ & 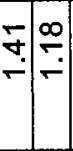 & & 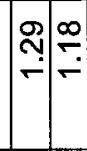 & & & & & & 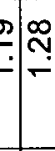 \\
\hline 品 & & 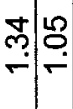 & $\stackrel{\infty}{=}$ & & ?ִ & & & & : & 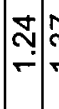 & 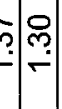 & $\stackrel{m}{-}$ & $\stackrel{m}{-}$ & $\stackrel{n}{r}: \stackrel{m}{m}$ & ชิ & 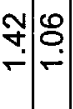 & | & 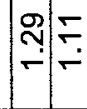 & $\stackrel{\nabla}{-}$ & 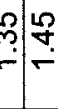 & & & $\stackrel{\mathscr{T}}{\stackrel{2}{*}}$ & $\stackrel{\sim}{r}$ \\
\hline$r$ & & 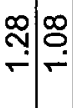 & 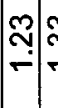 & & & & & & & 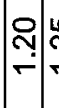 & 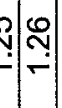 & ঙֶ. & $\stackrel{n}{m}$ & 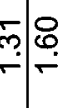 & 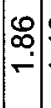 & 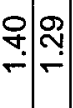 & $\begin{array}{l}\infty \\
\stackrel{\leftrightarrow}{-} \\
\sim\end{array}$ & 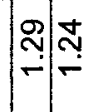 & $\stackrel{m}{\rightarrow}$ & 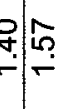 & & & & ז̊ \\
\hline y & & $\begin{array}{l}\qquad \\
\stackrel{8}{*}\end{array}$ & প্: & & 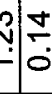 & & & & $\stackrel{n}{n}$ & : & 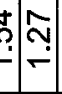 & & $\stackrel{\oplus}{\div}$ & 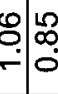 & $\left|\begin{array}{c}\bar{n} \\
\text { in }\end{array}\right|$ & 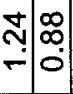 & $\stackrel{2}{\circ}$ & $\mid \stackrel{N}{m}$ & $\therefore$ & 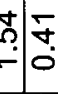 & & & 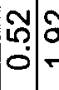 & : \\
\hline & & 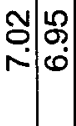 & 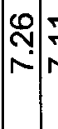 & 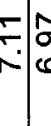 & in & & ப̦ & 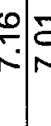 & 5 & : & 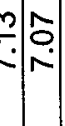 & $\stackrel{9}{\circ}$ & : & 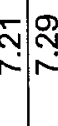 & 象 & 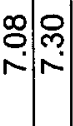 & ָָ. & 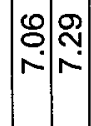 & $\left.\stackrel{ }{\sim}\right|_{r} ^{8}$ & Cִ & $\mid$ & & 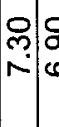 & 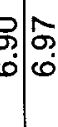 \\
\hline v & & 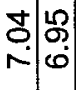 & $\infty$ & $\underset{c}{ \pm} \mid \begin{array}{l}a \\
a \\
c\end{array}$ & 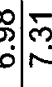 & & : & $=8$ & 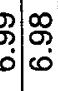 & व: & 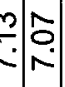 & & 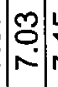 & & 8 & $\begin{array}{l}n \\
\end{array}$ & $\mid$ & $\begin{array}{l}0 \\
\\
\end{array}$ & $\mid$\begin{tabular}{lll}
$\infty$ & \multicolumn{1}{c}{} \\
\hdashline & 0 & 0
\end{tabular} & \begin{tabular}{l|l}
0 \\
0
\end{tabular} & & § & 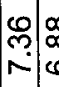 & $\begin{array}{l}\infty \\
\infty \\
0 \\
0\end{array}$ \\
\hline $1 \frac{10}{2}$ & & 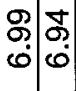 & mֶ: & s. & వి & & & 2 & $\begin{array}{l}0.0 \\
0\end{array}$ & S: & $\therefore$ & & : & & ?ִ & 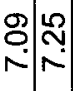 & $\mid$ & 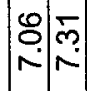 & 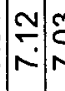 & & & $\stackrel{4}{3}$ & & \begin{tabular}{c|l}
$\bar{\sigma}$ & 8 \\
$\dot{0}$ & 0
\end{tabular} \\
\hline & & $\omega$ & $L^{\circ}$ & $\overline{\bar{\omega}} \overline{\bar{\omega}}$ & $\overline{\bar{s}}$ & $-\lrcorner$ & $\square$ & $-\overline{\bar{u}}$ & - & -1 & $-\Delta$ & & - & - & \begin{tabular}{|l|}
$\vec{w}$ \\
\end{tabular} & $-\lrcorner \mid \begin{array}{l}\vec{\infty} \\
\stackrel{\mu}{>}\end{array}$ & -1 & $-\lrcorner$ & $-1-$ & & $\mid \begin{array}{l}\vec{\omega} \\
\end{array}$ & & $\vec{\omega}$ & ـــــ \\
\hline & & & $\begin{array}{l}3 \\
\square\end{array}$ & 5 & $\stackrel{\infty}{=}$ & $\begin{array}{l} \\
\dot{\nabla} \\
\end{array}$ & $\stackrel{r}{m}$ & 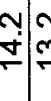 & $\begin{array}{l}\vec{v} \\
\end{array}$ & $\stackrel{\sim}{\sim}$ & 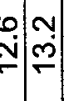 & & 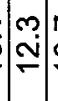 & & 0 & 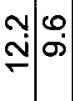 & : & $\stackrel{\dot{m}}{\stackrel{\leftrightarrow}{\rightleftarrows}}$ & $\stackrel{0}{=}$ & 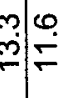 & & & $\left.\stackrel{0}{r}\right|^{\alpha}$ & 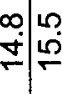 \\
\hline$\stackrel{\mathbb{2}}{\stackrel{2}{0}}$ & & \begin{tabular}{l|l} 
\\
\\
în
\end{tabular} & 字: & 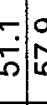 & & 字 & & 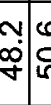 & 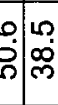 & S & 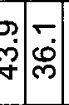 & $\begin{array}{l}\sigma \\
\dot{e} \\
\dot{e}\end{array}$ & 字 & 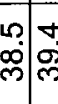 & $\begin{array}{l} \\
\dot{q}\end{array}$ & 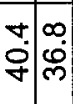 & $\mid \begin{array}{l}\overrightarrow{0} \\
\dot{q} \\
\dot{q}\end{array}$ & 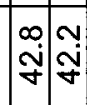 & $\begin{array}{lll}0 & 5 \\
& 5\end{array}$ & "ִ. & : & $\begin{array}{l}m \\
\dot{v} \\
\dot{y}\end{array}$ & {$\left[\begin{array}{c}- \\
\infty \\
\infty\end{array}\right]$} & \begin{tabular}{l|c}
$\infty$ & 0 \\
$\dot{8}$ & $\overline{7}$
\end{tabular} \\
\hline 它|号 & & 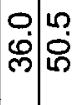 & $\mid \begin{array}{l}\sigma \\
\dot{p} \\
\vdots\end{array}$ & $\vec{m}$ & & $\dot{q}$ & 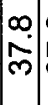 & \begin{tabular}{l|l}
0 \\
\\
\end{tabular} & 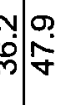 & : & $\begin{array}{lll}0 \\
\dot{m} \\
\dot{y}\end{array}$ & is & $\vec{f}$ & 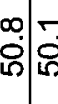 & 呙 & fִ & $\mid \begin{array}{l}0 \\
\dot{\sigma} \\
\dot{q}\end{array}$ & 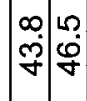 & 客: & 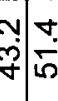 & $\begin{array}{l}0 \\
\dot{i} \\
0\end{array}$ & & $\mid \begin{array}{l}0 \\
\hat{b} \\
\hat{\kappa}\end{array}$ & : \\
\hline & & 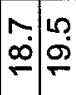 & 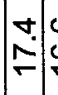 & ف & $\Rightarrow$ & 2 & $\bar{i}$ & 9 & $=\frac{N}{N}$ & స్. & 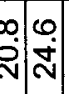 & ֻ & $\frac{\operatorname{s}}{\mathrm{N}}$ & הి & 足 & \begin{tabular}{l|l}
\multirow{N}{*}{} & $\infty$ \\
$\stackrel{N}{*}$ & \multirow{N}{*}{}
\end{tabular} & $\begin{array}{l}\text { Na } \\
\text { Nิ }\end{array}$ & $\begin{array}{l}\stackrel{m}{=} \\
\stackrel{\infty}{=} \\
\infty\end{array}$ & $\begin{array}{ll}0 \\
0 \\
0\end{array}$ & \begin{tabular}{l|l}
$\infty$ \\
\end{tabular} & $=\begin{array}{l}0 \\
\dot{\sigma}\end{array}$ & $\stackrel{m}{\sim}$ & $\sigma a$ & 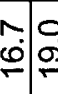 \\
\hline & & & 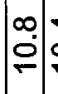 & \begin{tabular}{lll}
8 \\
\hdashline
\end{tabular} & 0 & $\vec{m}$ & $\stackrel{-}{=}$ & $\hat{0}=$ & $\stackrel{\infty}{\Rightarrow} \stackrel{\infty}{\digamma}$ & $F$ & \begin{tabular}{lll}
0 \\
$\dot{*}$ & 0 \\
\hdashline & 0
\end{tabular} & 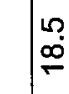 & 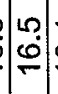 & $\stackrel{\infty}{\infty}$ & $=$ & 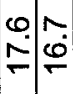 & : & $\begin{array}{c}m \\
0 \\
0\end{array}$ & $\underset{\square}{\Psi}$ & $\begin{array}{lll}0 \\
: \\
:\end{array}$ & & $\bar{\sigma}$ & $\stackrel{\sim}{\sim}$ & $\begin{array}{lll}5 \\
\stackrel{m}{=}\end{array}$ \\
\hline$\frac{n}{2}$ & & & $\stackrel{s}{\mathrm{t}}$ & $\begin{array}{r}\text { Ny} \\
\dot{v}\end{array}$ & 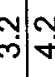 & 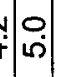 & & & $\begin{array}{l}\dot{7} \\
\end{array}$ & 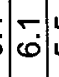 & 足: & षे & $\mid \begin{array}{l}\infty \\
0 \\
0\end{array}$ & & $\begin{array}{l}\infty \\
\infty \\
\infty\end{array}$ & $\begin{array}{lll}m & 0 \\
\oplus & 0 & 0\end{array}$ & $\left|\begin{array}{l}0 \\
0 \\
0\end{array}\right|$ & \begin{tabular}{|c|c|c|} 
& 0 \\
0 & 0 &
\end{tabular} & : & 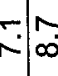 & $\dot{\sigma}$ & & $\therefore: 0$ & 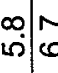 \\
\hline & & & & & $=$ & $\therefore$ & $\stackrel{\square}{-}$ & & $\stackrel{\infty}{-\infty}$ & 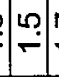 & $\begin{array}{l}\therefore \\
\therefore\end{array}$ & $\overline{\mathrm{i}}$ & $\mathrm{j}$ & $\infty$ & 10 & 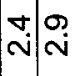 & $\stackrel{m}{\sim}$ & $\mid$\begin{tabular}{l|l}
0 & 0 \\
$\sim$ & $\sim$ \\
$N$
\end{tabular} & $\stackrel{m}{n} \mid c$ & \begin{tabular}{c|c}
0 \\
$\stackrel{\sim}{*}$
\end{tabular} & 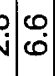 & $\begin{array}{l}\infty \\
\sim \\
\sim\end{array}$ & $\rightarrow 0$ & $\stackrel{0}{r} \mid \frac{1}{\gamma}$ \\
\hline & & 이뭉 & $\stackrel{?}{\longrightarrow}$ & $\begin{array}{c}r \\
0\end{array}$ & $\begin{array}{c}0 \\
0\end{array}$ & \begin{tabular}{ll|}
0 \\
0 \\
0
\end{tabular} & 10 & $\begin{array}{l}0 \\
0 \\
0\end{array}$ & $\begin{array}{l}0 \\
0\end{array}$ & $\mid \begin{array}{c}n \\
0\end{array}$ & $\stackrel{10}{0}$ & $\stackrel{\leftrightarrow}{\circ}$ & $\mid$ & $\begin{array}{l}0 \\
0\end{array}$ & 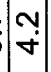 & $|\stackrel{0}{\circ}| \stackrel{0}{-}$ & $\hat{0}$ & 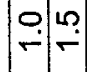 & 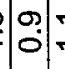 & $\because$ & $=0$ & & 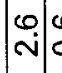 & $\begin{array}{l}0 \\
0 \\
0\end{array}$ \\
\hline 芯|吉 & & 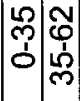 & & 周 & & $\mid \begin{array}{l}0 \\
\vdots \\
\vdots \\
0\end{array}$ & $\mid \begin{array}{l}\infty \\
0 \\
0 \\
0\end{array}$ & के & & $\left|\begin{array}{l}\mid \\
\vdots \\
\vdots \\
\grave{n}\end{array}\right|$ & 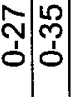 & ָָ & $\begin{array}{l}\mathfrak{N} \\
\mathfrak{N} \\
0\end{array}$ & 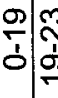 & & 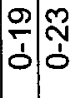 & ָָ̃ & 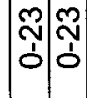 & 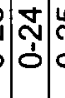 & 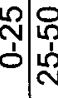 & 勺ै & & $\mid$\begin{tabular}{l}
$\infty$ \\
\hdashline \\
0 \\
$\infty$ \\
\hdashline
\end{tabular} & 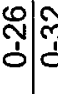 \\
\hline$\infty$ & & $1<0$ & & & 离 & & & & & $\frac{5}{4}$ & 워워 & & & ㅇㅝㄸㄷㅏ & & 월울 & 4 & 원? & 20 & & 0 & & . & 이인 \\
\hline $\begin{array}{l}\frac{\overline{0}}{\pi} \\
\stackrel{10}{-}\end{array}$ & $=$ & 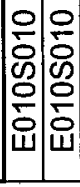 & \begin{tabular}{|l}
0 \\
0 \\
0 \\
0 \\
\end{tabular} & 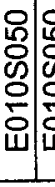 & 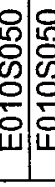 & 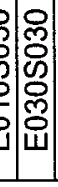 & 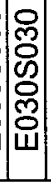 & 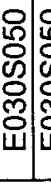 & 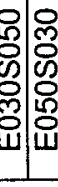 & 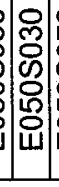 & 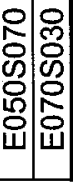 & 送 & 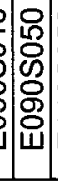 & 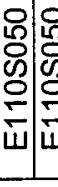 & 号 & 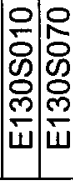 & 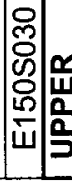 & 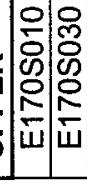 & 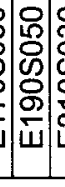 & 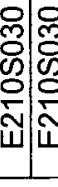 & 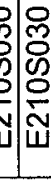 & 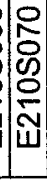 & 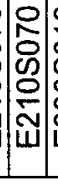 & 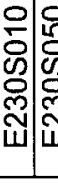 \\
\hline
\end{tabular}




\begin{tabular}{|c|c|c|c|c|c|c|c|c|c|c|c|c|c|c|c|}
\hline $\begin{array}{l}\mathbf{z} \\
\mathbf{z} \\
\mathbf{0} \\
\mathbf{0}\end{array}$ & & $\begin{array}{l}\mathbb{N} \\
\mathbf{\infty} \\
0 \\
0\end{array}$ & 잉 & $\stackrel{\mathscr{\omega}}{\sim}$ & 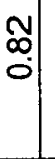 & ڤִ & $\begin{array}{l}\tilde{N} \\
0\end{array}$ & & N. & $\underset{N}{\stackrel{N}{*}}$ & $\tilde{\tau}$ & & ח & \begin{tabular}{c}
$\mathcal{N}$ \\
$\infty$ \\
\hdashline
\end{tabular} & $\begin{array}{l}\text { o. } \\
\text { o }\end{array}$ \\
\hline $\begin{array}{l}\mathbf{v} \\
\mathbf{\infty} \\
\mathbf{\infty}\end{array}$ & & $\begin{array}{c}\infty \\
0 \\
0\end{array}$ & б. & $\stackrel{0}{0}$ & $\begin{array}{c}\widetilde{N} \\
\infty \\
0\end{array}$ & $\begin{array}{c}\text { హ్ } \\
\text { హ్ }\end{array}$ & $\hat{\widehat{A}}$ & & б. & $\stackrel{Ð}{\sim}$ & $\begin{array}{l}\text { R } \\
\text { : }\end{array}$ & & $\begin{array}{l}0 \\
⿱ \\
0\end{array}$ & $\begin{array}{l}\bar{\infty} \\
0 \\
\end{array}$ & $\stackrel{m}{\circ}$ \\
\hline 吕 & & $\begin{array}{c}\mathscr{D} \\
\infty \\
0\end{array}$ & $\mid \begin{array}{l}0 \\
\infty \\
0 \\
0\end{array}$ & $\begin{array}{c}\mathscr{Q} \\
\stackrel{+}{-}\end{array}$ & \begin{tabular}{c}
\multirow{N}{\infty}{} \\
\hdashline \\
\hdashline
\end{tabular} & 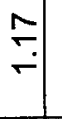 & $\begin{array}{l}0 \\
\stackrel{0}{0} \\
0\end{array}$ & & $\begin{array}{l}m \\
\\
\end{array}$ & 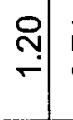 & $\begin{array}{l}\Gamma \\
0 \\
0\end{array}$ & & 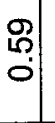 & $\begin{array}{c}\mathscr{m} \\
\infty \\
0 \\
0\end{array}$ & চ্. \\
\hline : & & $\stackrel{+}{+}$ & $\begin{array}{l}m \\
0\end{array}$ & $\check{0}$ & $\begin{array}{l}\infty \\
\dot{+} \\
\end{array}$ & $\stackrel{m}{\sim}$ & $\begin{array}{l}\infty \\
\dot{\forall} \\
\end{array}$ & & $\stackrel{+}{\dot{m}}$ & \begin{tabular}{l|l}
$\infty$ & \\
0
\end{tabular} & $\begin{array}{l}0 \\
\dot{\forall}\end{array}$ & & $\begin{array}{l}0 \\
0 \\
0\end{array}$ & $\begin{array}{c}\dot{0} \\
\dot{m}\end{array}$ & $\stackrel{m}{\square}$ \\
\hline $\begin{array}{l}z \\
\Sigma \\
I\end{array}$ & & $\begin{array}{l}8 \\
6 \\
6\end{array}$ & $\begin{array}{l}\hat{\imath} \\
\dot{\varphi}\end{array}$ & $\begin{array}{l}\stackrel{0}{N} \\
\end{array}$ & $\begin{array}{l}1 \\
0 \\
0\end{array}$ & \begin{tabular}{c}
$\widetilde{N}$ \\
$\infty$ \\
\hdashline
\end{tabular} & $\begin{array}{l}\infty \\
⿱ \\
0\end{array}$ & & 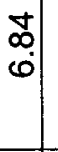 & $\begin{array}{l}\mathscr{D} \\
\dot{0}\end{array}$ & $\begin{array}{l}\mathbf{U} \\
0 \\
0\end{array}$ & & 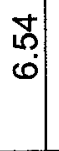 & $\begin{array}{l}0 \\
\infty \\
0\end{array}$ & $\begin{array}{l}0 \\
\infty \\
\dot{0}\end{array}$ \\
\hline $\begin{array}{l}\mathbf{N} \\
\mathbf{T}\end{array}$ & & $\begin{array}{l}\hat{1} \\
6\end{array}$ & $\begin{array}{l}0 \\
0 \\
0 \\
\end{array}$ & $\frac{m}{i}$ & $\begin{array}{l}\mathscr{8} \\
\stackrel{0}{0} \\
\end{array}$ & $\begin{array}{c}0 \\
0 \\
0 \\
0\end{array}$ & $\begin{array}{l}0 \\
\stackrel{0}{0} \\
\dot{0}\end{array}$ & & 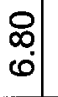 & $\begin{array}{l}\hat{6} \\
\dot{0}\end{array}$ & $\begin{array}{l}\bar{\emptyset} \\
\dot{\varphi}\end{array}$ & & \begin{tabular}{l}
8 \\
\hdashline \\
0
\end{tabular} & $\begin{array}{c}\mathscr{\infty} \\
\hat{\omega}\end{array}$ & $\begin{array}{l}\$ \\
\dot{0}\end{array}$ \\
\hline זٓ & & $\begin{array}{l}8 \\
0 \\
0\end{array}$ & $\begin{array}{l}0 \\
0 \\
0 \\
\end{array}$ & $\stackrel{\substack{m \\
\sim}}{\sim}$ & $\begin{array}{l}\mathscr{S} \\
\dot{\varphi}\end{array}$ & $\begin{array}{c}0 \\
\infty \\
0 \\
\end{array}$ & $\begin{array}{c}\circ \\
\infty \\
0 \\
\end{array}$ & & $\begin{array}{l}0 \\
\infty \\
0\end{array}$ & $\begin{array}{l}\infty \\
6 \\
0 \\
0\end{array}$ & $\begin{array}{l}\hat{0} \\
0\end{array}$ & & \begin{tabular}{l}
9 \\
\hdashline \\
0
\end{tabular} & $\begin{array}{c}\mathbb{1} \\
0 \\
0\end{array}$ & $\begin{array}{l}0 \\
0 \\
\dot{0}\end{array}$ \\
\hline $\begin{array}{l}\mathbf{x} \\
\mathbf{m} \\
\mathbf{5}\end{array}$ & & $\bar{\omega}$ & क & $\begin{array}{l}\overrightarrow{0} \\
\longleftarrow\end{array}$ & $\overrightarrow{\bar{\omega}}$ & $\bar{\omega}$ & $\overline{\bar{\omega}}$ & & 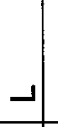 & - & - & & -1 & -1 & \lrcorner \\
\hline$\frac{2}{4}$ & & $\begin{array}{l}\dot{\forall} \\
\dot{ \pm}\end{array}$ & 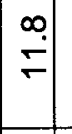 & $\stackrel{m}{\infty}$ & $\dot{\sigma}$ & $\begin{array}{l}10 \\
\dot{ \pm}\end{array}$ & $\begin{array}{l}m \\
\infty \\
\infty\end{array}$ & & ָั. & $\begin{array}{l}0 \\
0 \\
0\end{array}$ & $\begin{array}{c}0 \\
\stackrel{0}{\circ} \\
\sim\end{array}$ & & $\begin{array}{l}\mathscr{c} \\
\stackrel{\sigma}{\sigma}\end{array}$ & 용 & $\begin{array}{l}0 \\
\dot{+}\end{array}$ \\
\hline ち & & $\begin{array}{l}\circ \\
8 \\
8\end{array}$ & $\mid \begin{array}{l}10 \\
10 \\
L\end{array}$ & $\underset{\sim}{\sim}$ & ㄷ. & 官 & $\begin{array}{l}0 \\
\dot{0} \\
\text { in }\end{array}$ & & $\begin{array}{l}0 \\
\dot{p} \\
\dot{y}\end{array}$ & $\frac{5}{8}$ & $\begin{array}{c}\check{-} \\
\dot{q} \\
\dot{q}\end{array}$ & & 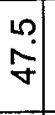 & \begin{tabular}{l} 
Na \\
\multirow{\gamma}{*}{}
\end{tabular} & \begin{tabular}{|l|} 
\\
0 \\
$\dot{Q}$ \\
\end{tabular} \\
\hline $\begin{array}{l}\text { ¿ } \\
\text { 心 }\end{array}$ & & $\begin{array}{c}0 \\
\stackrel{\omega}{N}\end{array}$ & 官 & : & $\stackrel{0}{m}$ & $\begin{array}{l}\forall \\
\dot{m}\end{array}$ & $\begin{array}{l}\infty \\
0 \\
0\end{array}$ & & $\begin{array}{l}\infty \\
\dot{0} \\
0\end{array}$ & $\begin{array}{l}\dot{J} \\
\stackrel{y}{*}\end{array}$ & $\begin{array}{l}\dot{0} \\
\dot{0}\end{array}$ & & 吕 & 灾 & \begin{tabular}{|c|}
0 \\
p. \\
\end{tabular} \\
\hline$\stackrel{\mathscr{0}}{\stackrel{4}{5}}$ & & $\stackrel{\vec{m}}{\sim}$ & \begin{tabular}{|l|}
\multicolumn{1}{|c|}{} \\
0 \\
\end{tabular} & ஸి. & $\stackrel{\hat{\omega}}{\circ}$ & $\frac{0}{\grave{N}}$ & $\stackrel{0}{\circ}$ & & $\begin{array}{l}0 \\
\infty \\
\stackrel{0}{0}\end{array}$ & $\begin{array}{l}\infty \\
\text { Na }\end{array}$ & $\begin{array}{l}0 \\
\text { N̦}\end{array}$ & & $\begin{array}{l}0 \\
\stackrel{0}{\circ}\end{array}$ & $\begin{array}{l}0 \\
\dot{v}\end{array}$ & $\mid \begin{array}{l}0 \\
\stackrel{0}{0}\end{array}$ \\
\hline$\stackrel{\infty}{\mathbb{\Psi}}$ & & $\begin{array}{l}0 \\
\dot{0}\end{array}$ & $\stackrel{0}{\sim}$ & $\frac{N}{m}$ & $\begin{array}{l}0 \\
\infty\end{array}$ & $\mid \begin{array}{l}\infty \\
n \\
n\end{array}$ & $\stackrel{10}{\circ}$ & & $\stackrel{m}{=}$ & $\begin{array}{c}+ \\
\stackrel{0}{\sim}\end{array}$ & $\begin{array}{l}\infty \\
\infty \\
\infty\end{array}$ & & $\stackrel{\mathscr{O}}{\stackrel{N}{\sim}}$ & $\underset{\dot{J}}{+}$ & $\mid \begin{array}{c}0 \\
\stackrel{m}{\sigma}\end{array}$ \\
\hline$\stackrel{\infty}{\Sigma}$ & & $\stackrel{\rho}{\mathrm{N}}$ & \begin{tabular}{|l|} 
\\
$\sim$ \\
$N$
\end{tabular} & $\stackrel{n}{\mp}$ & $\begin{array}{l}\text { S. } \\
\text { in }\end{array}$ & N̦ & m. & & $\begin{array}{l}\dot{v} \\
\dot{\forall}\end{array}$ & \begin{tabular}{|l|} 
\\
\end{tabular} & $\begin{array}{l}\dot{m} \\
\dot{\nabla}\end{array}$ & & $\begin{array}{l}+ \\
\dot{v}\end{array}$ & $\left|\begin{array}{c}0 \\
10 \\
10\end{array}\right|$ & $\dot{0}$ \\
\hline $\mathscr{\mathcal { S }}$ & & $\stackrel{\infty}{\sim}$ & $\hat{0}$ & m. & $\stackrel{\nabla}{\mathrm{N}}$ & $\stackrel{+}{-}$ & $\begin{array}{l}\infty \\
0 \\
0\end{array}$ & & $\overline{\mathrm{N}}$ & $\therefore$ & 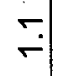 & & $\stackrel{N}{\sim}$ & $\stackrel{\rho}{-}$ & $\mid \begin{array}{l}m \\
\sim \\
\sim\end{array}$ \\
\hline 乡̧ & & ఫे. & N̦ & $\stackrel{\Upsilon}{\sim}$ & $\stackrel{+}{0}$ & $\begin{array}{l}m \\
0\end{array} \mid$ & N̦ & & $\begin{array}{l}\infty \\
0\end{array}$ & $\check{0}$ & $\underset{o}{ }$ & & กั & $\hat{0}$ & 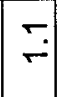 \\
\hline$\frac{\mathbf{T}}{\mathbf{5}}$ & & $\begin{array}{c}\grave{m} \\
\dot{d}\end{array}$ & $\left|\begin{array}{l}0 \\
0 \\
1 \\
4 \\
m\end{array}\right|$ & $\begin{array}{c}+ \\
\text { 点 }\end{array}$ & ల్లి & $\left|\begin{array}{l}10 \\
0 \\
1 \\
0 \\
0\end{array}\right|$ & $\stackrel{\grave{\jmath}}{\grave{b}}$ & & $\frac{10}{\grave{c}}$ & 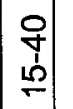 & సু & & ఫ্t & $\mid \frac{\infty}{c}$ & $\mid \begin{array}{l}f \\
b \\
0 \\
0\end{array}$ \\
\hline $\begin{array}{l}\mathbf{Z} \\
\mathbf{N} \\
\mathbf{I}\end{array}$ & & 둔 & เ్ & 芫 & 产 & ติ & 둔 & & $\frac{5}{4}$ & $\mid \begin{array}{c}\mathbf{\infty} \\
\mid\end{array}$ & 둔 & & $\frac{5}{4}$ & 둥 & $\underline{\Phi}$ \\
\hline 으 & 嵒 & $\begin{array}{l}\frac{1}{8} \\
0 \\
\vdots \\
0 \\
0 \\
\text { ய. }\end{array}$ & 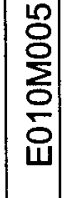 & 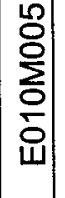 & 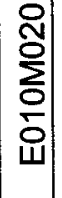 & 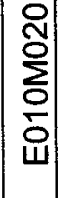 & 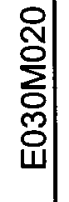 & 을 & 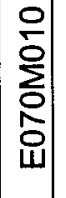 & $\left|\begin{array}{l}0 \\
0 \\
0 \\
0 \\
0 \\
0 \\
\text { Un }\end{array}\right|$ & 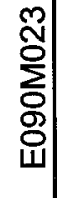 & $\begin{array}{l}\frac{\alpha}{u} \\
\frac{a}{a} \\
\frac{a}{J}\end{array}$ & $\begin{array}{l}\frac{10}{8} \\
\frac{0}{0} \\
\frac{0}{0} \\
\frac{w}{4}\end{array}$ & 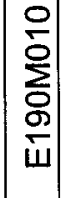 & $\mid \begin{array}{l}0 \\
\frac{0}{0} \\
\frac{1}{0} \\
\frac{O}{5} \\
\dot{w}\end{array}$ \\
\hline
\end{tabular}




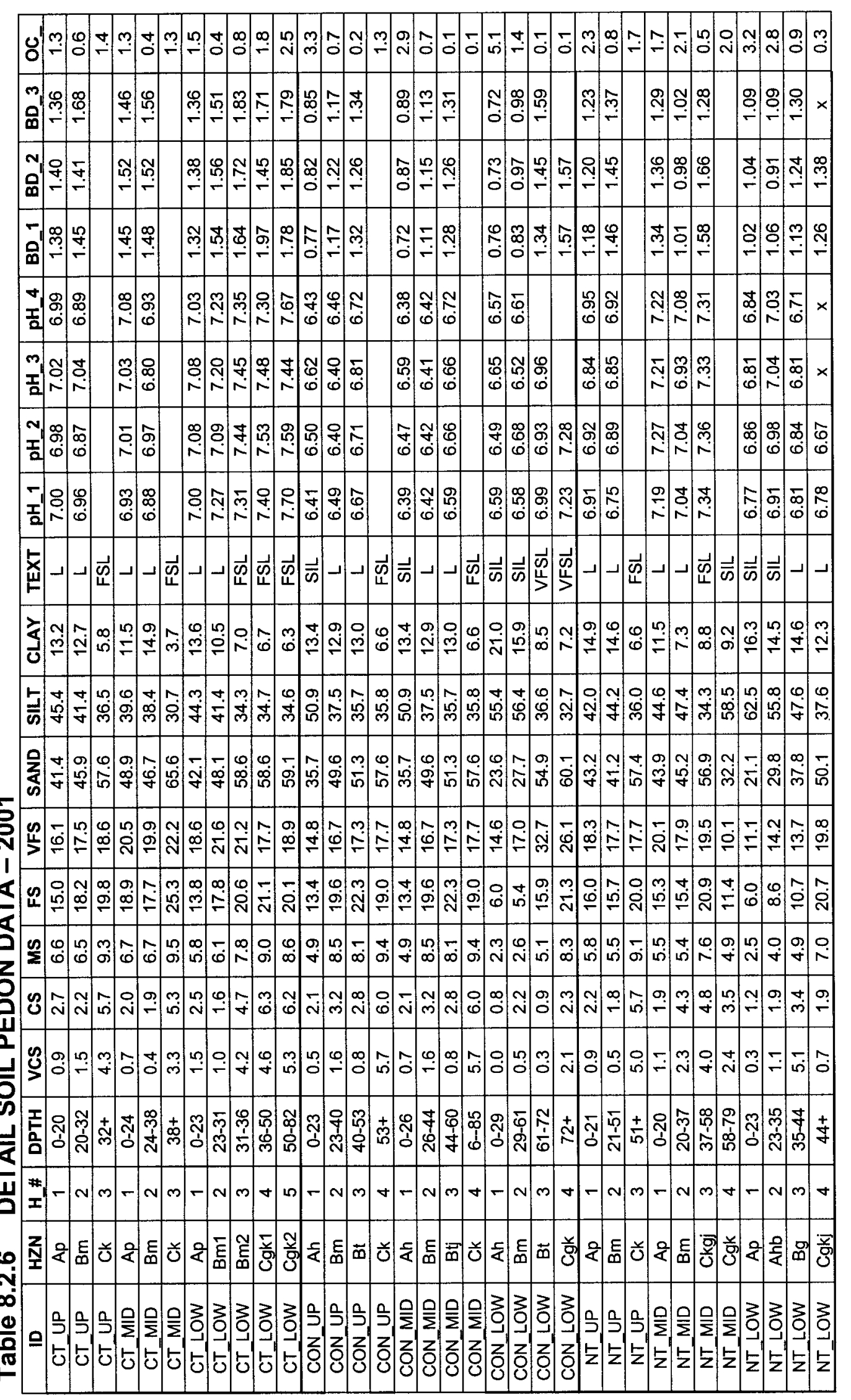


Table 8.2.7 SOLUM DEPTH MEASUREMENT TRANSECTS BY SLOPE POSITION -2001.

\begin{tabular}{|c|c|c|c|c|c|c|c|c|}
\hline \multicolumn{3}{|c|}{ No-till } & \multicolumn{3}{|c|}{ Control } & \multicolumn{3}{|c|}{ Conventional } \\
\hline UPPER & MID & LOWER & UPPER & MID & LOWER & UPPER & MID & LOWER \\
\hline $\begin{array}{l}\text { Solum } \\
\text { (cm) }\end{array}$ & $\begin{array}{l}\text { Solum } \\
\text { (cm) }\end{array}$ & $\begin{array}{l}\text { Solum } \\
\text { (cm) }\end{array}$ & $\begin{array}{l}\text { Solum } \\
\text { (cm) }\end{array}$ & $\begin{array}{l}\text { Solum } \\
\text { (cm) }\end{array}$ & $\begin{array}{l}\text { Solum } \\
(\mathrm{cm})\end{array}$ & $\begin{array}{l}\text { Solum } \\
\text { (cm) }\end{array}$ & $\begin{array}{l}\text { Solum } \\
\text { (cm) }\end{array}$ & $\begin{array}{l}\text { Solum } \\
\text { (cm) }\end{array}$ \\
\hline 43 & 45 & 86 & 50 & 50 & 55 & 27 & 33 & 36 \\
\hline 51 & 65 & 67 & 45 & 43 & 49 & 49 & 51 & 38 \\
\hline 41 & 50 & 82 & 42 & 53 & 56 & 52 & 50 & 35 \\
\hline 60 & 65 & 85 & 45 & 43 & 60 & 33 & 27 & 39 \\
\hline 37 & 40 & 61 & 42 & 48 & 56 & 51 & 27 & 34 \\
\hline 60 & 43 & 78 & 53 & 41 & 75 & 57 & 35 & 40 \\
\hline 32 & 32 & 71 & 58 & 42 & 72 & 54 & 29 & 40 \\
\hline 32 & 28 & 57 & 55 & 47 & 74 & 45 & 35 & 50 \\
\hline 38 & 27 & 65 & 55 & 50 & 76 & 41 & 28 & 56 \\
\hline 36 & 40 & 52 & 47 & 44 & 50 & 48 & 22 & 56 \\
\hline 56 & 48 & 67 & & & & 28 & 27 & 30 \\
\hline 50 & 37 & 55 & & & & 51 & 33 & 56 \\
\hline 55 & 40 & 70 & & & & 41 & 37 & 52 \\
\hline 25 & 41 & 48 & & & & 40 & 30 & 64 \\
\hline 43 & 37 & 70 & & & & 52 & 26 & 44 \\
\hline 42 & 57 & 55 & & & & 35 & 20 & 56 \\
\hline 38 & 62 & 60 & & & & 21 & 31 & 45 \\
\hline 38 & 40 & 60 & & & & 37 & 36 & 49 \\
\hline 40 & 38 & 40 & & & & 44 & 22 & 50 \\
\hline 35 & 44 & 65 & & & & 32 & 20 & 49 \\
\hline & 42 & 78 & & & & 38 & 20 & 65 \\
\hline & 38 & & & & & 25 & 38 & 54 \\
\hline & 38 & & & & & 35 & 36 & 61 \\
\hline & 35 & & & & & 46 & 40 & 51 \\
\hline & 35 & & & & & 47 & 20 & 48 \\
\hline & 43 & & & & & 40 & 24 & 48 \\
\hline & 35 & & & & & 43 & 26 & 34 \\
\hline & 30 & & & & & 37 & 24 & 37 \\
\hline & 34 & & & & & 24 & 35 & 55 \\
\hline & 35 & & & & & 41 & 28 & 26 \\
\hline & 33 & & & & & 32 & & \\
\hline
\end{tabular}




\subsection{TILLAGE SYSTEM INFORMATION}

\section{Introduction}

The traditional role for tillage systems has been to provide weed control and prepare a seedbed that will give good crop stands and high yields. More recently, tillage and cropping systems have been changed to accomplish the same goals while reducing soil erosion through less intensive or no cultivation. High fuel costs and shortage of labour may also cause reduced tillage to be favourable.

The switch to a different tillage system should be based on the system's compatibility with the farm's soil types, slopes, drainage, moisture regime and temperature. The tillage system's effect on erosion control, timeliness, the potential for controlling weeds, insects and diseases and the profitability of the farm operation are also important considerations. No one tillage system is best for Ontario conditions because there is so much variability in soils, crops and climate. In fact, the tillage system may rotate with the crop. Allow for the use of the most appropriate tillage for the crop to be grown.

\section{Conventional Tillage}

Conventional tillage is any tillage system that attempts to bury most of the previous crop residue, leaving less than $30 \%$ of the soil surface covered with residue after planting. Usually the moldboard plow is used in conjunction with a variety of other tillage implements. The principal advantages of the moldboard system are that machinery is familiar and widely available and it is adaptable to a wide range of soil conditions. Moldboard plowing increases porosity, allowing for good air exchange, root proliferation and water infiltration, especially when rainfall is above average. The increased porosity can be lost with excessive secondary tillage or in soils with poor structural stability. Many livestock producers view the moldboard plow as the most effective way of incorporating manure and breaking up sod fields. The main weakness of the moldboard system is the high costs of equipment, fuel and labour associated with seedbed preparation. With little or no residue cover, there is a high risk for soil erosion by wind and water.

Different crops leave different residue levels after harvest, generally increasing as you progress from soybeans to small grains to corn. Perennial pasture and hay crops (sod), because of the plant density, growth habit and length of establishment, offer the greatest soil coverage and are the most effective in preventing erosion.

\section{No-Till Systems}

No-till systems provide the greatest opportunity to leave protective crop residues on the soil surface. They also have the greatest potential for reducing tillage costs, offset somewhat by the need to control weeds in nearly 
all cases with a preplant "burndown" herbicide application. Numerous options exist both in the original design and in the modifications available for row crop planters or seed drills to be considered "no-till" capable. The term "no-till" refers to any system that confines all tillage and seeding operations to one pass of the planting equipment regardless of the various equipment designs or modifications and regardless of the amount of in-row soil disturbance they may cause.

The success of no-till systems is often dependent on a range of factors other than the equipment design. Two of these - soil drainage and crop rotation - have a significant influence on the performance of all no-till systems.

http://www.gov.on.cal 